\title{
Efeito da época de queima em um campo sujo de Cerrado
}

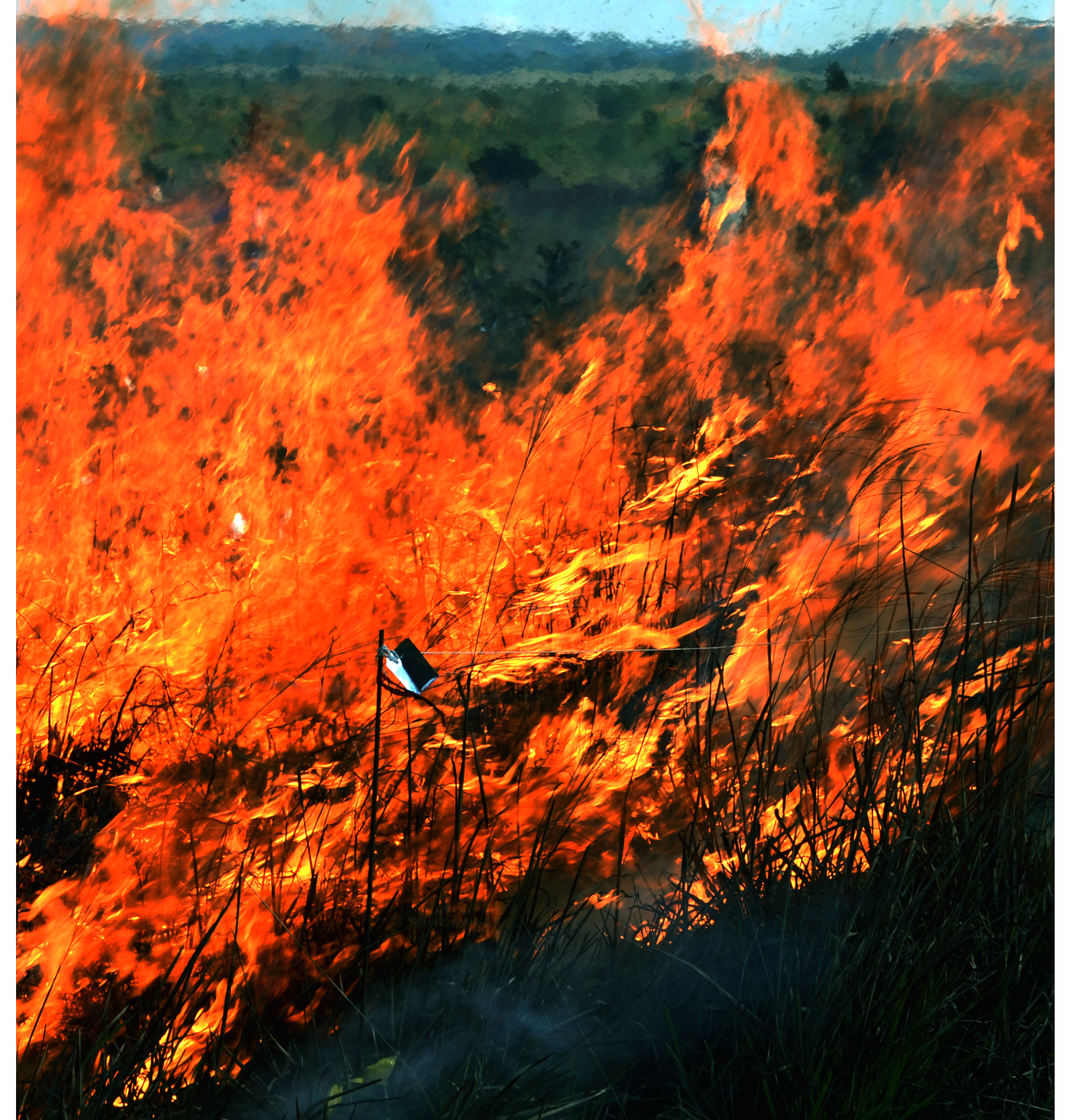




\title{
Efeito da época de queima em um
}

\author{
campo sujo de Cerrado
}

\section{Effect of fire seasonality in a Brazilian}

\section{savanna}

Paula Zaterka Giroldo

Versão original da dissertação apresentada ao Instituto de Biociências da Universidade de São Paulo para a obtenção do título de Mestre em Ciências Biológicas na área de Ecologia.

Orientadora: Profa. Dra. Vânia Regina Pivello

São Paulo 2016 


\section{Ficha catalográfica}

\section{Zaterka Giroldo, Paula}

Efeito da época de queima em um campo sujo de Cerrado

Número de páginas: 75

Dissertação (Mestrado) - Instituto de Biociêcias da Universidade de São Paulo.

Departamento de Ecologia.

1. Cerrado. 2. Manejo de fogo. 3. Conservação. I. Universidade de São Paulo. Instituto de Biociências. Departamento de Ecologia.

\section{Comissão Julgadora}

Prof. Dr.

Prof. Dr.

Profa. Dra. Vânia Regina Pivello (Orientadora) 


\section{Agradecimentos}

Não à toa essa dissertação foi escrita na primeira pessoa do plural. Este estudo não seria possível sem a ajuda de um número sem fim de pessoas.

..Gostaria de agradecer primeiramente às Instituições que ampararam este mestrado.

À Capes, que financiou parte deste projeto.

Ao Departamento de Ecologia do Instituto de Biociências por propiciar um ambiente de estudo tão estimulante.

À FAPESP que concedeu apoio ao Projeto 2015/06743-0, ao qual este mestrado está vinculado.

E aos funcionários da Estação Ecológica de Itirapina. Helena e Denise, sem o apoio de vocês este projeto não teria acontecido. Ao Gilson, seu Dito, seu João, seu Zé, Major, Chico e a todos os outros que garantiram nossa segurança em campo, ajudaram em nossas coletas de biomassa e possibilitaram um ambiente de trabalho tão agradável! À dona Isabel por garantir sempre uma ótima hospedagem.

..Não menos importante, agradeço aos que me ampararam durante este percurso:

Agradeço à Vânia Pivello por uma orientação extremamente humana, que extrapolou os muros da Universidade. Obrigada por possibilitar que eu entrasse de cabeça no mestrado e, mais tarde, dividisse a vida acadêmica com a vida escolar.

Ao meu Comitê de Acompanhamento: Sérgio Tadeu, Ramón Vallejo e Alessandra Fidelis, obrigada pela disponibilidade, dedicação e orientação. À Alessandra Fidelis pela paciência em orientar meus primeiros passos em campo e por me aproximar do LEVeg, que me rendeu tantos aprendizados e amizades valiosas.

Ao Paulo Inácio, Adriana Martini e Alexandre Adalardo pela amizade e por ressignificarem o meu conceito do que é ser professor. Ao Glauco Machado pelo curso de campo (duas vezes). Ao Paulo Sano e à doce Beca por me apresentarem ao Jalapão e me mostrarem (na alma) qual o real objeto do meu estudo. Ao Paulo Inácio e Eduardo Santos pelas valiosas orientações nas análises.

À Melina Leite, amiga e parceira das análises deste trabalho. Este mestrado não teria tomado forma sem a sua dedicação. Eu espero que você tenha a 
oportunidade de continuar seus estudos e que reconheçam, ao menos, que quanto maior a sua qualificação, maior e melhor serão os frutos de seu trabalho. Muito obrigada.

Às mulheres do LEVeg, símbolos de resistência e força. Elizabeth Gorgone, mentora, revisora e irmã, faço de suas palavras as minhas: obrigada por ser sempre tão querida e amiga, mesmo em momentos tão difíceis. À Mariana Rissi e à Talita Zupo pela presença.

Aos queridos do Lepac: Leandro Tambosi, Mari Vidal, Natalia Aristizabal e Adrian González pelas conversas, discussões e apoio. Aos amigos e parceiros de coletas: Helena Chiaretti, Guilherme Antar, Diana Garcia, Luisa Novara, Gabriel Kayano, Victor Keller, Vitor Barão e Luciano Fioroto. Ao Vitor Barão, pela concessão da foto que inaugura o 'material e métodos' dessa dissertação e pela foto aérea da Tipuana Imagens Aéreas. À Diana Garcia, Melina Leite e Elizabeth Gorgone pelas revisões e colaborações substanciais ao manuscrito final. À Julia Audi e ao Bruno Pierro por aguentarem a barra que foi morar comigo durante esta última etapa do trabalho.

À Anna Penna, que garantiu minha sanidade mental ao me mostrar que ambas estávamos loucas. Ao Diogo Melo, Guilherme Pato e Sara pelas conversas, orientações e apoio. Ao Leonardo Caqui Borges pela presença constante e sempre divertida, pelos empurrões carinhosos e por me presentear com listas do que eu deveria ou não deveria fazer em uma sexta-feira a noite. E por contribuir com o aprimoramento (ou não) do meu senso estético (até os 45 minutos do segundo tempo).

Ao Colégio Santa Cruz, nas figuras de Ricardo Mesquita, Cristiane Motta e conselho do $8^{\circ}$ ano, pelo apoio e compreensão durante o término desta dissertação.

Por fim, agradeço à minha mãe, minha metade, e ao meu pai, meu inteiro, por disporem de tudo e mais um pouco para que eu estivesse aqui hoje. Ao Renato, por ser sempre fonte de inspiração. Ao Fernando, querido irmão mais velho. E ao Zulu, pelo amor e parceria em um período de tão intensas transformações. 


\section{Sumário}

Resumo

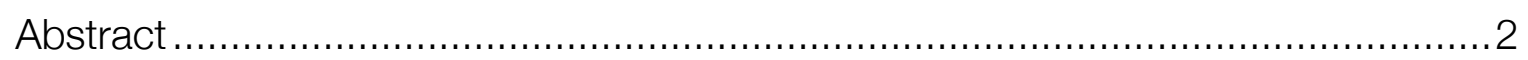

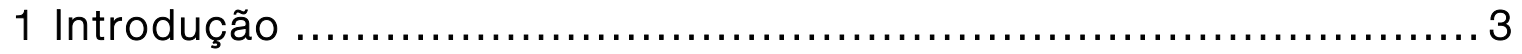

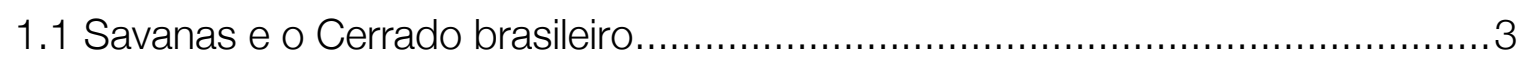

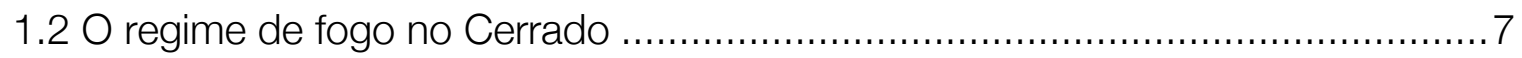

$1.3 \mathrm{O}$ manejo de fogo no Cerrado, justificativa deste estudo................................10

2 Material e métodos.................................................... 13

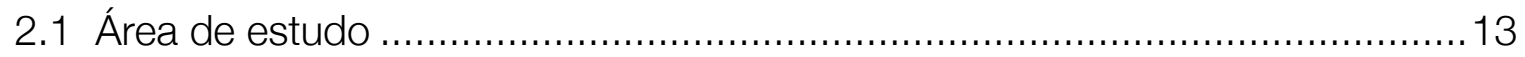

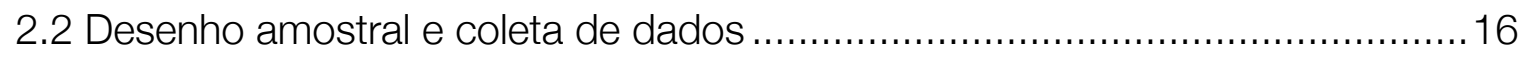

2.2.1 Estabelecimento das parcelas e dos tratamentos de queima ...................17

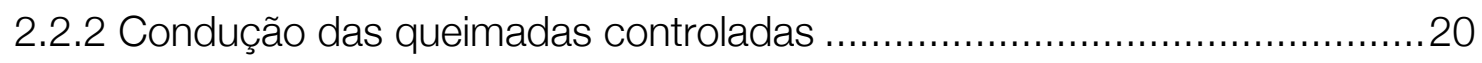

2.2.3 Coleta de dados: solo e componentes do estrato rasteiro ........................21

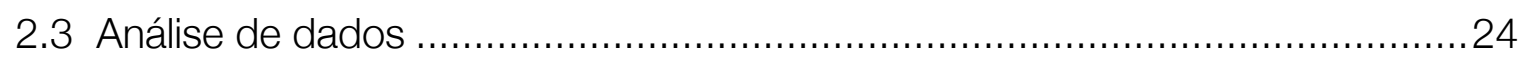

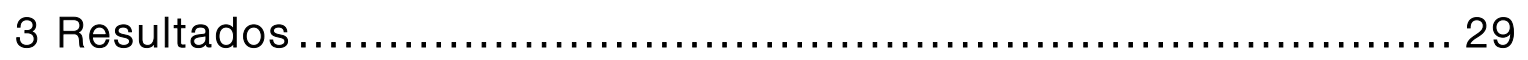

3.1. Variação da cobertura média conforme sazonalidade .................................29

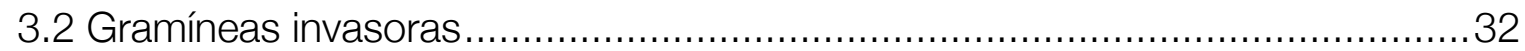

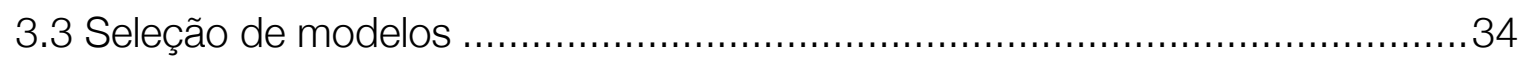

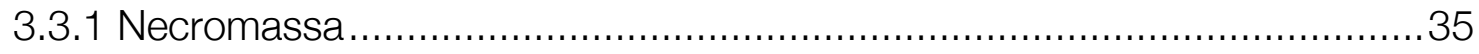

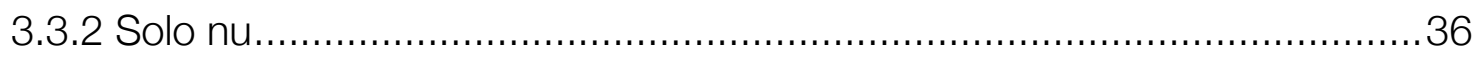

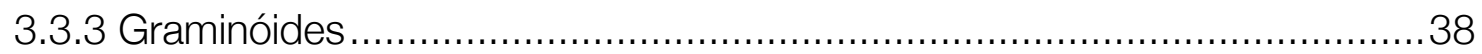

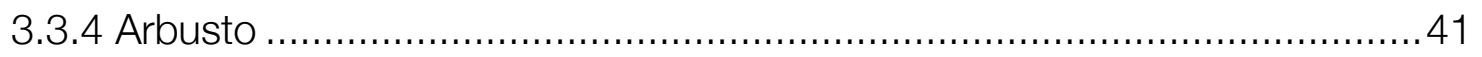

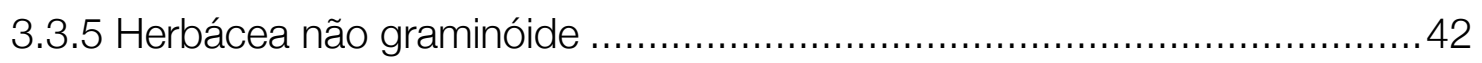

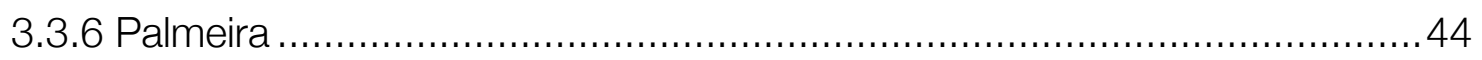

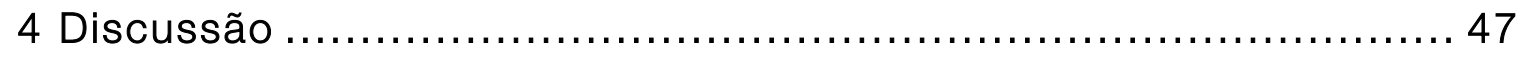

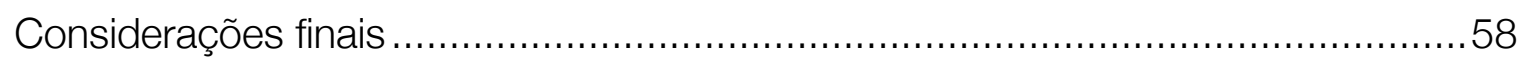

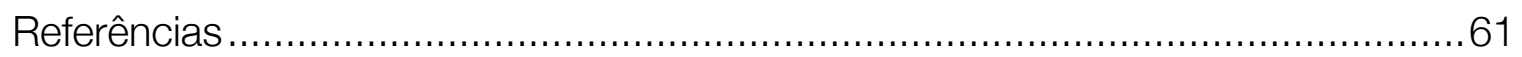

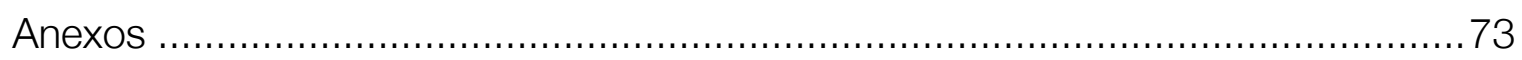




\section{Resumo}

O fogo é um fator ecológico essencial no Cerrado e promotor de sua evolução. Não apenas a incidência do fogo afeta as respostas dos ecossistemas, mas principalmente o regime de queima, composto por componentes temporais, espaciais e de magnitude. O manejo por meio de queimadas controladas é legalmente permitido no Brasil, mas ainda é encarado com restrições. Como consequência, há uma lacuna no conhecimento das respostas da vegetação ao fogo. Este projeto avaliou o efeito da época do fogo na comunidade nativa de um campo sujo com presença de espécies invasoras na Estação Ecológica de Itirapina, SP. Estabelecemos 16 parcelas $(15 \times 15 \mathrm{~m})$ e determinamos 3 tratamentos de queima - precoce, modal e tardia - e controle, cada qual com 4 réplicas. Em cada parcela, foram instaladas 10 sub-parcelas fixas $(1 \times 1 \mathrm{~m})$, nas quais foram obtidos dados de estimativa de cobertura de graminóides, arbustos, herbáceas não graminóides, palmeiras, solo nu e necromassa. Os resultados mostram que diferentes épocas de queima geraram diferentes efeitos em gramíneas e solo nu, mas essas diferenças não se mantiveram um ano após as queimas. Constatamos a diminuição dos valores iniciais de cobertura de necromassa e o aumento na cobertura de arbustos para todos os tratamentos de queima. Não obtivemos resultados conclusivos para herbáceas não graminóides e vimos que a cobertura de palmeiras não foi afetada pelo fogo. Os resultados evidenciam a resiliência do Cerrado, já que o estrato herbáceo-arbustivo se regenerou dentro de 1 ano. A recuperação da vegetação pôde ser explicada pela sazonalidade climática, sendo que uma estação chuvosa foi suficiente para que as diferenças entre as épocas de queima desaparecessem. O manejo de fogo para redução de material combustível foi comprovado e vimos que pode ser realizado em qualquer época do ano. Obtivemos indícios de que a queima pode aumentar a susceptibilidade de invasão por Urochloa brizantha e indicamos que o manejo de fogo em ambientes invadidos por $U$. brizantha seja realizado com cautela, até que tenhamos certeza de que o fogo não facilita a proliferação dessa espécie invasora. 


\section{Abstract}

Fire is an essential ecological factor that has promoted the evolution of Cerrado vegetation. Not only the incidence of fire affects the ecosystem, but mainly the fire regime, which is characterized by variability in space, time, and magnitude. Time, specifically, is related to fire frequency and seasonality. The use of fire as a management tool is legally admitted in the Brazilian protected areas, but it is still seen with great restrictions. As a consequence there is a knowledge gap on the vegetation responses to fire. This project evaluated short time effects of fire season on the herbaceous community of a "campo sujo" (open savanna), in the Itirapina Ecological Station, a protected area in the State of São Paulo, Brazil. We established 16 plots $(15 \times 15 \mathrm{~m})$ and three fire treatments - burning in the early, middle or late dry season - and control (not burning), each treatment with four replicates. In each plot we established ten fixed subplots $(1 \times 1 \mathrm{~m})$, where we estimated the vegetation cover of grasses, shrubs, forbs, palms, as well as bare soil and dead biomass, before burning and every four months during 12 months. We found that grasses and bare soil cover responded differently to the fire season, but differences among treatments disappeared after one year. Litter cover decreased and shrubs cover increased in every fire treatment after one year. Palms were not affected by any fire treatment, and we did not obtain conclusive results for forbs. Our results show that Cerrado vegetation is very resilient, since the components of the herbaceous community recovered within a year. The vegetation recovery was influenced by climate seasonality, and differences among fire seasons disappeared after just one rainy season. When considered as a management tool, fire was efficient in decreasing the amount of dead biomass after one year, and for this purpose it can be applied at any time of the year. Evidence suggested that fire might increase the invasion by Urochloa brizantha, an African grass. For this reason we suggest caution when using fire as a management tool in invaded ecosystems until one is sure that fire will not trigger or facilitate invasion processes by $U$. brizantha. 


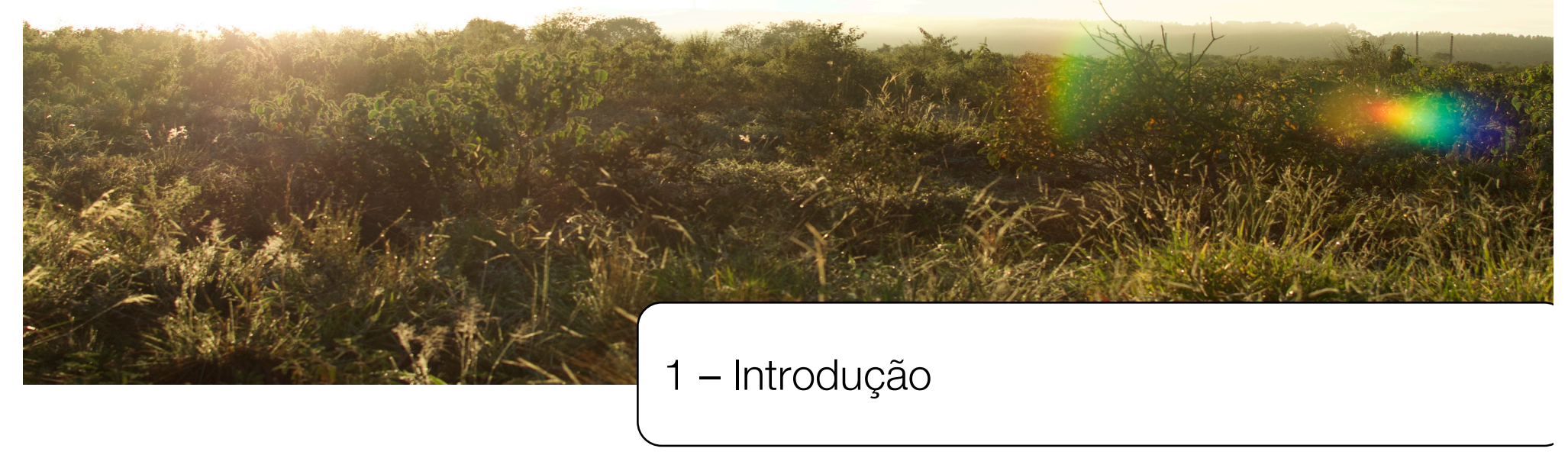

\subsection{Savanas e o Cerrado brasileiro}

Savanas ocupam cerca de um quinto da superfície terrestre global (Scholes \& Archer 1997) e apresentam grande importância socioeconômica, ambiental e cultural (Parr et al. 2014). Praticamente um quinto da população mundial vive em regiões que são ou que estiveram recentemente cobertas por savanas (Solbrig et al. 1996). Áreas de savana são responsáveis por 30\% da produção primária terrestre, seus serviços ecossistêmicos sustentam cerca de $20 \%$ da população mundial e, por outro lado, sofrem continuamente com a pressão e impactos de atividades humanas (Scholes \& Archer 1997).

O termo savana denota comunidades ou paisagens que apresentam um estrato herbáceo-arbustivo contínuo e elementos arbóreos esparsos (Scholes \& Archer 1997). O clima tipicamente savânico apresenta duas estações marcadas que se alternam, uma seca e outra chuvosa, que exercem pressão sobre a estrutura e o funcionamento das formações vegetais. A existência de diferentes 
formas de vida associada à sazonalidade climática faz com que estrutura e a função das savanas sejam diferentes de florestas e de campos abertos, principalmente no que diz respeito à co-dominância, distribuição e abundância relativa de tipos vegetais (Scholes \& Archer 1997).

O Cerrado é a maior formação savânica da América do Sul e ocupa aproximadamente um quarto do território brasileiro (Embrapa 1978; Ratter et al. 1997). O cerrado abrange fisionomias tipicamente savânicas, como é o caso do campo sujo, do campo cerrado e do cerrado sensu stricto, e fisionomias campestres e florestais, conhecidas como campo limpo e cerradão, respectivamente (Coutinho 1978; Castro et al. 1999). O estrato rasteiro dos cerrados é composto por gramíneas e outras herbáceas, bem como lenhosas de pequeno porte (Dasilva \& Nogueira 1999; Filgueiras 2000, 2002; Meirelles et al. 2002; Munhoz 2004).

O Cerrado é considerado a savana mais biodiversa do mundo e um hotspot mundial de biodiversidade, com altos índices de endemismo (Mittermeier, Myers \& Mittermeier 1999; Myers et al. 2000; Klink \& Machado 2005). Considerando todas as suas fisionomias, o Cerrado apresenta pelo menos 10 mil espécies de plantas, das quais pelo menos 44\% são endêmicas (Kier et al. 2005; Mendonça et al. 2008). A área de cerrado localizada no Brasil Central é conhecida como cerrado nuclear e áreas de transição do Cerrado com outros domínios (IBGE, 1993) são conhecidas como cerrado periférico. Áreas de cerrado periférico apresentam uma mistura de elementos florísticos de regiões adjacentes (Machado et al. 2004). O clima é tropical estacional e a média de precipitação anual varia de 1.100 mm a 1.600 mm, 
dos quais 90\% ocorrem na estação úmida, entre setembro e abril (Miranda et al. 2009). Os solos são, em sua maioria, distróficos, com pH baixo e altas concentrações de alumínio (Haridasan 1994).

A diversidade fitofisionômica e biológica do Cerrado está relacionada a inúmeros fatores, muitos dos quais relacionados à sua extensão geográfica. Há, por exemplo, variação de características latitudinais e altitudinais que se refletem em variações de pluviosidade e temperatura (Walter 1986). Há também variação nas características pedológicas, como profundidade, drenagem e fertilidade do solo (Henriques 2005), assim como geomorfológicas e hidrológicas (Goodland \& Pollard 1973; J.A. et al. 1977; Silva Júnior, Barros \& Cândido 1987; Haridasan 2000). A herbivoria (Roques, O’Connor \& Watkinson 2001; Augustine, Mcnaughton \& Frank 2003) e o fogo (Eiten 1972; Coutinho 1982, 1990) exercem pressão e modificam a paisagem do Cerrado.

Apesar do reconhecimento de sua importância ecológica, cerca de metade da área original do Cerrado foi transformada em pastagens plantadas e culturas anuais (Klink \& Machado 2005) e a destruição de seus ecossistemas continua de forma acelerada. Atualmente, estima-se que 55\% do domínio do Cerrado esteja em situação de degradação e que apenas 34\% da área nuclear do Cerrado esteja em bom estado de conservação (Machado et al. 2004). Como a última grande fronteira agrícola do mundo, o Cerrado sofre pressão para a abertura de novas áreas, visando à produção de carne e grãos para exportação (Sala et al. 2000; Klink \& Machado 2005) e seu material lenhoso é alvo de exploração para a produção de carvão (MMA 2011). Como resultado dessas transformações estão a fragmentação 
de habitats, extinção de biodiversidade, erosão de solos, desequilíbrios no ciclo de carbono, invasão por espécies exóticas e alterações no ciclo de queimadas (Klink \& Machado 2005; Pivello 2006a; Durigan, de Siqueira \& Franco 2007).

Espécies exóticas são consideradas invasoras quando conseguem se estabelecer em um novo ambiente, ultrapassando barreiras de sobrevivência, reprodução e dispersão (Richardson et al. 2000; Blackburn et al. 2011). Plantas invasoras normalmente atingem altas densidades e dominam a comunidade invadida, alterando sua composição, estrutura e processos naturais (Cronk \& Fuller 1995; Vilà et al. 2011; Gaertner et al. 2014). No Cerrado, inúmeras gramíneas de origem africana foram introduzidas, acidentalmente ou para pastagem. Duas dessas gramíneas são Melinis minutiflora P. Beauv. (capim-gordura) e Urochloa spp. (braquiária), que competem e afetam negativamente a abundância de espécies da comunidade herbáceo-arbustiva nativa (Pivello, Carvalho \& Lopes 1999a; Pivello, Shida \& Meirelles 1999b; Almeida-Neto et al. 2010).

Estudos sobre gramíneas invasoras revelam que Urochloa spp. e $M$. minutiflora são competidoras eficientes. As espécies possuem estrutura adensada que se reverte em grande quantidade de biomassa altamente inflamável, aumentando o risco de incêndios durante a estação seca (Berardi 1994; CastroNeves 2000). Também modificam o comportamento e o regime do fogo no Cerrado (Berardi 1994; Castro-Neves 2000; Mistry \& Berardi 2005; Rossi et al. 2014; Gorgone-Barbosa et al. 2015) e rebrotam rapidamente após o fogo, ocupando os espaços abertos na vegetação (Gorgone-Barbosa et al. dados não 
publicados), competindo com espécies nativas por recursos e degradando ainda mais o sistema.

\subsection{O regime de fogo no Cerrado}

O fogo, ao contrário da presença de espécies exóticas, é um fator ecológico essencial nas savanas e promotor de sua evolução (Bond \& Keeley 2005). A dependência da vegetação ao fogo foi observada nas pradarias americanas (Hanes 1971), em ecossistemas mediterrâneos (Keeley et al. 2012) e nas savanas africanas (Trollope 1982), australianas (Morgan 1999) e neotropicais (Coutinho 1990; Simon et al. 2009). Em cada um desses ambientes, a resposta da biota ao fogo está relacionada principalmente ao regime de queima (Whelan 1995; Hardesty, Myers \& Fulks 2005).

O regime de queima é caracterizado pela frequência (intervalo de retorno do fogo), intensidade (quantidade de calor liberado na frente de fogo), época (quando ocorre ao longo do ano), tipo do fogo (de superfície, de copa, a favor ou contra o vento) e extensão da queima (área total queimada) (Whelan 1995; Bond \& van Wilgen 1996; Bond \& Keeley 2005). Cada aspecto do regime de queima é determinado ainda por uma série de fatores bióticos e abióticos, como condições meteorológicas, o tipo de ignição (atrito entre rochas, raios, vulcanismo), o relevo, atributos do solo e características do material combustível (Pyke, Brooks \& D'Antonio 2010).

Salgado-Labouriau e Ferraz-Vicentini (1994) realizaram um estudo paleoclimático e paleovegetacional e registraram a ocorrência de queimadas há 
32.400 anos antes do presente (AP) na região de Goiás (Miranda et al. 2009). Estudos paleoecológicos revelam que a vegetação do Cerrado foi queimada com frequência por milhares de anos (Salgado-Labouriau 2005) e sugerem que o fogo é um dos determinantes de suas fisionomias, ao lado das condições de solo e da sazonalidade climática (Furley 1999).

A evolução do Cerrado na presença de fogo e a dependência de queimadas para a manutenção de espécies e de processos ecológicos situa a maior parte das suas fitofisionomias como sendo ecossistemas dependentes do fogo (Hardesty et al. 2005; Pivello 2011). São reconhecidas na vegetação nativa, especialmente em espécies endêmicas do Cerrado, estratégias adaptativas ao fogo frequente (Gottsberger \& Gottsberger, 2006), como por exemplo, a suberização de troncos e galhos (Coutinho 1990; Guedes 1993), a intensa capacidade de rebrota através da copa, rizomas, caule, raiz e estruturas subterrâneas (Souza \& Soares 1983; Medeiros 2002), a presença de estruturas que protegem gemas apicais, a deiscência de frutos e a germinação de sementes estimulada pelo fogo (Coutinho 1990; Landim \& Hay 1995).

Acredita-se que o regime natural de queimas no Cerrado era constituído por queimadas frequentes iniciadas por raios na estação úmida, associados a um mosaico de queimas com baixa frequência em épocas secas (Miranda et al. 2009). Segundo Dias (2006) esse regime de fogo deve ter sido similar àquele utilizado por populações indígenas, entre 4 mil anos AP e 300 anos AP (apud Miranda et al. 2009). Atualmente, foi constatada a alta frequência de incêndios nos meses de transição entre épocas úmidas e secas no Parque Nacional das Emas (Ramos- 
Neto \& Pivello 2000), no Parque Nacional da Serra da Canastra (Medeiros \& Fiedler 2004) e no Parque Nacional da Chapada dos Veadeiros (Fiedler, Melo \& Medeiros 2006). O fogo iniciado por raios em épocas úmidas apresenta menor intensidade e maior heterogeneidade espacial, pois a chuva garante que ele se apague rapidamente (Ramos-Neto \& Pivello 2000). Ademais, o maior grau de umidade do material combustível gera queimadas heterogêneas, em manchas (Miranda, Neto \& Neves 2010).

A expansão das populações e atividades humanas pelo território brasileiro gerou uma grande alteração no regime de fogo do Cerrado. O fogo utilizado em práticas agrícolas ou pastoris é hoje realizado durante os meses da estação seca, para a abertura e limpeza de áreas (Alho \& Martins 1995) e para o manejo de pastagens naturais ou plantadas (Coutinho 1990), estimulando o rebrotamento das ervas em época de escassez de forragem. Em função deste manejo, houve um aumento significativo na frequência de fogo e a mudança da época, da intensidade e do padrão espacial das queimadas (Coutinho 1982; Ramos-Neto \& Pivello 2000; Pivello 2011). Queimadas na estação seca comumente apresentam maior intensidade, maior abrangência espacial e maior uniformidade (Coutinho 1990; Ferraz-Vicentinni 1999; Ramos-Neto \& Pivello 2000). Ademais, queimadas antropogênicas na estação seca consomem grande parte do material combustível, limitando a ocorrência de queimadas naturais na estação úmida (Ramos-Neto \& Pivello 2000). 


\subsection{O manejo de fogo no Cerrado, justificativa deste estudo}

A crescente descaracterização dos regimes naturais de fogo geram implicações marcantes na biota e nos processos ecológicos (Hardesty et al. 2005; Pivello 2011). Regimes de fogo inadequados podem resultar em degradação do solo, facilitação da invasão biológica e perda de biodiversidade (Pivello 2011). Como consequência, organizações internacionais têm reconhecido a importância do fogo na conservação dos ecossistemas dependentes de fogo e estimulado o estabelecimento do manejo dessas paisagens com queimadas prescritas. A Association for Tropical Biology and Conservation (ATBC), por exemplo, publicou recentemente uma resolução apelando para que o governo brasileiro unisse esforços na promoção da pesquisa voltada à compreensão e ao manejo do fogo no Cerrado (ATBC 2012). Anteriormente, a organização não-governamental americana The Nature Conservancy (TNC) já havia publicado uma Iniciativa Global para o Manejo do Fogo (Myers 2006), reconhecendo o importante papel das queimadas nos ecossistemas dependentes de fogo.

Apesar de pouco usual em Unidades de Conservação do Brasil, o manejo com fogo é utilizado em diversas partes do mundo (Whelan 1995; Durigan \& Ratter 2016). Queimadas prescritas são apontadas como uma alternativa no controle de plantas e patógenos indesejáveis (Young, Mellbye \& Silberstein 1999; Stolle et al. 2003; DiTomaso et al. 2006), na manutenção de comunidades vegetais (Bunting, Kilgore \& Bushey 1987; Pivello 1992, 2006b), na redução de material combustível para evitar incêndios (Pivello 1992, 2006b; Williams et al. 1999; Fernandes \& 
Botelho 2003) e para restaurar regimes de fogo (Bonnicksen \& Stone. 1985; Baker 1994; Pivello 2011).

O uso do fogo como estratégia de manejo em áreas protegidas está previsto na legislação brasileira (Resolução CONAMA 11 - Artigo 3o. 1988; Novo Código Florestal - Cap. 9), mas a sua utilização ainda é uma questão polêmica. Como consequência, há uma lacuna no conhecimento das respostas da vegetação nativa à queima. Diante desta situação, e dado que queimadas descontroladas são, atualmente, uma das maiores ameaças ao Cerrado (Klink \& Machado 2005; Pivello 2006a; MMA 2011), é indispensável que se promova a experimentação in loco e em laboratório para fornecer as informações ainda desconhecidas e necessárias ao manejo das comunidades vegetais nativas de Cerrado.

Pesquisas sobre o efeito do fogo nas comunidades e ecossistemas geralmente são de longo prazo, principalmente no que diz respeito ao efeito da época e frequência de queima. Entretanto, alterações em populações e comunidades dependem de características individuais (Bond \& van Wilgen 1996), que podem ser observadas em curto prazo, e são importantes no reconhecimento de respostas do sistema ao fogo. Apesar do esforço recente de grupos de pesquisa para aumentar o entendimento sobre o efeito do fogo na vegetação do Cerrado (Dolores et al. 2010; Fidelis \& Pivello 2011; Antar 2015; Durigan \& Ratter 2016; Fichino et al. 2016; Gorgone-barbosa et al. 2016; Rissi 2016), ainda são poucas as informações disponíveis para gestores de Unidades de Conservação que realizam o manejo integrado do fogo (MMA 1999, 2004; Hoffman 2012). 
A escolha da época de queima por um gestor está normalmente relacionada a diferentes atributos do material combustível, dentre os quais a umidade. A manipulação da época de fogo gera queimas distintas, com magnitudes e aspectos espaciais diferentes, que pode influenciar a dinâmica das comunidades (Pyke et al. 2010). A época de queima pode influenciar, por exemplo, padrões de floração (Platt, Evans \& Davis 1988; Rissi 2016), a habilidade competitiva das espécies (Whelan 1995; Bond \& van Wilgen 1996) e a estrutura e dinâmica da vegetação (Miranda et al. 2009).

Com base nesse panorama, o objetivo deste estudo foi avaliar o efeito em curto prazo da época de queima na vegetação nativa de campo sujo, na Estação Ecológica de Itirapina, SP. Com base nas informações levantadas neste trabalho, pretendemos responder se diferentes épocas de queima afetam diferentemente os componentes da comunidade nativa herbáceo-arbustiva do campo sujo e de que forma. Com o presente estudo, esperamos contribuir com a expansão da base de conhecimento sobre efeitos do fogo no Cerrado, a fim de subsidiar estratégias de manejo. 


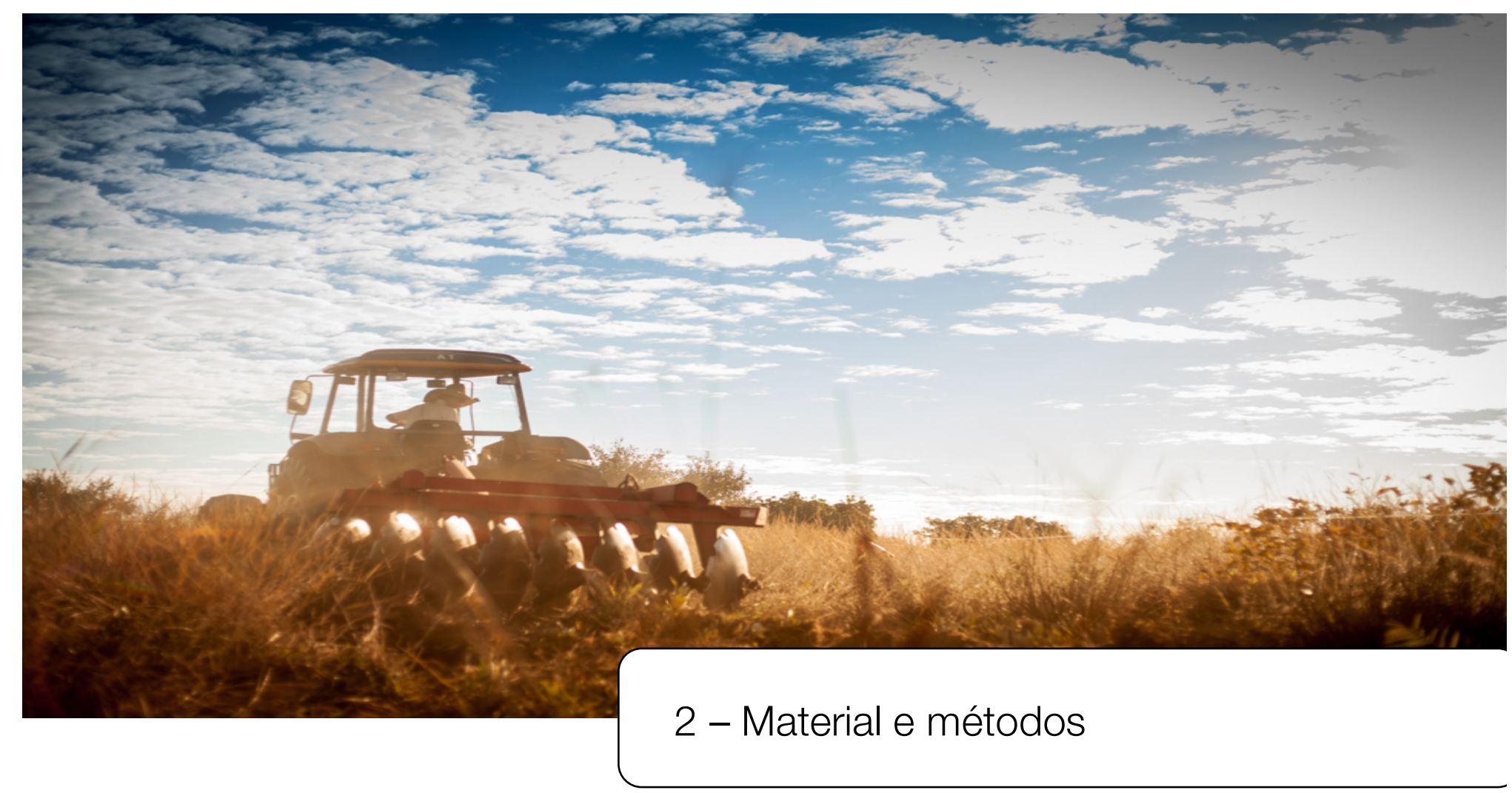

\section{1 Área de estudo}

Conduzimos este estudo na Estação Ecológica de Itirapina (EEI). A EEl está localizada no estado de São Paulo e conta com área de aproximadamente 2.300 ha (Zanchetta et al. 2006). Em seu interior, encontram-se as fisionomias de campo limpo, campo sujo e campo cerrado, além de porções menores de cerrado sensu stricto, mata de galeria e brejos. Algumas porções de campo limpo são alagáveis na estação chuvosa (Zanchetta et al. 2006).

Conduzimos os experimentos dentro da Zona de Interferência Experimental (ZIE), um local conhecido como "antigo talhão 93", onde é permitida a condução de pesquisas perturbatórias (Figuras 1 e 2). O antigo talhão 93 conta com uma área de aproximadamente 29 ha e recebe este nome porque abrigava um plantio de Pinus caribaea hondurensis, cujo corte foi realizado no ano 2000. Atualmente, é uma área de campo sujo em regeneração (Figura 3), que apresenta focos de invasão pelas gramíneas exóticas Melinis minutiflora (capim-gordura, Figura 4A) e Urochloa 
brizantha (capim-braquiária, Figura 4B). O antigo talhão 93 apresenta baixa riqueza quando comparado à áreas de campo sujo adjacentes (observação pessoal). Na área predominam graminóides e pequenos arbustos (tamanho inferior a 1,5 m). Estão presentes, em menor frequência, árvores esparsas, herbáceas não graminóides e palmeiras. Essa área apresenta um histórico de aproximadamente 20 anos de supressão de fogo. Como resultado, há uma quantidade expressiva de material combustível acumulado no solo.

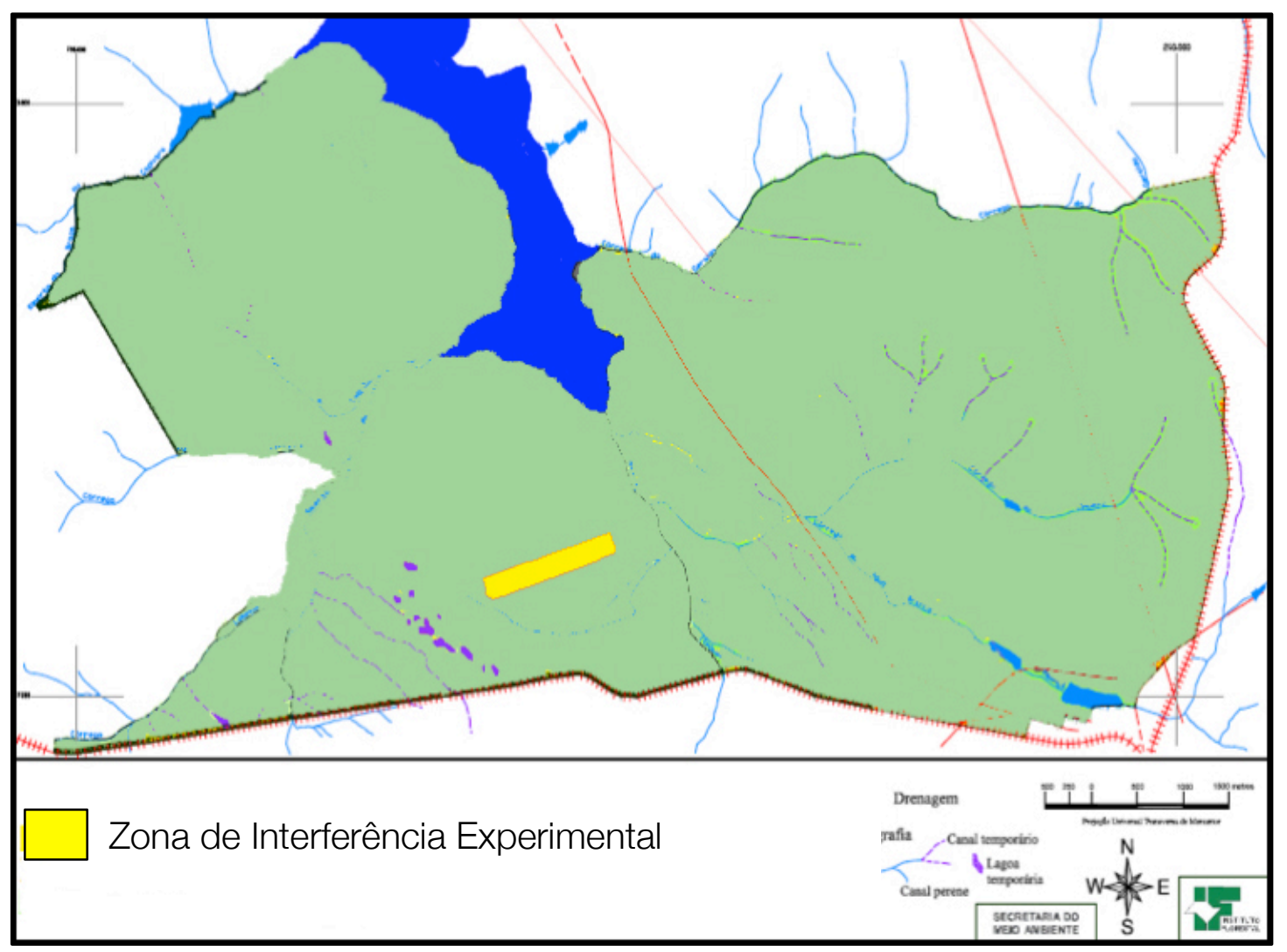

Figura 1: Detalhe da Zona de Interferência Experimental da Estação Ecológica e Experimental de Itirapina, Itirapina, SP. (Adaptado de ZANCHETTA et al., 2006). 


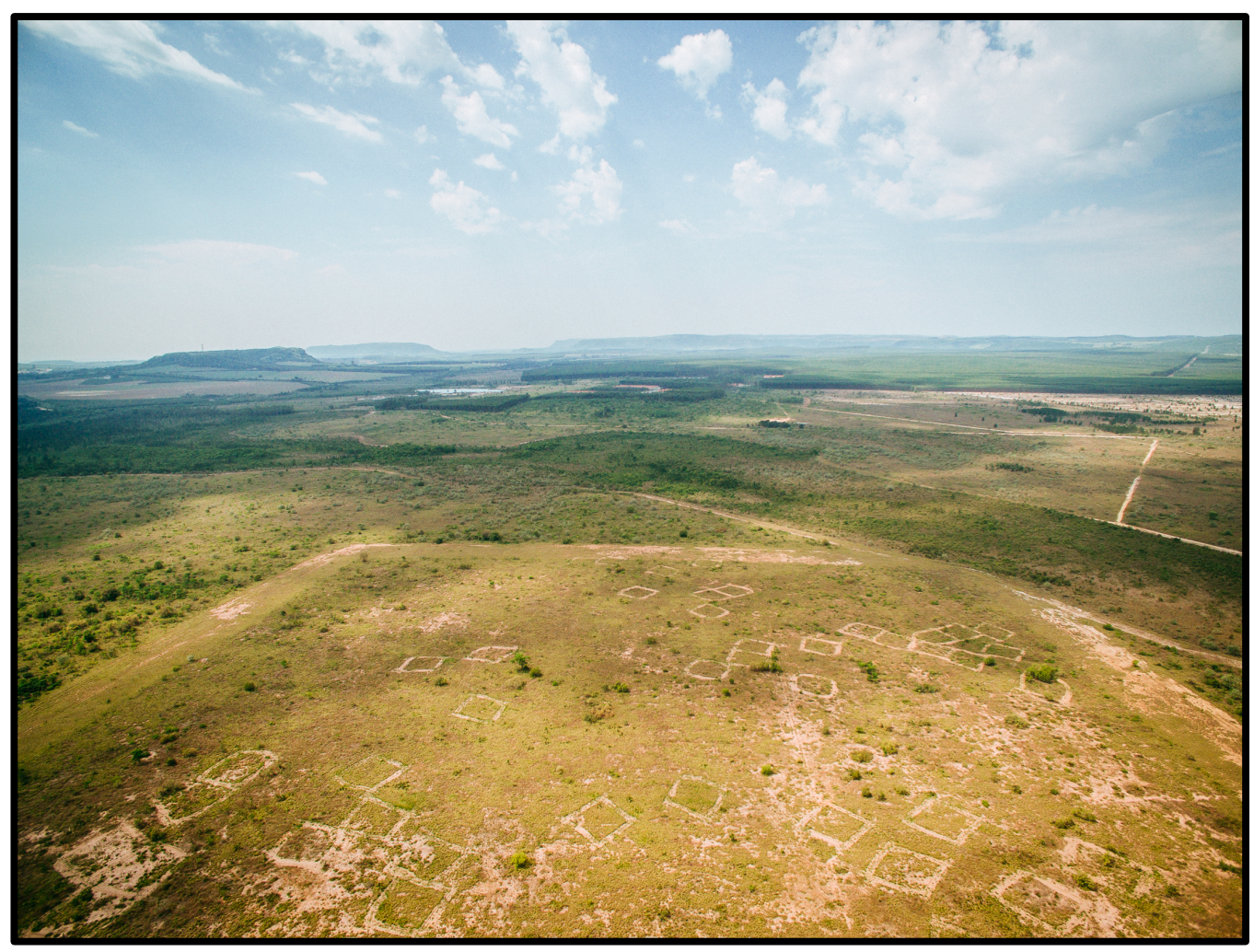

Figura 2: Fotografia aérea do antigo talhão 93, localizado na Zona de Interferência Experimental da Estação Ecológica de Itirapina. Os quadrados são as parcelas submetidas ao experimento de queima (Crédito: Tipuana Imagens Aéreas).

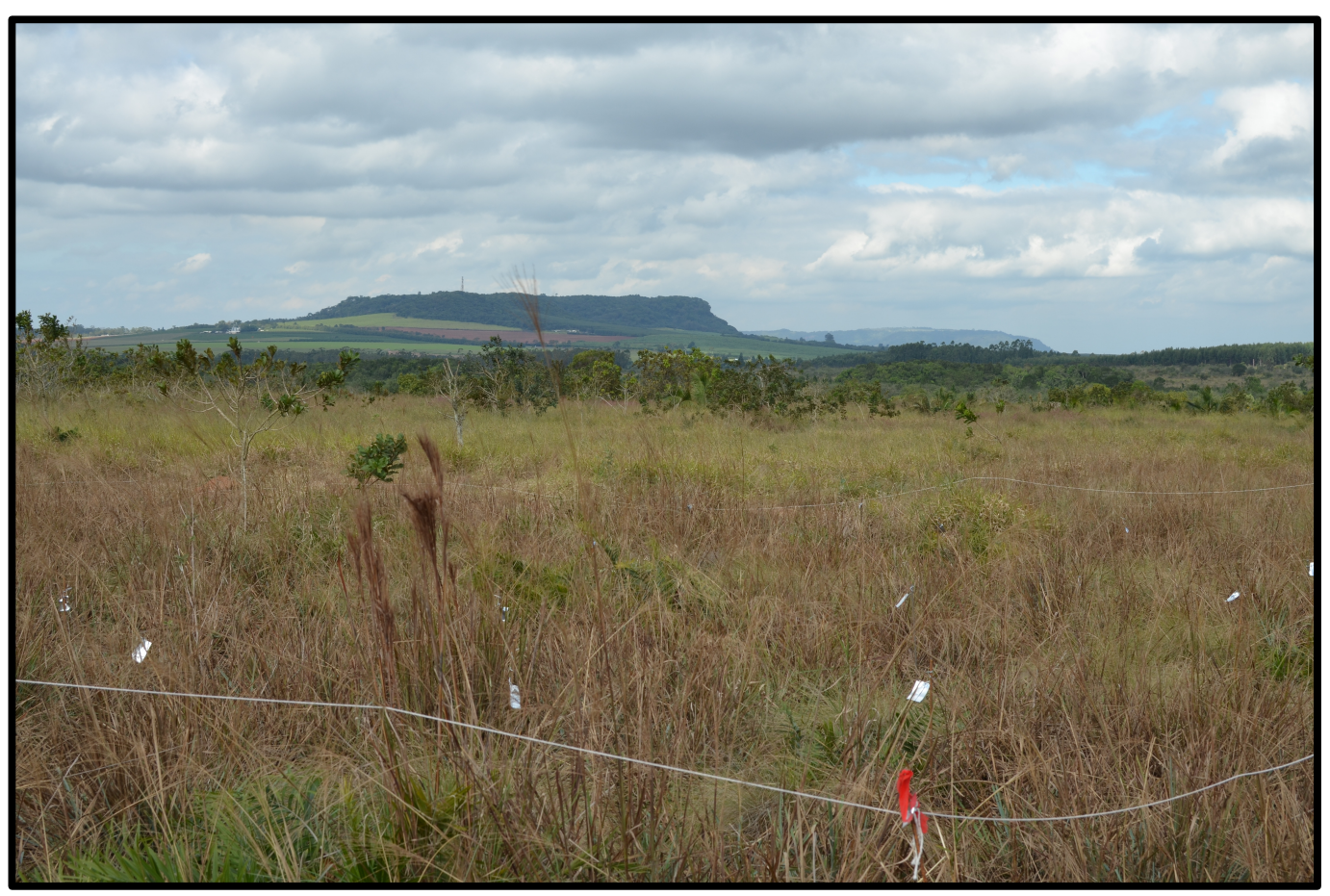

Figura 3: Aspecto do campo sujo localizado dentro da Zona de Interferência Experimental da Estação Ecológica de Itirapina. O barbante delimita a parcela submetida ao experimento e as placas metálicas delimitam as sub-parcelas fixas. 


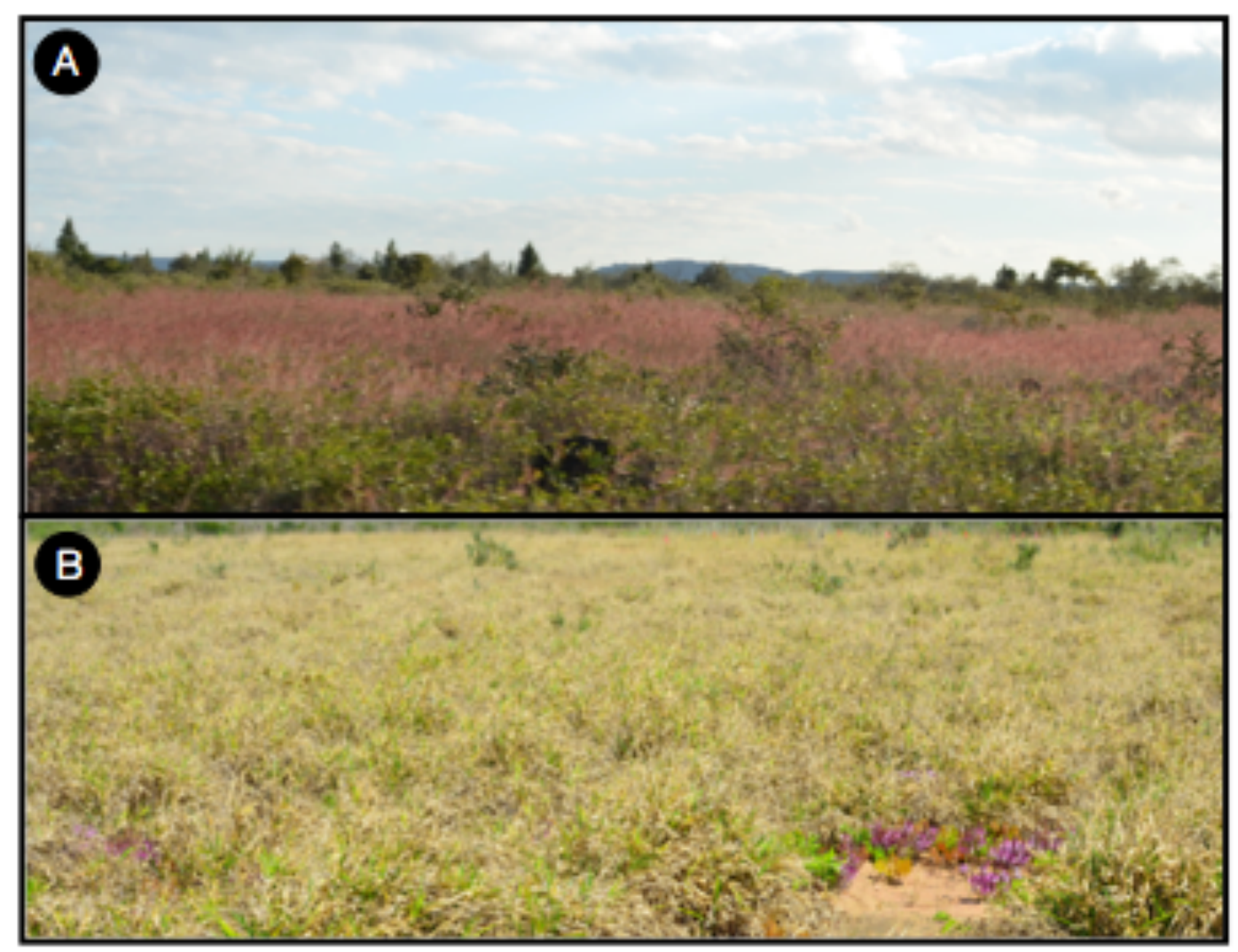

Figura 4: Aspecto do campo sujo com presença de espécies invasoras (Zona de Interferência Experimental da Estação Ecológica de Itirapina). A: Mancha de Melinis minutiflora, com inflorescências de cor roxa. B: Mancha de Urochloa brizantha.

\subsection{Desenho amostral e coleta de dados}

Para responder como épocas de queima afetam diferentemente os componentes do estrato rasteiro, delineamos um experimento com queimadas prescritas, que compreendeu atividades de campo pré-queima, queima e pós-queima. Durante o pré-queima estabelecemos parcelas, definimos três épocas de queima (aqui chamadas de tratamentos) e observamos o estrato rasteiro imediatamente antes das queimadas experimentais. Realizamos as queimadas controladas e observamos a recuperação do estrato herbáceo-arbustivo de cada tratamento por 
um ano. Descrevemos abaixo como foram realizadas cada uma das etapas de trabalho.

\subsubsection{Estabelecimento das parcelas e dos tratamentos de queima}

Consideramos como áreas elegíveis locais com dominância de espécies da comunidade herbáceo-arbustiva nativa. Estabelecemos aleatoriamente 16 parcelas experimentais de $15 \times 15$ m no antigo talhão 93 (Figura 5), 4 para cada um dos três tratamentos de queima e 4 parcelas que não foram submetidas à queima (controle). As parcelas apresentavam cobertura do solo de vegetação nativa superior a $60 \%$ e não continham árvores maiores que $1,5 \mathrm{~m}$ de altura. As laterais das parcelas ficavam distantes umas das outras por no mínimo $4 \mathrm{~m}$. Determinamos três épocas do ano para a realização dos tratamentos de queima, conforme a pluviosidade (tabela 1, Figura 6). Determinamos as datas das queimas Precoce e Tardia, visando simular queimadas naturais (Ramos-Neto \& Pivello 2000), entre estações secas e úmidas. Determinamos a data da queima Modal a fim de simular queimadas antropogênicas, no meio da estação seca (Coutinho 1990). 


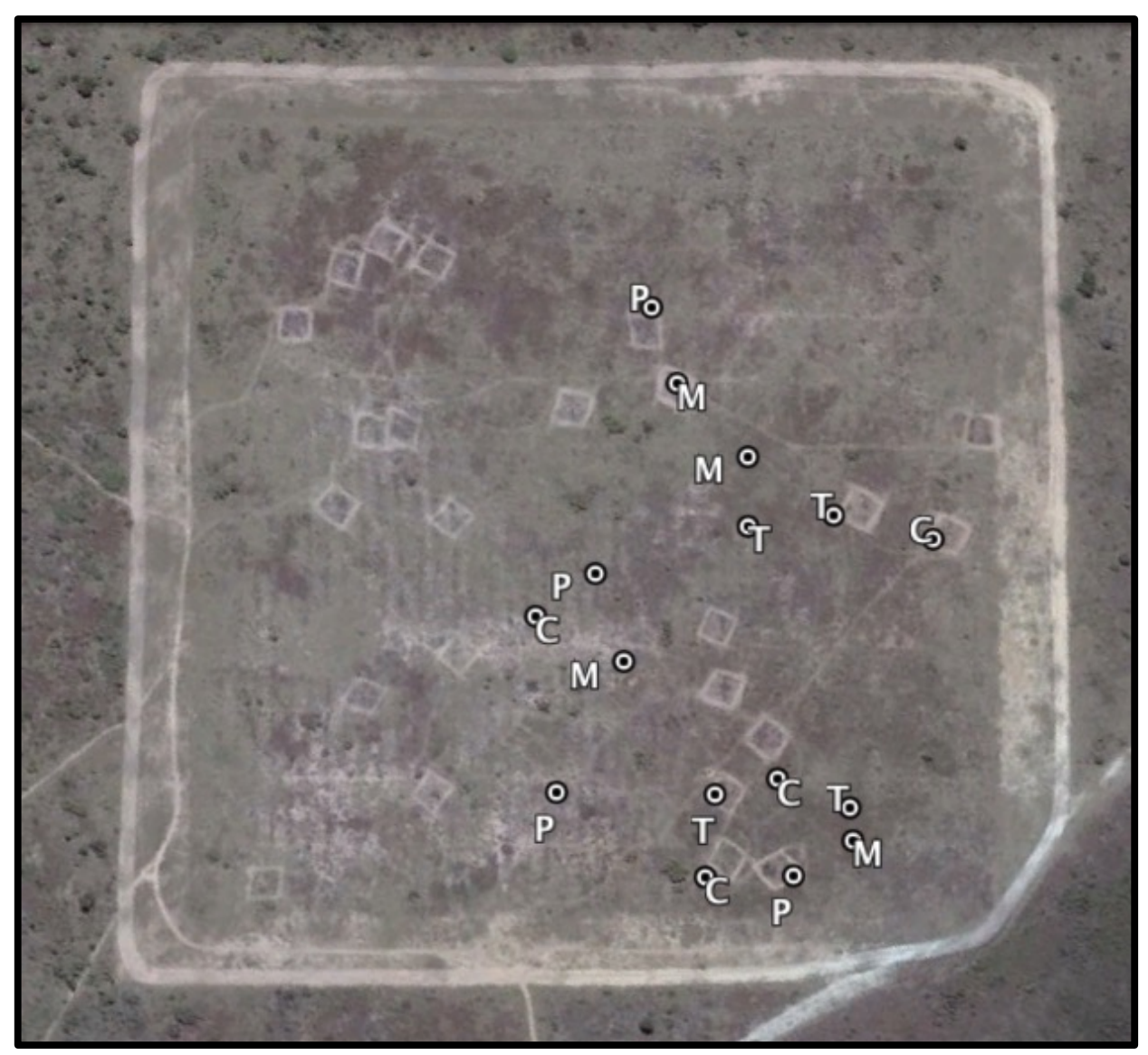

Figura 5: Imagem aérea do antigo talhão 93, localizado dentro da Zona de Interferência Experimental da Estação Ecológica de Itirapina. Os quadrados avistados são as parcelas submetidas ao experimento. (P) Queima Precoce, (M) Queima Modal, (T) Queima Tardia e (C) Controle (Fonte: Google Earth, 2016).

Tabela 1: Nome e sigla dos tratamentos de queima, mês em que realizamos cada queimada controlada e a relação de cada tratamento com a pluviosidade.

\begin{tabular}{lll}
\hline Tratamentos & Data & Relação com pluviosidade \\
\hline Precoce $(\mathrm{P})$ & Última semana de maio/2014 & Fim da estação chuvosa \\
Modal (M) & Primeira semana de agosto/2014 & Durante a estação seca \\
Tardia (T) & Última semana de outubro de 2014 & Início da estação chuvosa \\
\hline
\end{tabular}




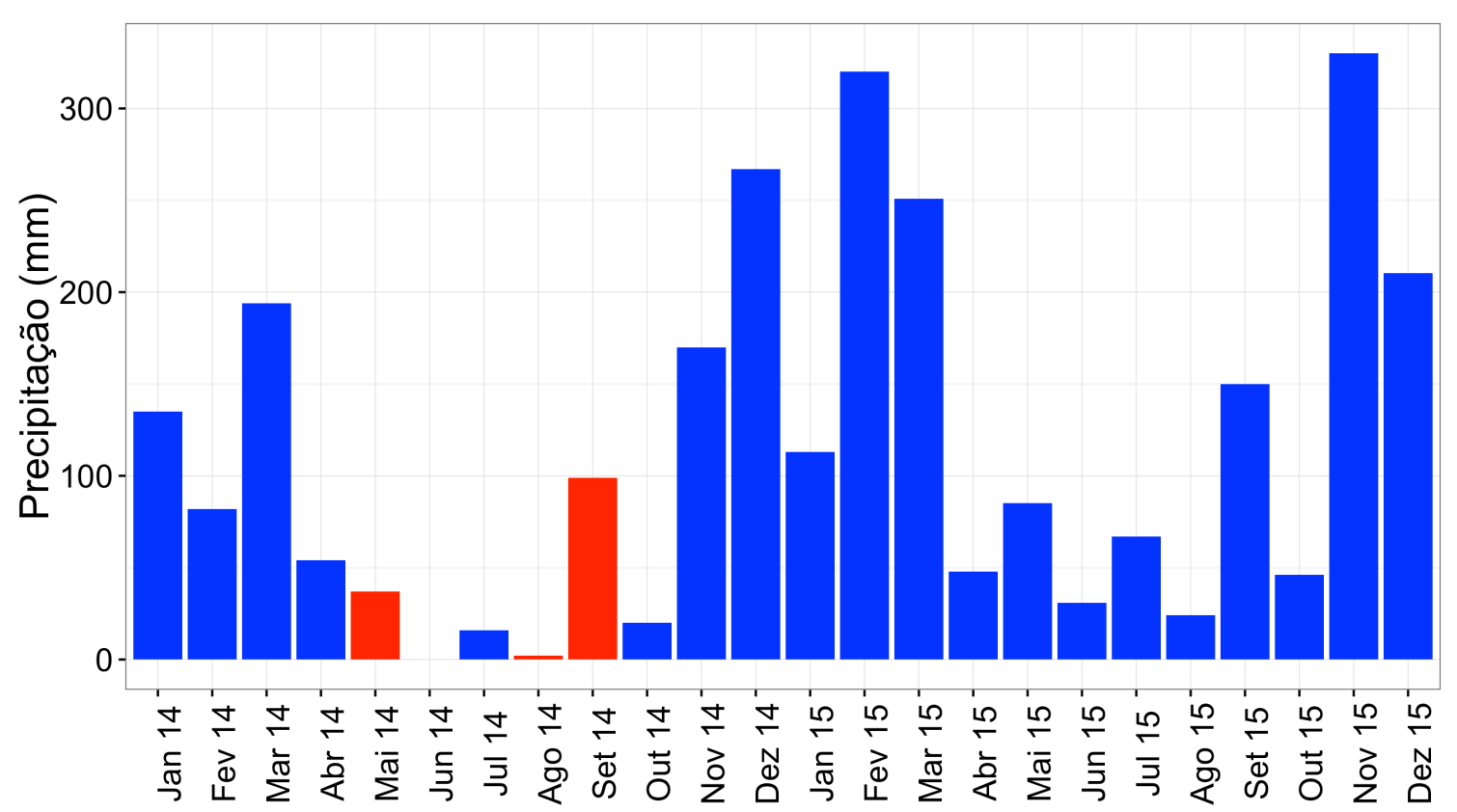

Figura 6: Precipitação mensal registrada na Estação Ecológica de Itirapina entre janeiro de 2014 e dezembro de 2015, período deste estudo. Barras vermelhas representam o mês em que foram realizadas as queimas controladas: última semana de maio (Precoce), primeira semana de agosto (Modal) e última semana de setembro (Tardia).

Para delimitarmos as sub-parcelas, consideramos que cada parcela era formada por 225 quadrados de $1 \mathrm{~m}^{2}$. Descartamos os quadrados que ficavam a até $2 \mathrm{~m}$ das bordas das parcelas para garantir que os limites da parcela não influenciassem os componentes do estrato rasteiro. Em seguida, sorteamos 10 quadrados dentre os restantes e estabelecemos 10 sub-parcelas de $1 \mathrm{~m}^{2}$. Realocamos a sub-parcela em um metro para o lado quando o local sorteado apresentava gramíneas exóticas, formigueiros e/ou troncos de Pinus, já que estes elementos alteram a estrutura e composição da comunidade vegetal e os parâmetros ambientais e de fogo. Portanto, no momento que precedeu as queimadas experimentais não havia nenhuma sub-parcela com presença de espécies exóticas. 


\subsubsection{Condução das queimadas controladas}

Estabelecemos aceiros de $3 \mathrm{~m}$ de largura ao redor de cada parcela. Aceiros constituem faixas de solo sem vegetação e têm como objetivo frear a propagação do fogo, impedindo que ele se alastre para além da área planejada. Realizamos as queimadas experimentais no início ou final do dia, com o auxílio de um "pinga-fogo" e consideramos a direção do vento com um anemômetro (headfire) no momento de iniciar cada queima (Whelan 1995). Conduzimos a queima controlada em cada parcela separadamente, garantindo eventos de fogo independentes e evitando, desta forma, pseudo-replicação. Realizamos todas as queimadas experimentais sob a supervisão de brigadas de incêndio certificadas pelo Centro Nacional de Prevenção e Combate aos Incêndios Florestais (PREVFOGO) e com a ajuda de pesquisadoras da UNESP - Rio Claro (Figura 7). 


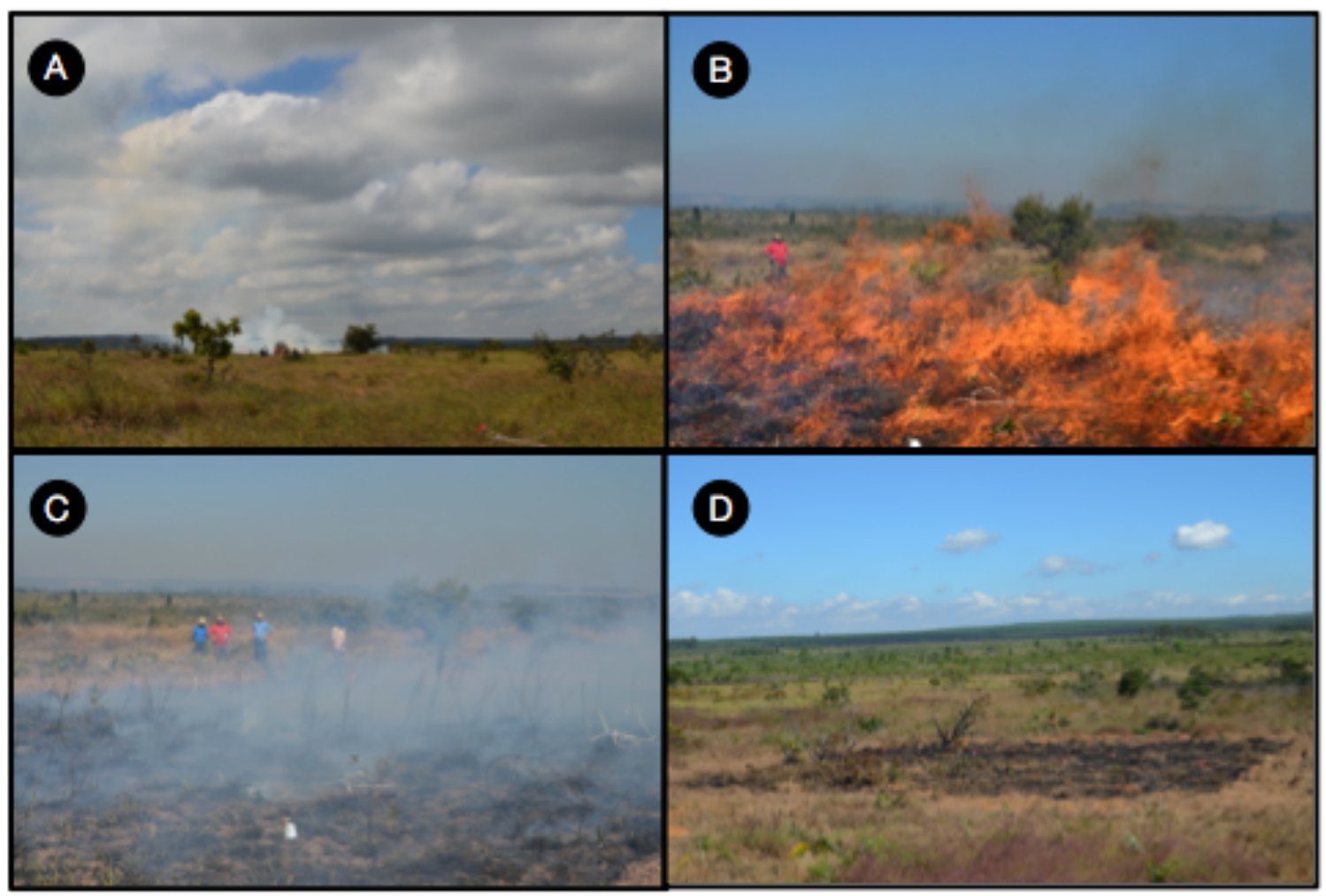

Figura 7: Queimadas realizadas na Zona de Interferência Experimental da Estação Ecológica de Itirapina. A: campo sujo com queimada realizada ao longe. B: queima em Maio de 2014. C: parcela recém queimada. D: aspecto da parcela após 1 hora da queima.

\subsubsection{Coleta de dados: solo e componentes do estrato rasteiro}

Considerando que a cobertura dos componentes rasteiros é afetada por fatores edáficos, foi preciso avaliar se o solo das parcelas possuíam características similares. Coletamos três amostras de solo em cada parcela antes do início das queimadas experimentais. Enviamos as amostras de solo ao CENA (Centro de Energia Nuclear na Agricultura, Campus Luiz de Queiroz), para análise da fertilidade das amostras (pH, Al/H, matéria orgânica, $\mathrm{P}, \mathrm{K}, \mathrm{Ca}, \mathrm{Mg})$ de acordo com o método oficial do Estado de São Paulo (IAC, Raij \& Quaggio 1983). A análise da textura foi realizada no Departamento de Ecologia da Universidade de São Paulo por um 
técnico especializado. Encontramos que as parcelas possuíam características similares (Anexo 1) e pudemos prosseguir com o levantamento de dados da cobertura dos componentes rasteiros.

Utilizamos a estimativa visual de cobertura como método para acessar informações sobre o estrato herbáceo-arbustivo, antes e após as queimadas controladas. A estimativa visual de cobertura é um método amplamente utilizado pela simplicidade e rapidez na coleta de dados. É considerado também um método mais eficiente do que os métodos de ponto e de linha para estimar a cobertura de espécies raras (Elzinga, Salzer \& Willoughby 1998). Entretanto, é um método criticado pelo viés associado ao observador (Coulloudon et al. 1996; Elzinga et al. 1998). Utilizamos algumas técnicas para reduzir esse viés. Utilizamos um quadrante de $1 \mathrm{~m}^{2}$ subdividido em 100 quadrados de $10 \mathrm{~cm}^{2}$ para garantir maior precisão nas estimativas visuais durante duas primeiras coletas (Elzinga et al. 1998). Por fim, apenas uma pessoa foi responsável pelos levantamentos de cobertura.

Estimamos visualmente a porcentagem de cobertura das parcelas submetidas a cada uma das três queimas controladas $(P, M$ e $T)$ e das parcelas controle, em quatro momentos ao longo de um ano (tabela 2). A cada observação de parcelas submetidas a um tratamento de queima, observamos também as parcelas controle. Apesar das parcelas controle serem as mesmas para todos os tratamentos de queima, a partir daqui irei me referir aos controles como Controle Precoce (CP), Controle Modal (CM) e Controle Tardia (CP) para fins didáticos. O que difere $\mathrm{O} \mathrm{CP}$, do $\mathrm{CM}$ e do CT é apenas o momento da observação, que coincide sempre com a observação do respectivo tratamento de queima. O tempo 
t0 representa a observação imediatamente anterior à queima, t1 é a observação 4 meses após a queima, t2 é a observação 8 meses após a queima e t3 é a observação 12 meses após a queima.

Tabela 2: Observações realizadas para cada tratamento de fogo e seu controle, entre maio de 2014 e setembro de 2015.

\begin{tabular}{ccccc}
\hline Coleta & $\begin{array}{c}\text { Tempo em relação } \\
\text { à queima }\end{array}$ & $\begin{array}{c}\text { Precoce e } \\
\text { Controle } \\
\text { Precoce }\end{array}$ & $\begin{array}{c}\text { Modal e } \\
\text { Controle } \\
\text { Modal }\end{array}$ & $\begin{array}{c}\text { Tardia e } \\
\text { Controle } \\
\text { Tardia }\end{array}$ \\
\hline t0 & 1 dia antes & mai/14 & ago/14 & set/14 \\
t1 & 4 meses após & set/14 & dez/14 & jan/15 \\
t2 & 8 meses após & jan/15 & abr/15 & mai/15 \\
t3 & 12 meses após & mai/15 & ago/15 & set/15 \\
\hline
\end{tabular}

Classificamos os componentes do estrato rasteiro em graminóides, arbustos, herbáceas não graminóides, palmeiras, necromassa e solo nu de acordo com as características de cada componente (tabela 3) e registramos as estimativas visuais de cobertura para cada um desses componentes em cada sub-parcela.

Tabela 3: Componentes do estrato rasteiro e respectivas definições.

Componentes do Definição
estrato rasteiro

Geralmente monocotiledôneas. Apresentam folhas lineares e

Graminóides eretas e possuem alto grau de rebrotamento. Incluem espécies dos grupos Poaceae, Xyridaceae, Eriocaulaceae, Amaryllidaceae, Liliaceae. 


\begin{tabular}{ll}
\hline $\begin{array}{l}\text { Herbáceas não } \\
\text { graminóides } \\
\text { (forbs) }\end{array}$ & $\begin{array}{l}\text { São ervas que não apresentam folhas lineares e eretas, } \\
\text { geralmente dicotiledôneas. Possuem menor grau de } \\
\text { rebrotamento que as graminóides. } \\
\text { Apresentam lenho e possuem menor grau de rebrotamento }\end{array}$ \\
$\begin{array}{l}\text { que as herbáceas não graminóides. Contemplam arbustos } \\
\text { de até 1,5 m de altura. }\end{array}$ \\
Palmeiras & Perenes, com caule do tipo estipe. \\
Solo nu & Biomassa seca e vegetação morta sobre o solo. \\
\end{tabular}

\subsection{Análise de dados}

Para caracterizar a dinâmica da cobertura do estrato rasteiro ao longo do tempo do experimento, analisamos qualitativamente os dados das parcelas controle e dos tratamentos. Durante o decorrer deste trabalho constatamos a invasão das parcelas experimentais pelas gramíneas exóticas Melinis minutiflora e Urochloa brizantha. Dados de estimativa de cobertura das espécies invasoras também foram analisados qualitativamente.

Considerando que a sazonalidade climática afeta a cobertura dos componentes do estrato rasteiro (Eiten 1972) e que as observações (t0, t1, t2 e t3) para cada queima foram realizadas em meses distintos do ano, não é possível comparar a estimativa de cobertura entre tempos de tratamentos de queima. Para tornar comparáveis os resultados dos diferentes tratamentos a cada tempo, nós utilizamos a diferença entre cada tratamento e seu controle a cada tempo. 
Para obter a diferença entre um tratamento e seu controle, geramos a mediana das coberturas de cada componente a cada tempo, para cada um dos controles (CP, $\mathrm{CM}$ e $\mathrm{CT})$. Em seguida, para cada componente a cada tempo, subtraímos a mediana de CP, CM e CT dos valores brutos de cobertura em P, M e T, respectivamente. Os dados de estimativa visual da cobertura para cada componente variavam entre 0 a 1 e ao subtrair controles dos respectivos tratamentos, geramos valores que variavam entre -1 a +1 . Valores positivos representam maior cobertura no tratamento do que no controle e valores negativos representam menor cobertura no tratamento do que no controle. Fizemos histogramas das diferenças $(\Delta)$ de cada componente para avaliar a distribuição dos dados (Anexo 2).

É preciso ressaltar que um mesmo conjunto de dados de diferenças pode ser gerado por conjuntos de dados de tratamentos e controles distintos. Suponha, por exemplo, um conjunto de dados onde a diferença de cobertura se mantém constante e inalterada ao longo do tempo (Figura 8A). Esta diferença pode ser proveniente da ausência de mudanças na cobertura ao longo do tempo nos grupos tratamento e controle (Figura 8B), mas pode também ser resultado de uma alteração de mesma magnitude nos grupos tratamento e controle (Figura 8C). Portanto, para investigar qual o processo que desencadeou as diferenças observadas é preciso retornar aos valores brutos e analisar as tendências da cobertura ao longo do tempo. 


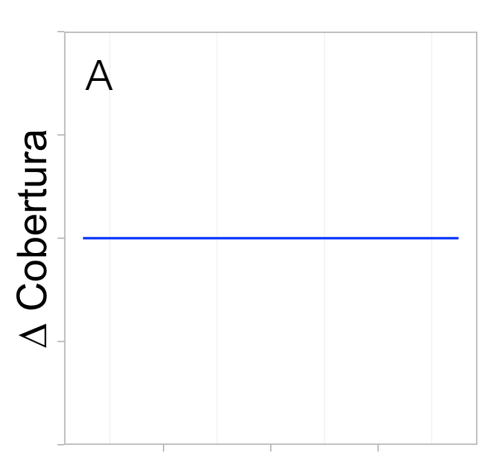

Tempo (mês)

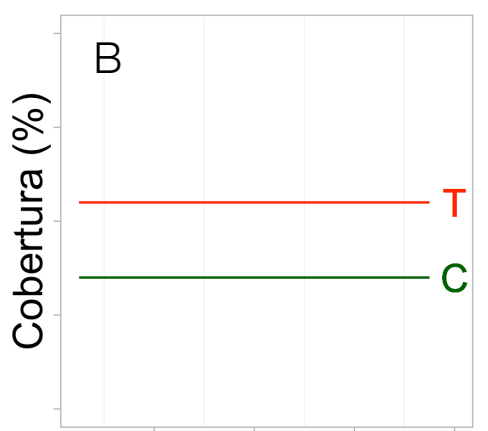

Tempo (mês)

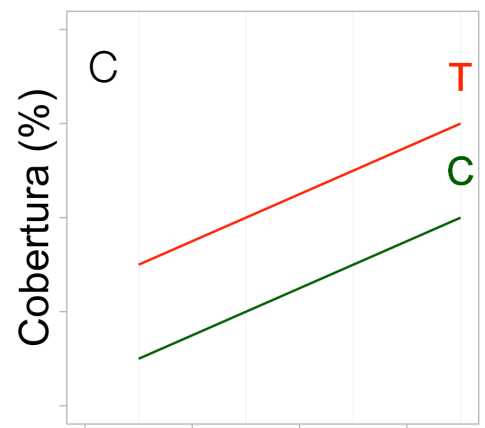

Tempo (mês)

Figura 8: Exemplo de um conjunto de dados teórico. (A) Valor de diferença (em azul) entre cobertura de grupos tratamento e controle ao longo do tempo. $O$ padrão encontrado pode ser oriundo de dados de cobertura constantes (B) ou crescentes (C) de grupos tratamento e controle. Linhas vermelhas com a letra $T$ representam dados teóricos do grupo tratamento e linhas verdes com a letra $\mathrm{C}$ representam dados teóricos do grupo controle.

Para entender como as diferentes épocas de queima interferem nos componentes do estrato rasteiro, modelamos as diferenças entre cobertura de tratamentos e controles (variáveis dependentes fixas) em função do tratamento de queima ( $\mathrm{P}, \mathrm{M}$ e $\mathrm{T})$ e do tempo após as queimas (t0, t1, t2 1 t3, variáveis independentes), para cada componente. Utilizamos modelos lineares gerais mistos (LMMs) quando a distribuição não se diferenciava de uma normal (necromassa, solo nu e graminóides) e modelos lineares generalizados mistos (GLMMs), quando a distribuição se aproximava de uma gama (arbustos, herbáceas não graminóides e palmeiras). No último caso, somamos 1 aos dados para deixá-los positivos.

Consideramos o tempo e o tratamento como efeitos fixos do modelo, de acordo com as hipóteses de que o tempo após a queima e diferentes épocas de queima podem influenciar a cobertura. Selecionamos a melhor estrutura aleatória entre três possibilidades para cada um dos componentes do estrato rasteiro (tabela 
4 - a, b e c), considerando a parcela, a parcela ao longo do tempo e ambos como efeitos aleatórios (Bates 2010)

Para cada componente do estrato rasteiro, construímos 5 modelos candidatos com todas as combinações aditivas e interativas das variáveis independentes, além do modelo nulo (Tabela 4 - 1 a 5). Os modelos descrevem a relação entre uma variável resposta e uma ou mais covariáveis (Bates 2010) e contemplam dados que não preenchem os requisitos de normalidade, homocedasticidade e/ou independência (Zuur et al. 2009), como é o caso dos dados deste estudo. Ao contrário do teste de hipóteses tradicional, a seleção de modelos é uma abordagem que permite que diferentes hipóteses sejam confrontadas. Os modelos representam hipóteses e a seleção ordena os modelos de acordo com o melhor ajuste aos dados, fornecendo suporte a uma hipótese em particular ou podendo ser utilizado para fazer inferências com base no peso de um conjunto de modelos que competem entre si (Burnham \& Anderson 2002; Johnson \& Omland 2016).

Os coeficientes dos modelos foram estimados por máxima verossimilhança. Comparamos os modelos utilizando a seleção de modelos baseadas no Critério de seleção de Akaike corrigido para pequenos tamanhos amostrais (AlCc, Burnham \& Anderson 2002). Consideramos o modelo com menor valor de AlCc como a hipótese estatística mais plausível e modelos com diferenças $\triangle \mathrm{AlCc}$ menores que dois como igualmente plausíveis. Desenvolvemos todas as análises de dados no ambiente de programação R (R Core Team 2015), com os pacotes Ime4 (Bates et al. 2015) e glmmADMB (Bolker et al. 2012). 
Tabela 4: Efeitos aleatórios (a, b e c) e efeitos fixos (1 a 5) utilizados na seleção de modelos.

\begin{tabular}{|c|c|c|c|}
\hline \multicolumn{2}{|c|}{ Efeitos } & Estrutura dos efeitos & Descrição do modelo \\
\hline \multirow{3}{*}{ 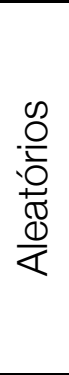 } & a & + (1|parcela/sub-parcela) & $\begin{array}{l}\text { Variação aleatória de sub-parcelas } \\
\text { aninhadas em parcelas. }\end{array}$ \\
\hline & b & + (tempo|parcela/sub-parcela) & $\begin{array}{l}\text { Variação aleatória de sub-parcelas } \\
\text { aninhadas em parcelas para cada } \\
\text { tempo. }\end{array}$ \\
\hline & c & $\begin{array}{l}\text { + (1|parcela) + } \\
\text { (tempo|parcela/sub-parcela) }\end{array}$ & Combinação dos efeitos 'a' e 'b' \\
\hline \multirow{5}{*}{ 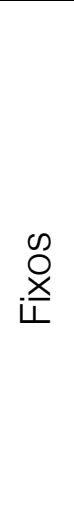 } & 1 & $\sim$ tratamento*tempo & $\begin{array}{l}\text { Tratamento, tempo e a interação entre } \\
\text { eles como efeitos fixos. }\end{array}$ \\
\hline & 2 & $\sim$ tratamento + tempo & Tratamento e tempo como efeitos fixos. \\
\hline & 3 & $\sim$ tratamento & Apenas tratamento como efeito fixo. \\
\hline & 4 & $\sim$ tempo & Apenas tempo como efeito fixo. \\
\hline & 5 & $\sim 1$ & Modelo nulo. \\
\hline
\end{tabular}




\section{3 - Resultados}

\subsection{Variação da cobertura média conforme sazonalidade}

Entre maio de 2014 e setembro de 2015, houve alteração de cobertura de componentes rasteiros das parcelas controle (Figura 9), com valores médios de cobertura variando de $56 \%$ a $72 \%$ para graminóides, $41 \%$ a $50 \%$ para necromassa, 32\% a 51\% para solo nu e 18\% para 45\% para arbusto, sendo que valores de palmeira e herbácea não graminóide permaneceram relativamente constantes. O período chuvoso que precede este aumento (janeiro a março de 2015, Figura 4) contou com $686 \mathrm{~mm}$ de chuva enquanto que o mesmo período em 2014 contou com precipitação de 411 mm (Figura 6).

Entre maio de 2014 e maio de 2015 os valores médios de cobertura em parcelas submetidas à queima Precoce oscilaram entre 32\% e $72 \%$ para graminóides, $19 \%$ e 58\% para solo nu, 22\% e 58\% para necromassa, 9\% e 26\% para arbusto, 9\% e 16\% para palmeira e 5\% e 7\% para herbácea não graminóide. Entre agosto de 2014 e agosto de 2015 os valores médios de cobertura em 
parcelas submetidas à queima Modal oscilaram entre $39 \%$ e $71 \%$ para graminóides, 20\% e 60\% para solo nu, 20\% e 58\% para necromassa, 18\% e 36\% para arbusto e permaneceram relativamente constantes para palmeira e herbácea não graminóide. Entre setembro de 2014 e setembro de 2015 os valores médios de cobertura em parcelas submetidas à queima Tardia oscilaram entre 51\% e 77\% para graminóides, 18\% e 58\% para solo nu, 20\% e 69\% para necromassa, 33\% e 44\% para arbusto e permaneceram relativamente constantes para palmeira e herbácea não graminóide. Como esperado, as queimas induziram alterações nos valores médios de cobertura dos componentes do estrato rasteiro (Figura 10). De maneira geral, notamos a diminuição da cobertura de necromassa e graminóide e o aumento na cobertura de arbustos e solo nu após a queima.

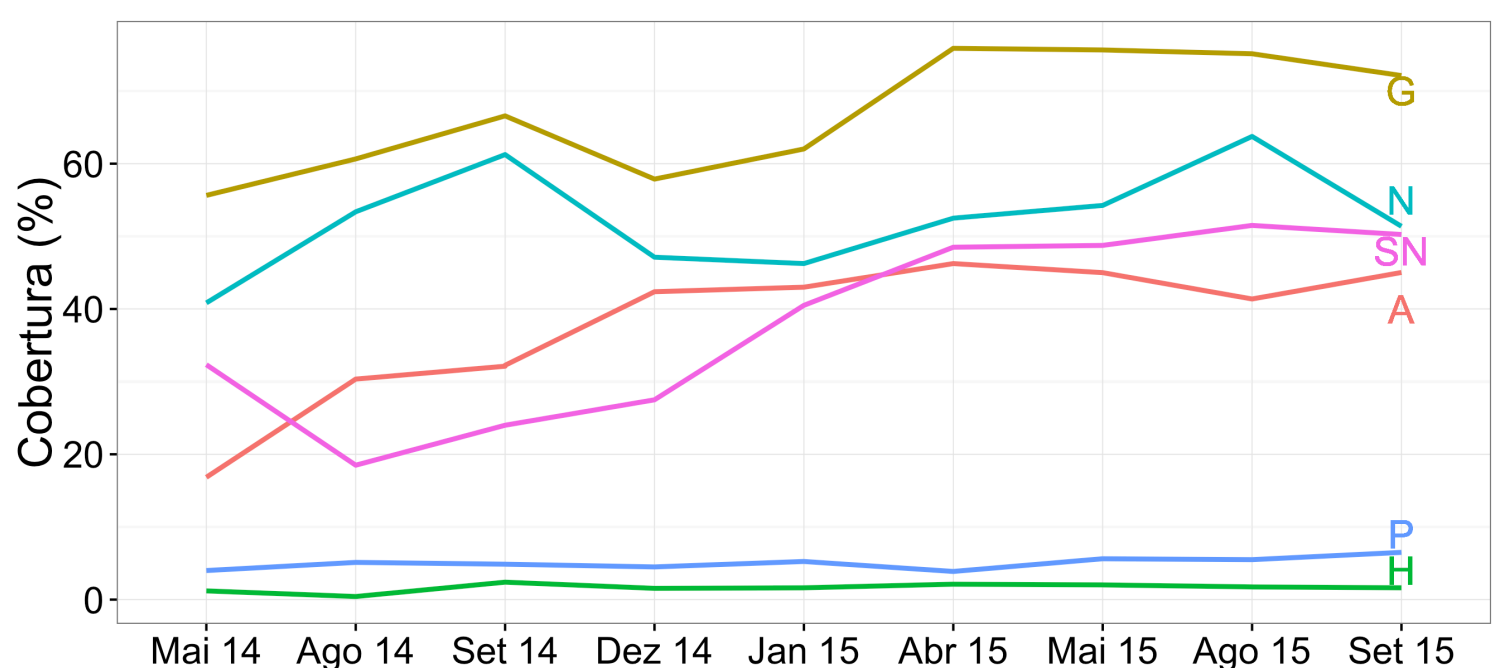

Figura 9: Variação na porcentagem de cobertura nas parcelas controle entre maio de 2014 e setembro de 2015. G=Graminóide, N=Necromassa, SN=Solo nu, A=Arbusto, $P=$ =Palmeira e H=Herbácea não graminóide. 


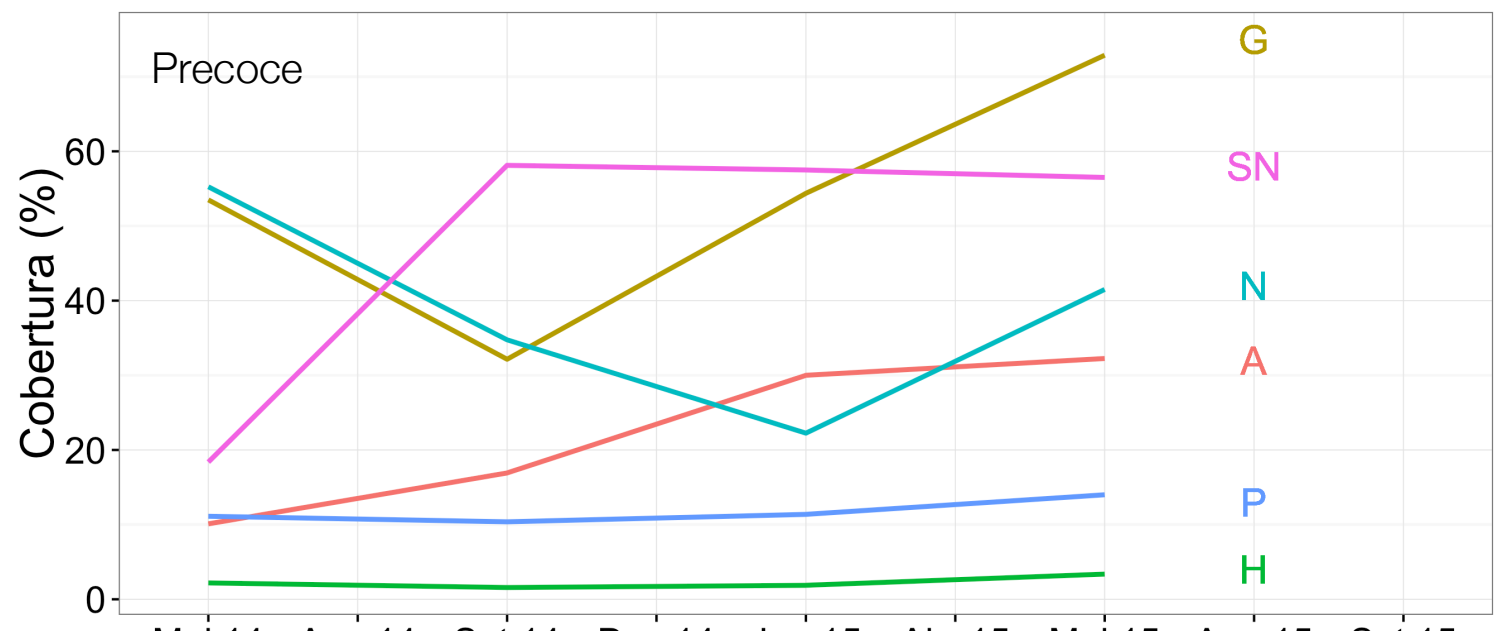

Mai 14 Ago 14 Set 14 Dez 14 Jan 15 Abr 15 Mai 15 Ago 15 Set 15

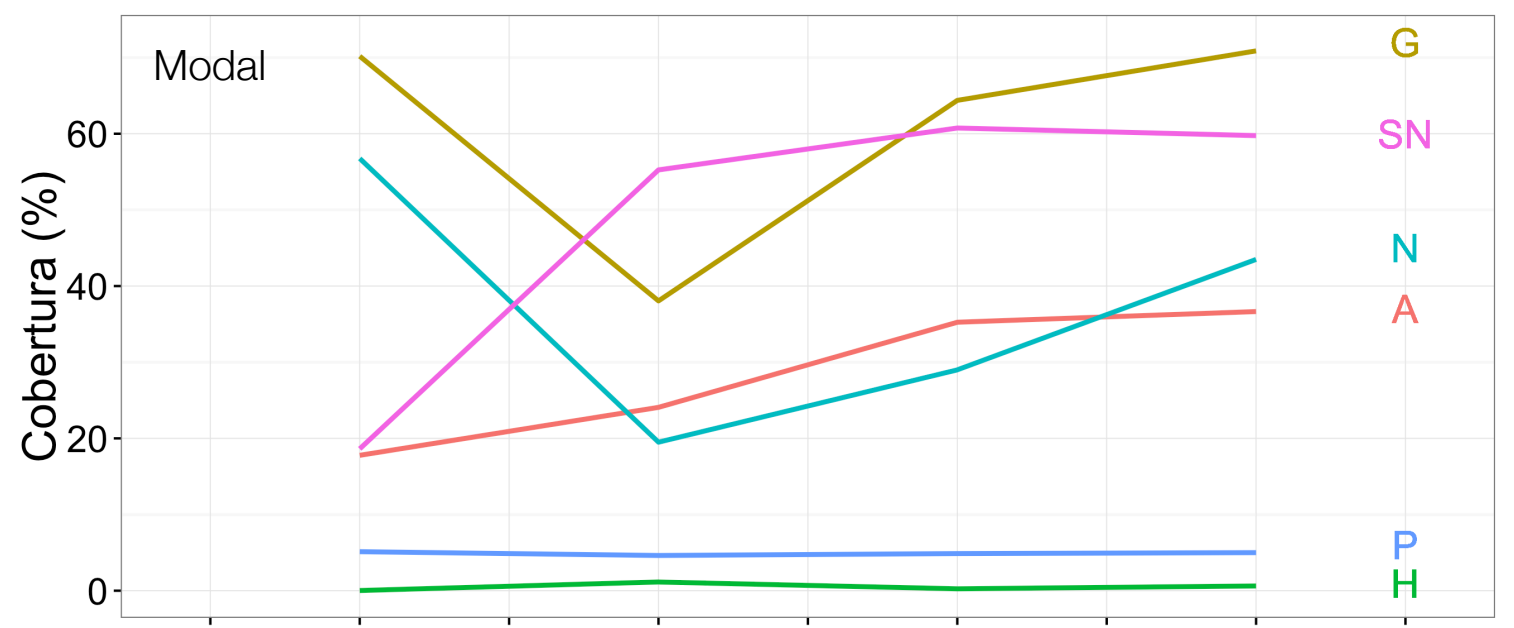

Mai 14 Ago 14 Set 14 Dez 14 Jan 15 Abr 15 Mai 15 Ago 15 Set 15

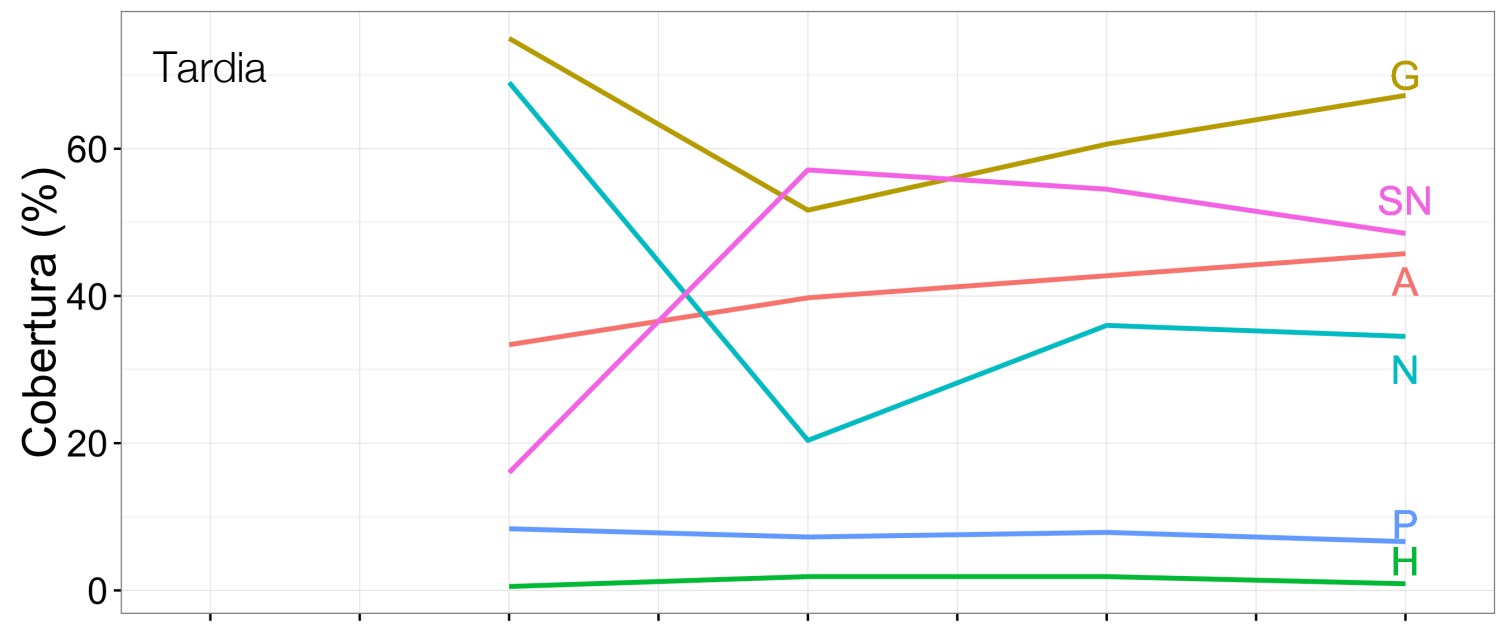

Maí 14 Ago 14 Set 14 Dez 14 Jan 15 Abr 15 Má 15 Ago 15 Set 15

Figura 10: Variação na porcentagem de cobertura nas parcelas submetidas às queimas Precoce, Modal e Tardia entre maio de 2014 e setembro de 2015. $\mathrm{G}=$ Graminóide, $\mathrm{N}=$ Necromassa, $\mathrm{SN}=$ Solo nu, $\mathrm{A}=$ Arbusto, P=Palmeira e $\mathrm{H}=$ Herbácea não graminóide. $\mathrm{O}$ mês de partida das linhas representa a amostragem imediatamente antes da queima. 


\subsection{Gramíneas invasoras}

Durante o decorrer deste trabalho constatamos a invasão de sub-parcelas pelas gramíneas exóticas Urochloa brizantha e Melinis minutiflora. No caso de U. brizantha, a invasão ocorreu nos tratamentos de fogo e nos controles (Figura 11). Nas parcelas submetidas à queima, a invasão ocorreu sempre durante a estação chuvosa. Para Precoce ocorreu entre t1 e t2 (setembro/14 e janeiro/15), para Modal entre t1 e t2 (dezembro/14 e abril/15) e para Tardia entre t0 e t1 (setembro/15 e janeiro/15). A presença de U. brizantha em sub-parcelas foi constatada 21 vezes no tratamento Tardia, 16 vezes no Precoce e 9 vezes no Modal. Os valores mais altos de cobertura de U. brizantha ocorreram no tratamento Tardia (60\%), seguido pela Modal (50\%) e pela Precoce (40\%).

No caso de Melinis minutiflora, a invasão ocorreu apenas nas parcelas controle (Figura 12). Em CP e CM, a invasão ocorreu entre t2 e t3 (janeiro a maio/15 e abril a agosto/15, respectivamente). Em CT a invasão ocorreu entre t1 e t2 (janeiro a maio/15). Constatamos a presença de M. minutiflora em sub-parcelas apenas uma vez em CP e CM e duas vezes em CT. Encontramos valores mais altos de cobertura de $M$. minutiflora na queima Tardia e na Modal (25\%), seguidos pela Precoce (10\%). 


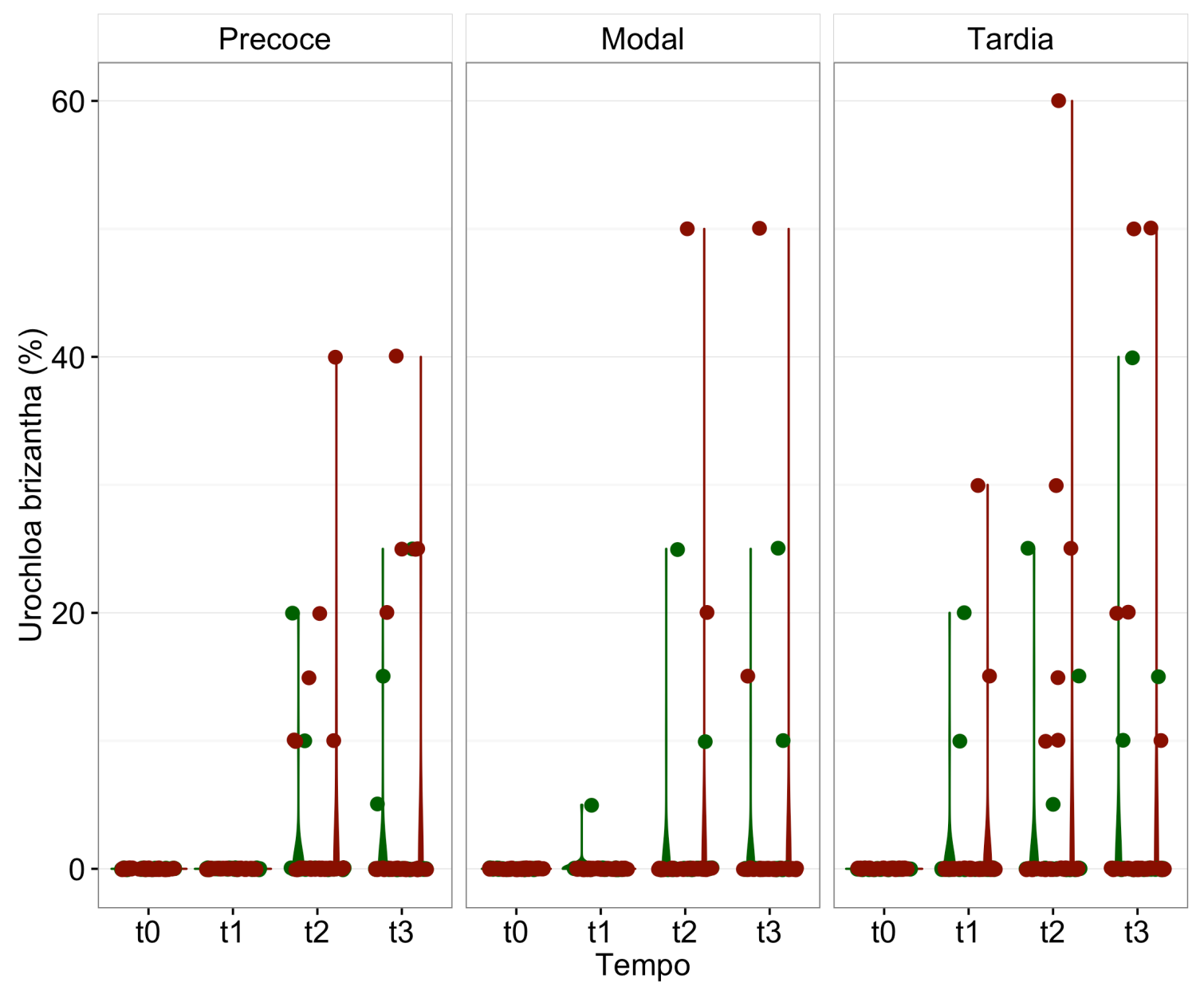

Figura 11: Cobertura de Urochloa brizantha, a cada tempo, nas parcelas controle (em verde) e nas parcelas submetidas à queima (em vermelho) nos tratamentos Precoce, Modal e Tardia. Pontos verdes representam eventos de invasão nas parcelas controle e pontos vermelhos indicam eventos de invasão nas parcelas submetidas à queima. As linhas representam valores máximos de cobertura encontrados e a espessura dos traços indica a densidade de pontos. (t0) imediatamente antes da queima; (t1) quatro meses após a queima; (t2) oito meses após a queima; e (t3) doze meses após as queimadas experimentais. 


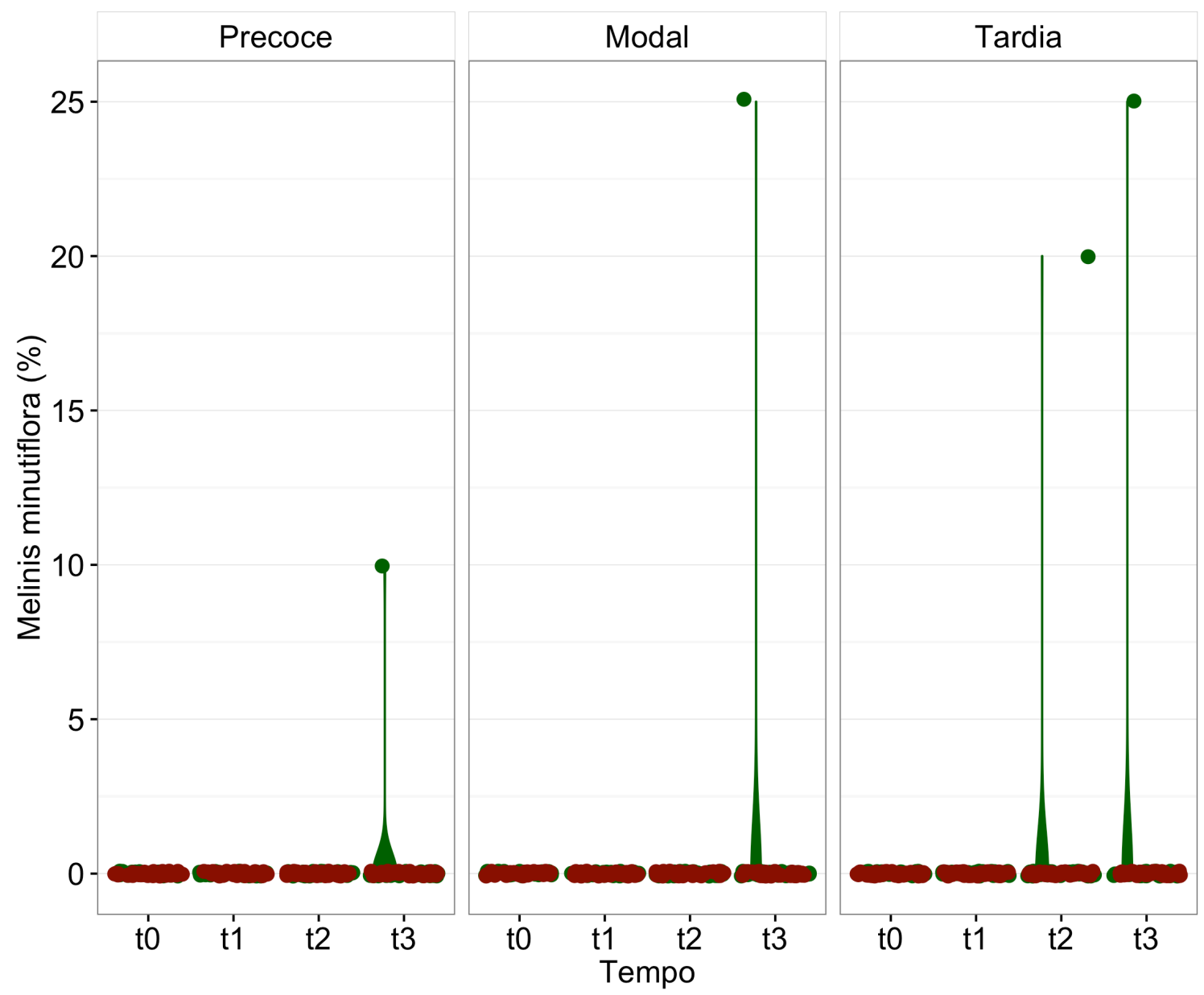

Figura 12: Cobertura de Melinis minutiflora, a cada tempo, nas parcelas controles (em verde) e nas parcelas submetidas à queima (em vermelho) nos tratamentos Precoce, Modal e Tardia. Pontos verdes representam eventos de invasão nas parcelas controle e pontos vermelhos indicam eventos de invasão nas parcelas submetidas à queima. As linhas representam valores máximos de cobertura encontrados e a espessura dos traços indica a densidade de pontos. (t0) imediatamente antes da queima; (t1) quatro meses após a queima; (t2) oito meses após a queima; e (t3) doze meses após as queimadas experimentais.

\subsection{Seleção de modelos}

Os gráficos desta subseção apresentam no eixo $Y$ a diferença entre os valores de cobertura dos tratamentos de queima e a mediana de seus controles, a cada tempo. A esta diferença atribuímos o símbolo $\Delta$. Os valores do eixo $Y$ variam de -1 $a+1$, sendo que valores positivos representam maior cobertura nos tratamentos do 
que nos controles e valores negativos representam menor cobertura nos tratamentos do que nos controles. Os resultados da seleção de estrutura aleatória de cada componente do estrato rasteiro pode ser encontrada no anexo 3.

\subsubsection{Necromassa}

O modelo mais plausível para a necromassa foi o que considerou o tempo como efeito fixo e a parcela variando ao longo do tempo como efeito aleatório (tabela 5). Não obtivemos indícios de que os tratamentos de queima afetaram $\Delta$ necromassa e encontramos que a regeneração pós-fogo foi influenciada pelo tempo após a queima. O padrão de recuperação foi similar para os três tratamentos de queima, com uma queda no $\Delta$ necromassa após a queima e seu aumento progressivo ao longo de um ano (Figura 13, valores de intercepto: $\mathrm{t} 0=0,10, \mathrm{t} 1=-0,28, \mathrm{t} 2=-0,20 \mathrm{e}$ t3=-0,16). Após um ano, os valores de $\Delta$ necromassa ainda não haviam retornado aos valores iniciais.

Tabela 5: Resultado da seleção de modelos para necromassa. Em evidência, o modelo considerado mais plausível.

\begin{tabular}{llcccc}
\hline \multicolumn{5}{c}{ Seleção de Modelos: Necromassa } \\
\hline Modelos & Efeitos & AICc & dAICc & df & weight \\
\hline Modelo 4 & tempo + (tempo|parcela) & $-525,3$ & 0,0 & 15 & 0,700 \\
Modelo 2 & tratamento + tempo + (tempo|parcela) & $-522,8$ & 2,5 & 17 & 0,202 \\
Modelo 1 & tratamento*tempo + (tempo|parcela) & $-521,4$ & 3,9 & 23 & 0,098 \\
Modelo 5 & 1 + (tempo|parcela) & $-496,6$ & 28,7 & 12 & $<0,001$ \\
Modelo 3 & tratamento + (tempo|parcela) & $-494,2$ & 31,1 & 14 & $<0,001$ \\
\hline
\end{tabular}




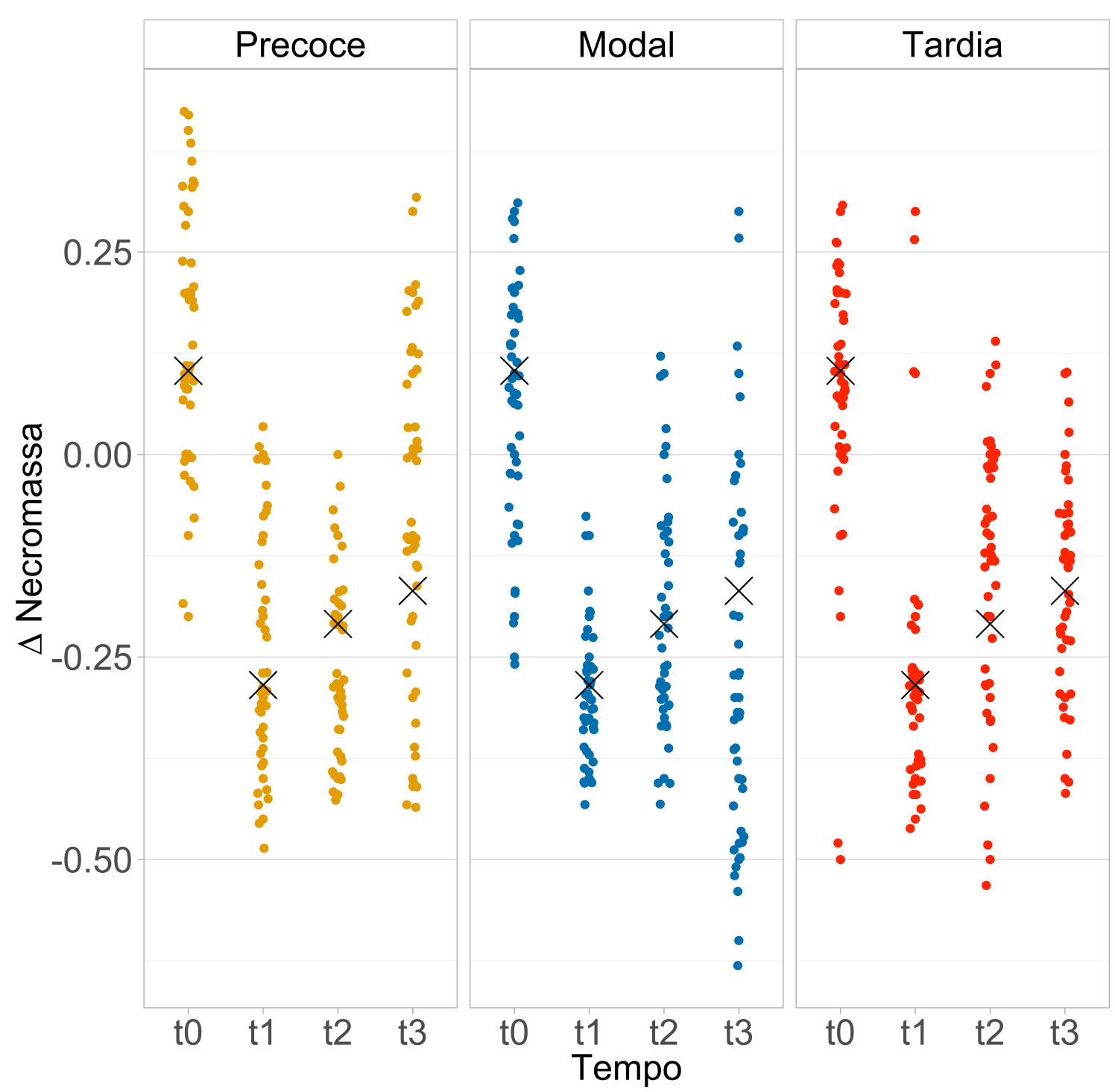

Figura 13: $\Delta$ Necromassa imediatamente antes (t0), quatro meses (t1), oito meses (t2) e doze meses (t3) após as queimadas experimentais, para cada tratamento de queima (Precoce, Modal e Tardia). Os X representam valores do intercepto do modelo selecionado. Valores positivos de $\Delta$ Necromassa representam valores maiores de cobertura no tratamento do que no controle e valores negativos representam valores de cobertura menores nos tratamentos do que no controle.

\subsubsection{Solo nu}

O modelo mais plausível para solo nu foi o modelo de interação entre tratamento e tempo, com a parcela como efeito aleatório (tabela 6). Encontramos, portanto, que o $\Delta$ solo foi afetado diferentemente pelas épocas de queima. Constatamos um 
aumento no $\Delta$ solo nu após a queima e sua diminuição progressiva ao longo de um ano (Figura 14) para os três tratamentos de queima. Entretanto, encontramos que a queima Precoce gerou valores maiores de $\Delta$ solo nu para todos os tempo após a queima (valores de interceptos: $\mathrm{t} 0=-0,11, \mathrm{t} 1=0,38, \mathrm{t} 2=0,17, \mathrm{t} 3=0,01$ ), seguida da queima Modal (valores de interceptos: $\mathrm{t} 0=-0,01, \mathrm{t} 1=0,25, \mathrm{t} 2=0,10, \mathrm{t} 3=0$ ) e da queima Tardia (valores de interceptos: $\mathrm{t} 0=-0,04, \mathrm{t} 1=0,17 \mathrm{t} 2=0, \mathrm{t} 3=-0,11$ ). Após um ano, os valores de $\Delta$ solo nu dos tratamentos Modal e Tardia retornam aos valores anteriores à queima, o que não ocorre para a queima Precoce.

Tabela 6: Resultado da seleção de modelos para solo nu. Em evidência o modelo considerado mais plausível.

\begin{tabular}{llcccc}
\hline \multicolumn{5}{c}{ Seleção de Modelos: Solo nu } \\
\hline Modelos & Efeitos & AlCc & dAICc & df & weight \\
\hline Modelo 1 & tratamento*tempo + (1|parcela) & $-312,0$ & 0,0 & 14 & 1 \\
Modelo 4 & tempo + (1|parcela) & $-285,5$ & 26,5 & 6 & $<0,001$ \\
Modelo 2 & tratamento + tempo + (1|parcela) & $-285,4$ & 26,6 & 8 & $<0,001$ \\
Modelo 5 & 1 + (1|parcela) & $-78,7$ & 233,3 & 3 & $<0,001$ \\
Modelo 3 & tratamento + (1|parcela) & $-78,7$ & 233,3 & 5 & $<0,001$ \\
\hline
\end{tabular}




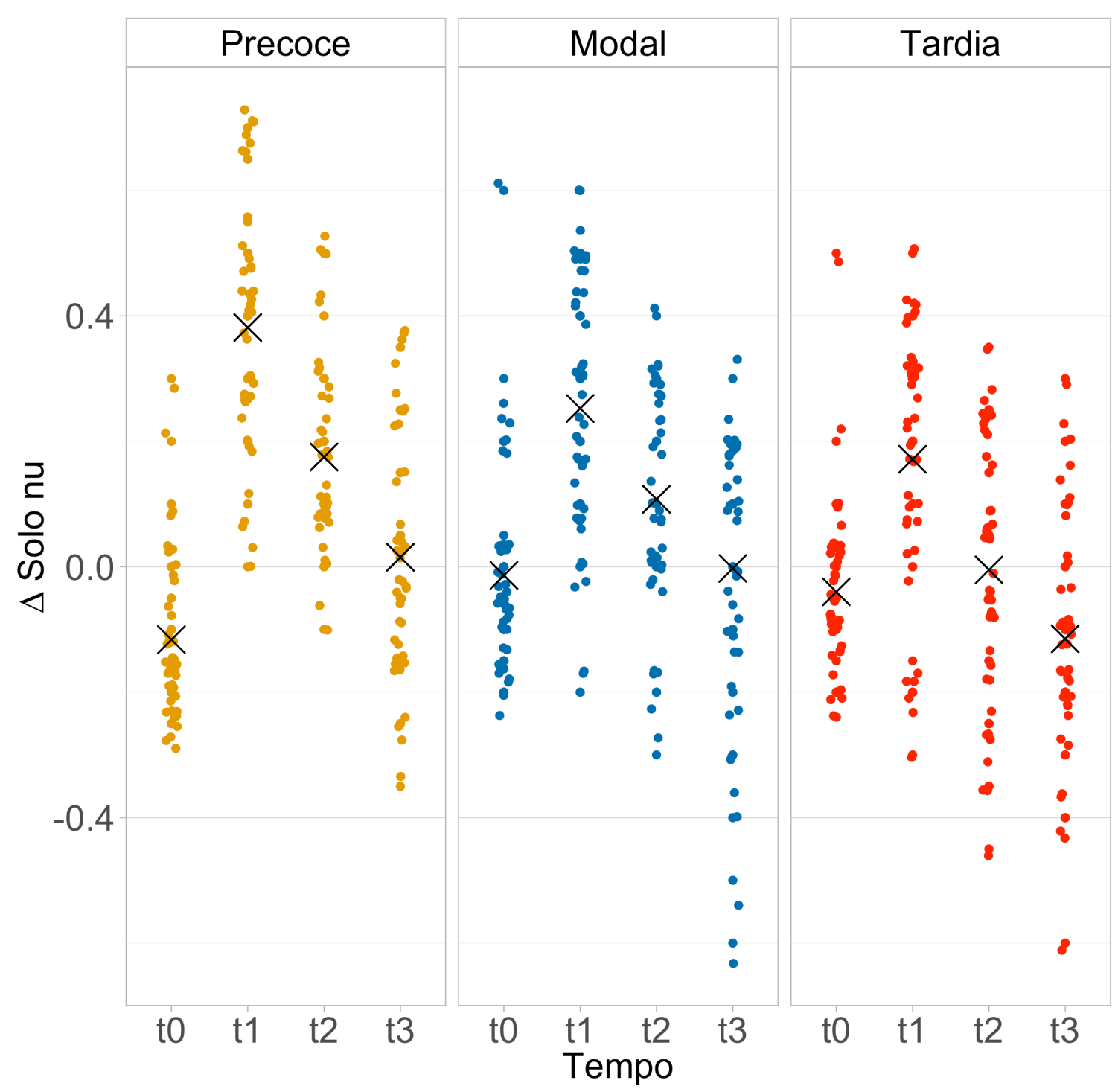

Figura 14: $\Delta$ Solo nu imediatamente antes (t0), quatro meses (t1), oito meses (t2) e doze meses (t3) após as queimadas experimentais, para cada tratamento de queima (Precoce, Modal e Tardia). Os X representam valores do intercepto do modelo selecionado. Valores positivos de $\Delta$ Solo nu representam valores maiores de cobertura no tratamento do que no controle e valores negativos representam valores de cobertura menores nos tratamentos do que no controle.

\subsubsection{Graminóides}

Duas estruturas aleatórias foram igualmente plausíveis para graminóides, a que apresentava apenas a parcela e a que apresentava a parcela variando ao longo do tempo como efeito aleatório. O modelo mais plausível para graminóides foi o de 
interação entre tratamento e tempo para ambas estruturas aleatórias (tabela 1). Encontramos, portanto, que $\Delta$ graminóide foi afetado diferentemente pelas épocas de queima (Figura 15). Para as queimas Precoce (valores de intercepto: t0=-0,04, $\mathrm{t} 1=-0,37, \mathrm{t} 2=-0,05, \mathrm{t} 3=-0,02)$ e Modal (valores de intercepto: $\mathrm{t} 0=0,05, \mathrm{t} 1=-0,22$, t2 $=-0,15, \mathrm{t} 3=-0,04)$ constatamos a queda de $\Delta$ graminóide de t0 para t1 e sua regeneração a partir de t1 para os dois tratamentos. Quando comparada à Modal, a queima Precoce apresentou valores mais baixos de $\Delta$ graminóide e uma recuperação mais rápida entre t1 e t2. No caso da queima Tardia constatamos a diminuição progressiva de $\Delta$ graminóide entre t0 e t2, sendo que a recuperação para o valor inicial ocorreu entre t2 e t3 (valores de intercepto: t0=0,05, t1 =-0,08, $\mathrm{t} 2=-0,14, \mathrm{t} 3=-0,02)$.

Tabela 7: Resultado da seleção de modelos para graminóides. Em evidência, o modelo considerado mais plausível.

\begin{tabular}{|c|c|c|c|c|c|}
\hline \multicolumn{6}{|c|}{ Seleção de Modelos: Graminóide } \\
\hline Modelos & Efeitos & $\mathrm{AICc}$ & $\mathrm{dAICc}$ & $d f$ & weight \\
\hline Modelo 1 & tratamento*tempo + (1|parcela) & $-137,4$ & 0,0 & 14 & 1 \\
\hline Modelo 4 & tempo + (1|parcela) & $-109,5$ & 27,9 & 6 & $<0,001$ \\
\hline Modelo 2 & tratamento + tempo + (1|parcela $)$ & $-106,1$ & 31,4 & 8 & $<0,001$ \\
\hline Modelo 5 & $1+(1 \mid$ parcela $)$ & $-23,7$ & 113,7 & 3 & $<0,001$ \\
\hline Modelo 3 & tratamento + (1|parcela) & $-20,3$ & 117,1 & 5 & $<0,001$ \\
\hline Modelo 1 & tratamento*tempo + (tempo|parcela) & $-137,2$ & 0,0 & 23 & 0,9839 \\
\hline Modelo 4 & tempo + (tempo|parcela) & $-128,5$ & 8,6 & 15 & 0,0133 \\
\hline Modelo 2 & tratamento + tempo + (tempo|parcela) & $-125,3$ & 11,9 & 17 & 0,0026 \\
\hline Modelo 5 & $1+$ (tempo|parcela) & $-119,3$ & 17,9 & 12 & $<0,001$ \\
\hline
\end{tabular}




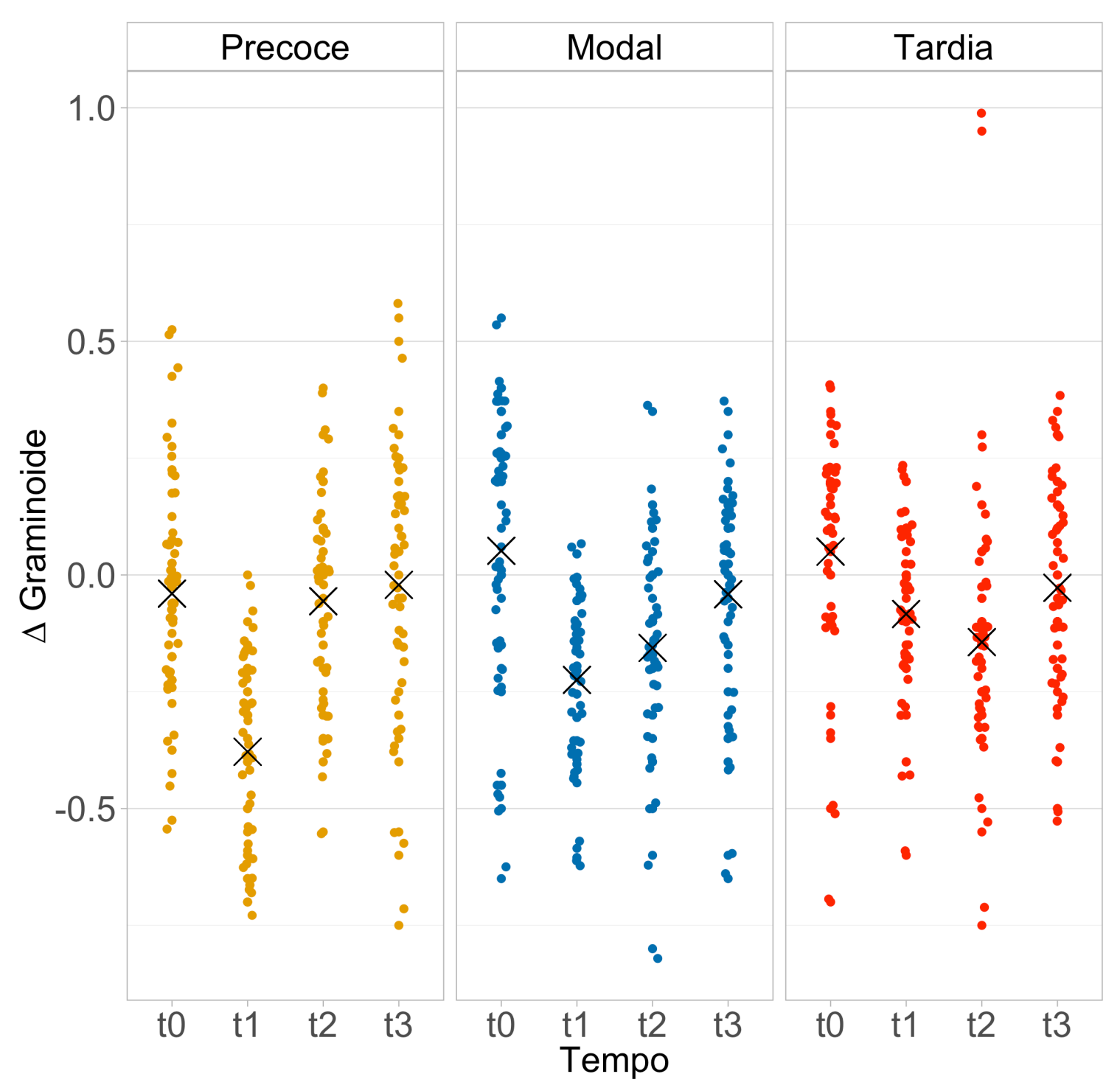

Figura 15: $\Delta$ Graminóide imediatamente antes (t0), quatro meses (t1), oito meses (t2) e doze meses (t3) após as queimadas experimentais, para cada tratamento de queima (Precoce, Modal e Tardia). Os X representam valores do intercepto do modelo selecionado. Valores positivos de $\Delta$ Graminóide representam valores maiores de cobertura no tratamento do que no controle e valores negativos representam valores de cobertura menores nos tratamentos do que no controle. 


\subsubsection{Arbusto}

O modelo mais plausível para explicar $\Delta$ arbusto foi o que considerou o tempo como efeito fixo e a parcela como efeito aleatório (tabela 8). Não obtivemos indícios de que os tratamentos de queima afetaram $\Delta$ arbusto e encontramos que a regeneração pós-fogo foi influenciada pelo tempo após a queima (Figura 16). Constatamos o aumento progressivo de $\Delta$ arbusto após a queima para todos os tratamentos (valores de intercepto: $\mathrm{t} 0=0,02, \mathrm{t} 1=0,04, \mathrm{t} 2=0,09$ e $\mathrm{t} 3=0,14$ ).

Tabela 8: Resultado da seleção de modelos para arbusto. Em evidência, o modelo considerado mais plausível.

\begin{tabular}{llcccc}
\hline \multicolumn{5}{c}{ Seleção de Modelos: Arbusto } \\
\hline Modelos & Efeitos & AICc & dAICc & df & weight \\
\hline Modelo 4 & tempo + (1|parcela) & $-2,5$ & 0,0 & 6 & 0,7874 \\
Modelo 2 & tratamento + tempo + (1|parcela) & 0,2 & 2,7 & 8 & 0,2045 \\
Modelo 1 & tratamento*tempo + (1|parcela) & 6,9 & 9,4 & 14 & 0,0072 \\
Modelo 5 & $1+(1 \mid$ parcela $)$ & 11,4 & 13,9 & 3 & $<0,001$ \\
Modelo 3 & tratamento + (1|parcela) & 14,1 & 16,6 & 5 & $<0,001$ \\
\hline
\end{tabular}




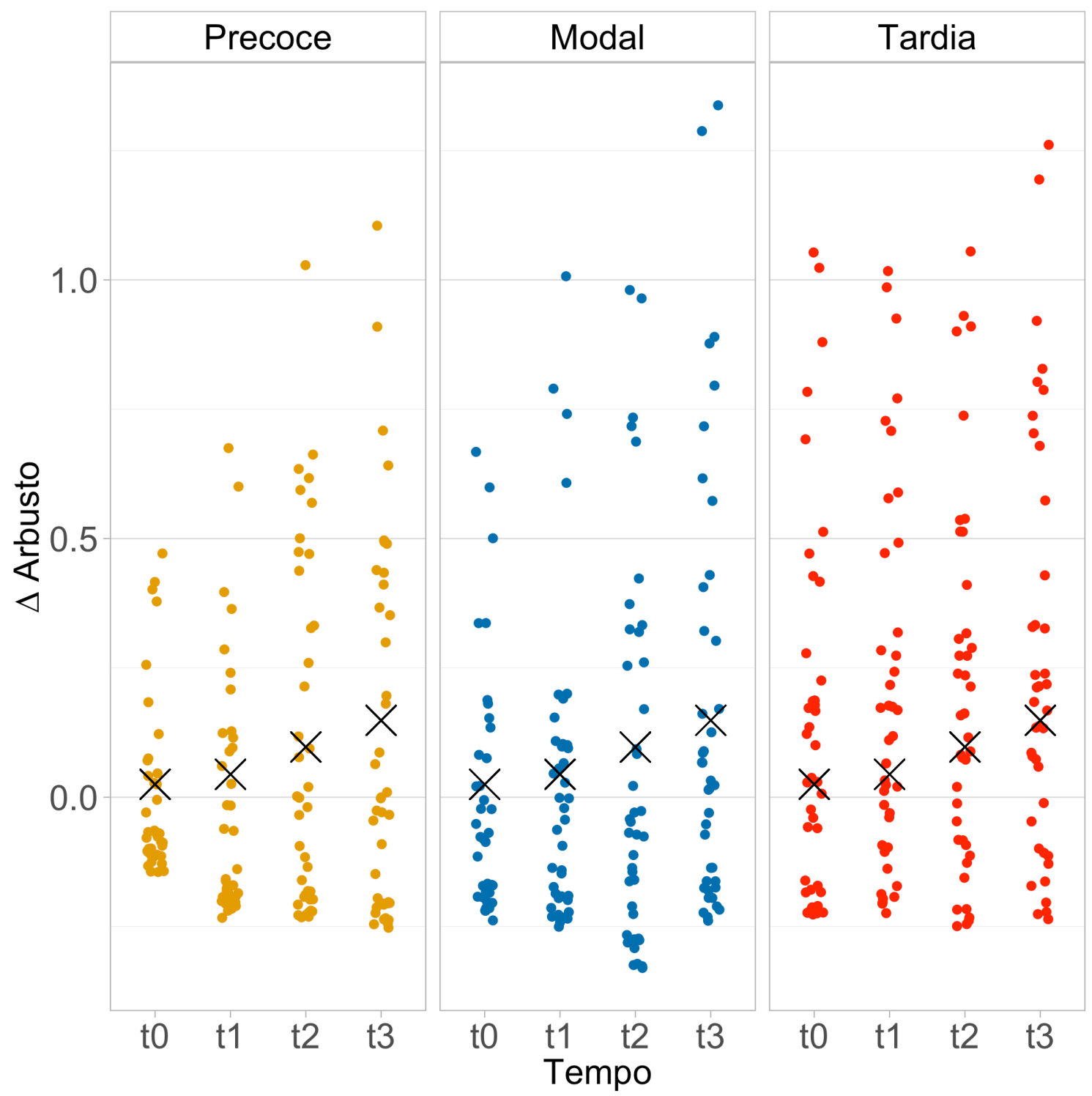

Figura 16: $\triangle$ Arbusto imediatamente antes (t0), quatro meses (t1), oito meses (t2) e doze meses (t3) após as queimadas experimentais, para cada tratamento de queima (Precoce, Modal e Tardia). Os X representam valores do intercepto do modelo selecionado. Valores positivos de $\Delta$ Arbusto representam valores maiores de cobertura no tratamento do que no controle e valores negativos representam valores de cobertura menores nos tratamentos do que no controle.

\subsubsection{Herbácea não graminóide}

A estrutura aleatória mais plausível para $\Delta$ herbácea não graminóide apresenta a parcela como efeito aleatório. Foram considerados igualmente 
plausíveis o modelo que apresenta o tratamento como efeito fixo (valores de intercepto: precoce=0,02, modal=0,005, tardia=0,013) e o modelo nulo (tabela 9; valor de intercepto do modelo nulo= 0,013). O tratamento Modal apresentou menores valores de $\Delta$ herbácea não graminóide do que os tratamentos Modal e Tardia (Figura 17), o que explica a seleção do modelo 3. No entanto, constatamos a grande concentração de zeros em todos os tempos, tanto para tratamentos como para controles. Os zeros representam ausência de herbáceas não graminóides nas sub-parcelas, o que significa a baixa frequência de herbáceas não graminóides na comunidade analisada. Essa similaridade, por sua vez, explica a seleção do modelo nulo.

Tabela 9: Resultado da seleção de modelos para herbácea não graminóide. Em evidência os modelos considerados igualmente plausíveis.

\begin{tabular}{llcccc}
\hline \multicolumn{5}{c}{ Seleção de Modelos: Herbácea não graminóide } \\
\hline Modelos & Efeitos & AlCc & dAICc & df & weight \\
\hline Modelo 3 & tratamento + (1|parcela) & $-1660,9$ & 0,0 & 5 & 0,6497 \\
Modelo 5 & $1+(1 \mid$ parcela $)$ & $-1659,1$ & 1,8 & 3 & 0,2639 \\
Modelo 2 & tratamento + tempo + (1|parcela) & $-1656,1$ & 4,8 & 8 & 0,0602 \\
Modelo 4 & tempo + (1|parcela) & $-1654,3$ & 6,5 & 6 & 0,0250 \\
Modelo 1 & tratamento*tempo + (1|parcela) & $-1648,3$ & 12,5 & 14 & 0,0012 \\
\hline
\end{tabular}




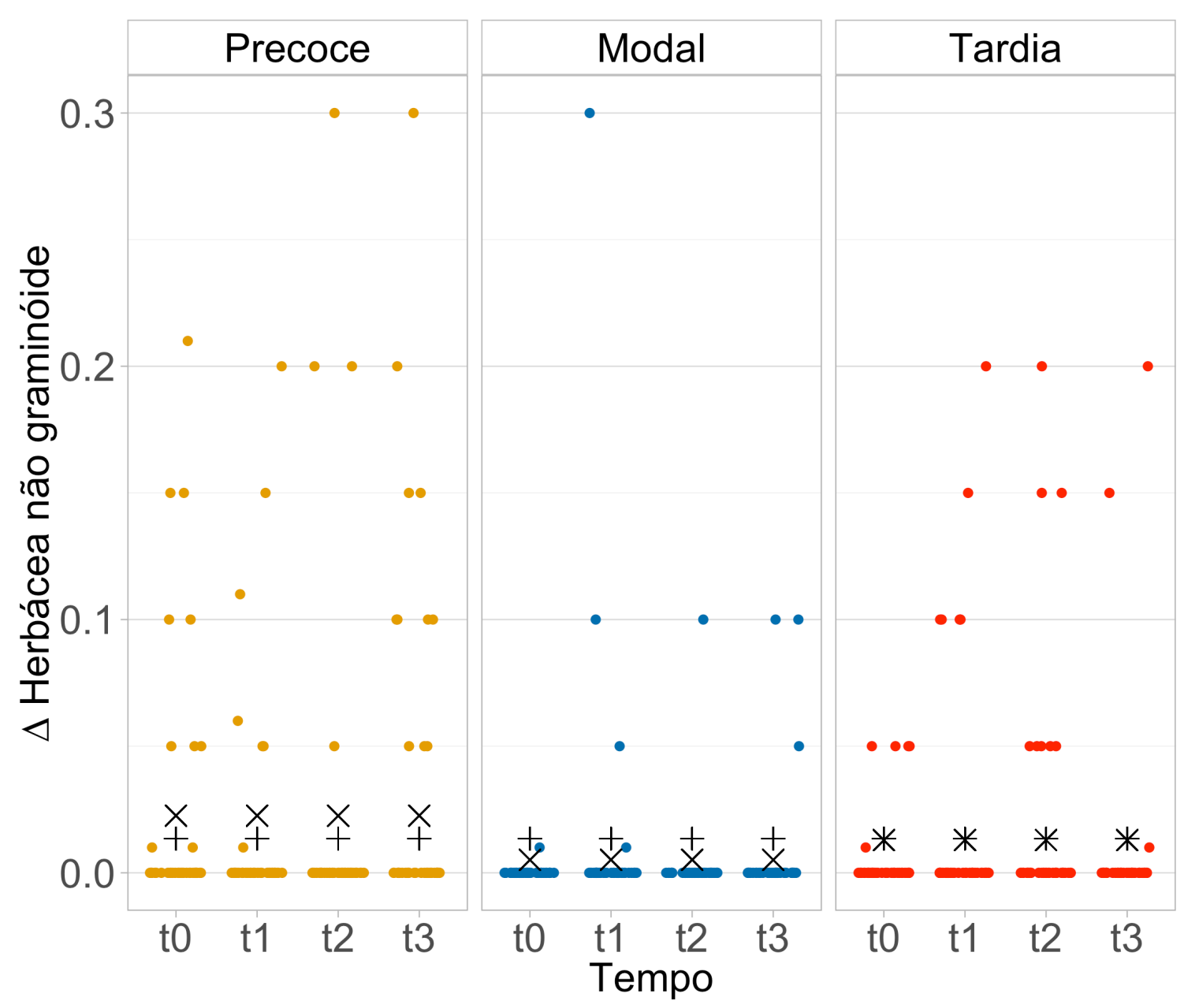

Figura 17: $\Delta$ Herbácea não graminóide imediatamente antes (t0), quatro meses (t1), oito meses (t2) e doze meses (t3) após as queimadas experimentais, para cada tratamento de queima (Precoce, Modal e Tardia). Os símbolos + e X representam os intercepto dos modelo selecionados (nulo e com o tratamento com efeito fixo, respectivamente). No caso da queima tardia o valor do intercepto dos modelos se sobrepõem. Valores positivos de $\Delta$ Arbusto representam valores maiores de cobertura no tratamento do que no controle e valores negativos representam valores de cobertura menores nos tratamentos do que no controle.

\subsubsection{Palmeira}

A estrutura aleatória considerada mais plausível para palmeira foi a que considera a parcela como efeito aleatório. O modelo nulo foi considerado o mais plausível (tabela 10). Não existe diferença entre tempos de um mesmo tratamento e entre os tratamentos de queima (Figura 18, valor de intercepto=0,07). Há uma 
grande concentração de zeros em todos os tempos. Os zeros representam ausência de palmeiras nas sub-parcelas, o que significa a baixa frequência de palmeiras na comunidade analisada. Essa similaridade explica a seleção do modelo nulo.

Tabela 10: Resultado da seleção de modelos para palmeira. Em evidência o modelo considerado mais plausível (modelo 5).

\begin{tabular}{llcccc}
\hline \multicolumn{5}{c}{ Seleção de Modelos: Palmeira } \\
\hline Modelos & Efeitos & AICc & dAICc & df & weight \\
\hline Modelo 5 & $1+(1 \mid$ parcela $)$ & $-502,5$ & 0,0 & 3 & 0,7651 \\
Modelo 3 & tratamento + (1|parcela) & $-499,6$ & 2,9 & 5 & 0,1822 \\
Modelo 4 & tempo + (1|parcela) & $-496,7$ & 5,8 & 6 & 0,0428 \\
Modelo 2 & tratamento + tempo + (1|parcela) & $-493,8$ & 8,7 & 8 & 0,0099 \\
Modelo 1 & tratamento*tempo + (1|parcela) & $-482,4$ & 20,1 & 14 & $<0,001$ \\
\hline
\end{tabular}




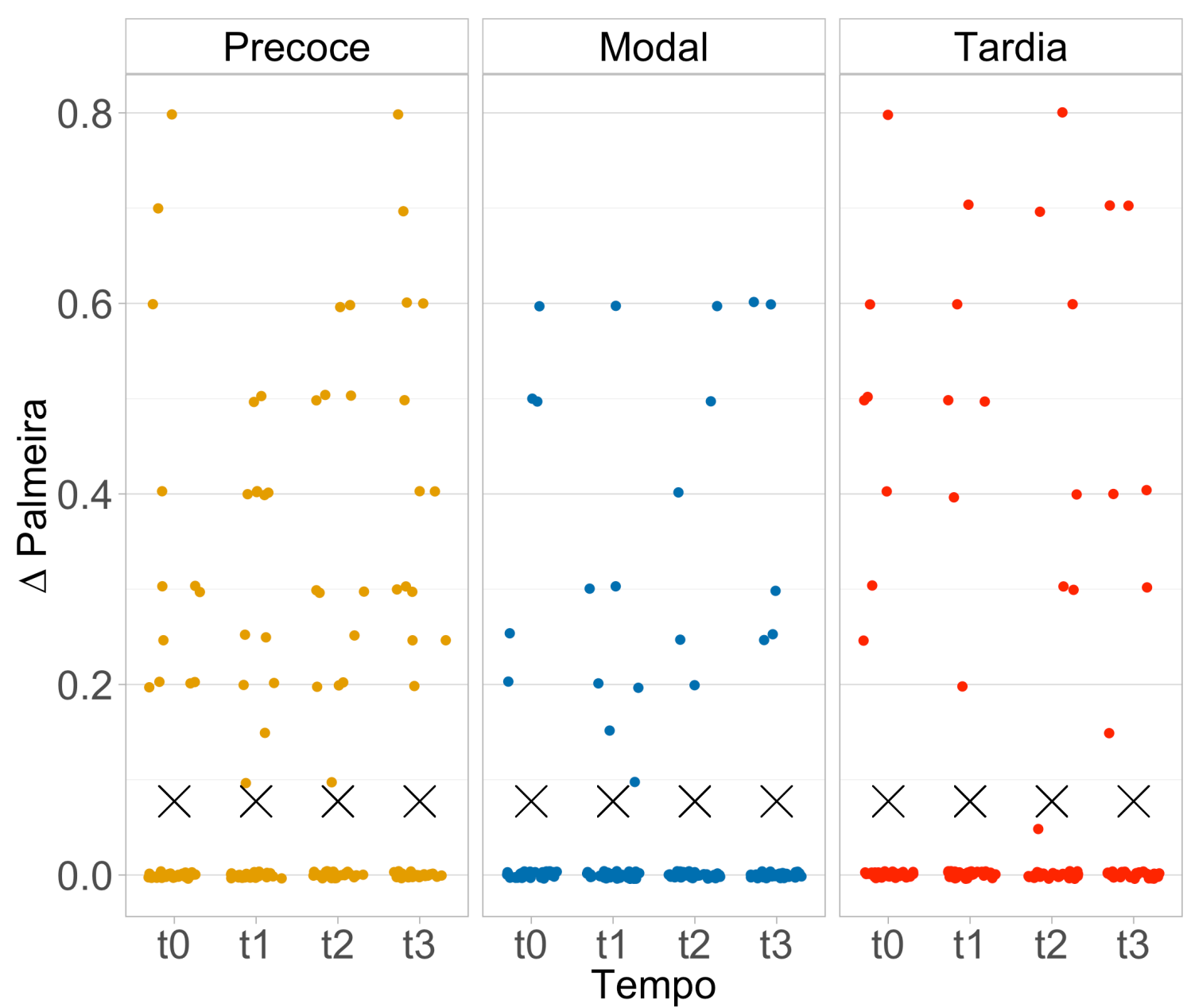

Figura 18: $\triangle$ Palmeira imediatamente antes (t0), quatro meses (t1), oito meses (t2) e doze meses (t3) após as queimadas experimentais, para cada tratamento de queima (Precoce, Modal e Tardia). Os X representam valores do intercepto do modelo selecionado. Valores positivos de $\Delta$ Palmeira representam valores maiores de cobertura no tratamento do que no controle e valores negativos representam valores de cobertura menores nos tratamentos do que no controle. 


\section{4 - Discussão}

Entre maio de 2014 e maio de 2015, constatamos a variação da cobertura de componentes rasteiros das parcelas controle, com valores médios de cobertura maiores em 2015 para graminóides, necromassa, solo nu e arbusto. Podemos atribuir essa variação à quantidade de água recebida pelo sistema. O período chuvoso de 2014 contou com precipitação de $411 \mathrm{~mm}$, enquanto que o período chuvoso de 2015, que precede o aumento dos valores médios de cobertura, contou com 686 mm de chuva. A quantidade e variação da precipitação são fatores que explicam variações e dinâmicas nas comunidades vegetais em diversos ecossistemas no mundo (Gaitán et al. 2014; Xu, Medvigy \& Rodriguez-Iturbe 2015). Em savanas africanas, por exemplo, o aumento na precipitação tende a favorecer o crescimento de gramíneas, em detrimentos de árvores. No entanto, as graminóides mostram-se mais sensíveis ao estresse hídrico e perdem sua biomassa rapidamente em condições mais secas (Xu et al. 2015). Já em regiões áridas da Patagônia argentina, a temperatura e a precipitação explicam mais de $60 \%$ do 
aumento da cobertura de gramíneas (Gaitán et al. 2014). No Cerrado, a sazonalidade e a precipitação são fatores fundamentais para a dinâmica das comunidades vegetais herbáceas e arbóreas e é possível encontrar uma correlação positiva entre precipitação e índice de vegetação NDVI (Bustamante, Alvalá \& Randow 2012). Rissi (2016) estudou o efeito da época de queima na dinâmica de um campo sujo na Reserva Natural da Serra do Tombador, em Goiás, encontrou variação nos valores de cobertura das parcelas controle e também as atribuiu à sazonalidade climática. Em seu trabalho, constatou valores mais baixos para graminóides, herbáceas não graminóides e arbustos nos meses de outubro, além de encontrar tendência de diminuição de solo nu nos controles ao longo dos dois anos de estudo. Neste estudo, a maior pluviosidade no período de 2015 coincide com o desenvolvimento de graminóides e arbustos, que, por sua vez, produziram maior biomassa, contribuindo com valores maiores de necromassa posteriormente.

Quanto às invasoras, encontramos valores maiores de cobertura e um maior número de eventos de invasão pela espécie Urochloa brizantha em parcelas submetidas à queima do que em parcelas controle. Este é um indício de que ambientes queimados podem ter maior susceptibilidade à invasão por U. brizantha do que ambientes não queimados. O fogo promove mudanças de condições ambientais e de disponibilidade de recursos em curto prazo, na medida em que consome a biomassa, disponibilizando nutrientes, e aumenta a quantidade de solo nu, disponibilizando espaço para estabelecimento (Whelan 1995). Como consequência, há maior incidência de luz solar e maior variação diária de temperatura do solo (Coutinho 1990; Santana, Baeza \& Blanes 2012; Fidelis \& 
Blanco 2014).

Constatamos ainda que a invasão por U. brizantha ocorreu em parcelas controle e em parcelas submetidas à queima, sempre na estação chuvosa, época em que as espécies alocam recursos para germinação e brotamento. Entretanto, encontramos maiores valores de cobertura em parcelas recém queimadas quando comparadas a seus controles. O fogo remove a biomassa aérea e promove o aumento de espaços disponíveis para a recolonização da vegetação. Valores mais altos de cobertura podem estar associados à abertura de espaço promovida pelo fogo e à consequente diminuição da competição por recursos. Portanto a associação do fogo, que garante maior disponibilidade de recursos, com a época chuvosa pode favorecer ainda mais a invasão do Cerrado de U. brizantha.

A alteração de condições e recursos geradas pela queima também pode interferir na interação entre espécies e aumentar a susceptibilidade do ambiente à novos processos de invasão (Lonsdale 1999; Davis, Grime \& Thompson 2000). Dimitrakolopoulos e colaboradores (2005) verificaram, por exemplo, que o fogo alterou o balanço de nutrientes do solo, gerando aumento da susceptibilidade à invasão de comunidades herbáceas no Mediterrâneo. Gorgone-Barbosa e colaboradores (2016) encontraram um aumento de 40\% na germinação de sementes de $U$. brizantha submetidas à flutuações de temperatura em laboratório. O aumento da germinação leva ao aumento na probabilidade de estabelecimento de plântulas, elucidando parte do processo de invasão por U. brizantha em ambientes que sofreram algum tipo de distúrbio. Desta forma, o fogo pode, indiretamente, aumentar a capacidade de invasão desta espécie na medida em que 
estimula a germinação e brotamento, além de deixar o ambiente mais susceptível a sua ocupação e expansão.

Já para M. Minutiflora, constatamos apenas a invasão de sub-parcelas controle. Damasceno e colaboradores (dados não publicados) observaram, nesta mesma área de estudo, a redução de cobertura de M. Minutiflora após o fogo em parcelas predominantemente cobertas por ela, indicando baixa resistência da espécie ao fogo. Uma explicação alternativa para a ausência de M. minutiflora em parcelas controle e para o menor número de eventos de invasão em parcelas controle, quando comparado com U. brizantha, reside na estratégia de regeneração de $M$. minutiflora. A principal estratégia de restabelecimento de $M$. Minutiflora é via sementes (Filgueiras 1990; Martins, Hay \& Carmona 2009) e não o rebrotamento. As sementes têm, entretanto, alto grau de esterilidade natural (Martins et al. 2009). Desta forma, M. Minutiflora apresenta um menor taxa de recolonização pós-fogo quando comparada à U. brizantha. Marinho \& Miranda (2013) avaliaram o efeito do fogo anual na mortalidade e no banco de sementes de M. Minutiflora e encontraram mortalidade de $26 \%$ dos indivíduos para cada uma das queimas e uma redução de 50\% no banco de sementes após dois anos. Concluíram assim que o fogo anual é uma boa ferramenta de manejo para o controle desta espécie invasora (Marinho \& Miranda 2013).

As três épocas de queima afetaram igualmente a cobertura de necromassa das parcelas queimadas quando comparadas à seus controles. Constatamos a diminuição do $\Delta$ necromassa após o fogo e um ano após as queimas, sendo que os valores não retornaram aos valores iniciais. O mesmo ocorreu para os valores 
médios de cobertura de necromassa. Portanto, podemos concluir que o fogo consumiu a matéria morta, reduzindo significativamente a cobertura de necromassa e confirmando a efetividade do manejo de fogo na redução de material combustível em curto prazo. Este resultado foi descrito na literatura (Pivello 1992, 2006b; Williams et al. 1999; Fernandes \& Botelho 2003) e indica que, para esta área, a queima prescrita não precisa ser realizada anualmente e sim com intervalos de tempo mais longos. Ademais, a queima pode ser realizada em qualquer época do ano se o objetivo do manejo for reduzir a quantidade de necromassa e o risco de incêndio associado. Rissi (2016), também encontrou que a época da queima não afetou a quantidade de necromassa em um campo sujo em Goiás. Constatou também que, após dois anos, a quantidade de necromassa era maior do que a encontrada antes da queima e era a mesma quando comparada com áreas não queimadas, demonstrando potencial para uma nova queima. Portanto, o uso do fogo como ferramenta para o manejo de combustível disponível no solo é efetivo, pois limita a ocorrência de incêndios de grandes proporções ao reduzir a quantidade de biomassa combustível (Govender, Trollope \& Van Wilgen 2006; Fidelis \& Pivello 2011; Durigan \& Ratter 2016). Este é um resultado importante do ponto de vista do manejo, pois, como relatam Fernandes \& Botelho (2003), a diminuição na incidência de queimas de grandes proporções implica em aumento da segurança de brigadas de incêndios, diminuição da quantidade e de tipos de ações de combate ao fogo e redução do custo associado à supressão de fogo (Fernandes \& Botelho 2003; Durigan \& Ratter 2016). A redução de necromassa pode ainda facilitar o restabelecimento de espécies nativas na área, uma vez que 
aumenta a disponibilidade de luz e espaço nas áreas recém queimadas (Whelan 1995). Rissi (2016) não encontrou alterações de riqueza e diversidade em curto prazo após as queimas, evidenciando que a facilitação promovida pela redução da quantidade de biomassa pode ou não estar associada à riqueza e diversidade de espécies.

As três épocas de queima afetaram diferentemente o solo nu quando comparados a seus respectivos controles. Encontramos valores mais altos de $\Delta$ solo nu após a queima Precoce, seguida das queimas Modal e Tardia, respectivamente. Constatamos um aumento de aproximadamente 3 vezes no valor médio de cobertura de solo nu após as queimas. Paralelamente, constatamos a tendência de aumento de solo nu a partir de janeiro de 2015 nas parcelas controle. Este aumento é anti-intuitivo, já que constatamos o aumento simultâneo da cobertura dos componentes vegetais. O aumento na cobertura de solo nu pode estar relacionado à dinâmica da comunidade vegetal, com aumento da mortalidade de algumas espécies e recrutamento de outras. Gymnopogon foliosus (Willd.) Nees e Axonopus pressus (Nees ex Steud.) Parodi, por exemplo, são graminóides e possuem estruturas completamente diferentes que influenciam a estimativa de cobertura visual de solo nu. Enquanto G. foliosus apresenta indivíduos esparsos que possibilitam o avistamento do solo, $A$. pressus forma densa touceiras sobre $\mathrm{o}$ solo. Para melhor averiguar como se deu o aumento no valor médio do solo nu nos controles, é necessário investigar alterações na composição de espécies que integram um mesmo componente do estrato rasteiro e que passariam despercebidas pela análise por componentes. Por exemplo, em um estudo em 
Córdoba, na Espanha, a época de queima não afetou a cobertura dos componentes herbáceos e lenhosos, nem de grandes grupos analisados (monocotiledôneas, dicotiledôneas, anuais e perenes) (Céspedes et al. 2014). Entretanto, este estudo constatou a alteração na dominância de espécies do componente arbustivo (Céspedes et al. 2014), revelando que mudanças na composição de espécies não se refletem, necessariamente, em mudanças entre grandes grupos.

A quantidade de solo nu está diretamente associada ao consumo de biomassa pela queima e sua regeneração pós-fogo (Bond \& van Wilgen 1996; Fidelis, Lyra \& Pivello 2012), que por sua vez está relacionada com a precipitação. A queima Precoce atingiu valores mais altos de $\Delta$ solo nu do que a queima Modal, provavelmente em função da baixa recolonização dos grupos vegetais durante a estiagem dos meses de junho e julho. Após um ano, entretanto, os valores de $\Delta$ solo nu das queimas Precoce e Modal retornaram aos valores iniciais, revelando que uma estação chuvosa foi suficiente para que a comunidade vegetal se reestabelecesse. Para a queima Tardia, a recuperação dos valores iniciais de $\Delta$ solo nu ocorreu oito meses após a queima, sendo que após um ano as parcelas controle apresentavam valores de solo nu maiores do que as parcelas queimadas. Considerando que o valor médio de solo nu aumentou nas parcelas controle a partir de Janeiro de 2015, é possível que esse aumento tenha sido responsável, juntamente com a rápida regeneração da vegetação promovida pela precipitação, pelos valores mais baixos de $\Delta$ solo nu na queima tardia 4 e 8 meses após a queima (janeiro e maio de 2015, respectivamente). 
As três épocas de queima afetaram diferentemente graminóides quando comparados a seus respectivos controles. Para as queimas Precoce e Modal constatamos a queda no $\Delta$ graminóide após a queima e a recuperação dos valores iniciais ao longo de um ano. No caso da queima Tardia, constatamos a diminuição do $\Delta$ graminóide ao longo de oito meses após a queima. Graminóides são, dentre os componentes do estrato herbáceo-arbustivo, os que apresentam maior resiliência (Bond, 2004). Sua capacidade de rebrote é atribuída ao crescimento contínuo dos meristemas intercalares, protegidos abaixo do solo ou acima do solo por bainhas (Bond \& van Wilgen 1996; Filgueiras 2002; Gottsberger \& SilberbauerGottsberger 2006).

Os valores mais altos de $\Delta$ solo nu ocorreram no t1 Precoce, assim como os valores mais baixos de $\Delta$ graminóide. O padrão encontrado para $\Delta$ graminóide na queima Tardia foi diferente dos encontrados para Precoce e Modal, principalmente em relação à observação realizada quatro meses após a queima, com um $\Delta$ graminóide maior do que o mesmo tempo das queimas Precoce e Modal. Observamos, também, valores médios de cobertura de graminóides maiores no t1 da Tardia do que Modal e Precoce. Atribuímos o maior valor de $\Delta$ graminóide em t1 à rápida regeneração do componente graminoso nos quatro meses chuvosos subsequentes à queima Tardia. Ao contrário das épocas Modal e Tardia, a primeira observação pós-queima Precoce foi realizada no final da estação seca, em Setembro de 2014. Portanto, é esperado que a regeneração pós queima Precoce seja mais baixa do que nas queimas Modal e Tardia em função da baixa precipitação nos quatro meses subsequentes à queima. Assim, a quantidade de 
solo nu estaria variando majoritariamente em função do crescimento da biomassa, principalmente gramíneas, que por sua vez variam conforme a pluviosidade. Este é um resultado condizente com um trabalho desenvolvido em Brasilia, no qual 70\% da biomassa rasteira se recuperou entre seis a dez meses após o fogo, em função da disponibilidade de chuvas (Andrade 1998). O padrão de recuperação do estrato graminoso aqui encontrado também está de acordo com trabalhos que estimam que a recuperação total da biomassa rasteira se dá entre 1 e 2 anos após a queima, dependendo da precipitação, fisionomia e condições edáficas (Batmanian \& Haridasan 1985; Coutinho 1990).

As três épocas de queima afetaram igualmente a cobertura de arbustos das parcelas queimadas quando comparadas à seus controles. Constatamos o aumento de $\Delta$ arbustos ao longo do tempo após todas as queimas. Constatamos também o aumento dos valores médios da cobertura de arbustos nos controles e em todos os tratamentos de queima. Portanto, o fogo estimulou o aumento na cobertura de arbustos. Rissi (2016) constatou o favorecimento da cobertura de arbustos após o fogo, mas em momentos distintos em cada queima (no período chuvoso após queimas Precoce e Tardia e no período seco dois anos após a queima Modal). Castro-Neves (2007) descreve que, embora saibamos da resposta negativa de indivíduos arbóreos ao fogo, pouco sabemos sobre a resposta de indivíduos lenhosos de pequeno porte à queima. Em nosso estudo, a regeneração pós-fogo dos arbustos ocorreu majoritariamente via rebrote (observação pessoal). O rebrote pós-fogo de pequenos arbustos foi descrito em Brasília (Hoffmann 1996; Hoffmann \& Solbrig 2002), no Mato Grosso (Souchie 2015) e na Austrália (Whelan 
1995) e sua importância na fixação de carbono foi destacada por Sato (2003). Esta estratégia está normalmente associada à quantidade de reservas nos tecidos radiculares e à presença de gemas radiculares ou axilares (Appezzato-da-glória et al. 2008). Considerando a supressão do fogo nos últimos 20 anos nesta área de estudo, é possível que os órgãos subterrâneos dos indivíduos deste grupo estejam bem desenvolvidos e relacionados à rápida regeneração dos arbustos após o fogo. O desenvolvimento de xilopódio na ausência de fogo foi comprovado por Rizzini e colaboradores (1961), mostrando que o desenvolvimento de órgãos subterrâneos de reserva pode ser uma capacidade da espécie, inerente à presença de fogo. Outros estudos, entretanto, revelam que espécies apresentam plasticidade fenotípica e autores sugerem que o desenvolvimento de xilopódios são adaptações ao fogo (Simon \& Pennington 2012). Estudos experimentais com ampla amostragem taxonômica são necessários para elucidar questões ainda abertas sobre a morfologia funcional da flora do Cerrado.

Pesquisas sobre efeito da frequência de fogo em fisionomias savânicas de Cerrado constataram baixa resistência de plântulas e lenhosas jovens ao fogo, principalmente em função da destruição de gemas apicais e do pequeno diâmetro do caule (Guedes 1993; Rocha-e-Silva \& Miranda 1996). Outras pesquisas constataram ainda que a supressão do fogo durante um período prolongado está relacionada ao adensamento da fisionomia de Cerrado, dependendo da precipitação, condições edáficas e pressão de propágulos (Pinheiro \& Durigan 2009). É preciso investigar o efeito da época e frequência de fogo, portanto, para avaliar se o aumento na cobertura de pequenos arbustos ocorre após queimadas 
frequentes.

Não obtivemos resultados conclusivos para $\Delta$ herbáceas não graminóides. Os valores médios de cobertura no controle e tratamentos de queima permaneceram próximos a zero, devido à baixa frequência de herbáceas não graminóides na área de estudo. Estudos sobre o efeito da época de fogo em áreas de cerrado aberto que apresentem maior frequência de herbáceas não graminóides podem contribuir sobre o entendimento da regeneração pós-fogo deste grupo. Por exemplo, Rissi (2016) constatou na reserva do Tombador, em Goiás, o favorecimento da cobertura de herbáceas não graminóides no meio da estação seca em queimas tardias. Antar (2015) constatou um maior valor de densidade de plantas do estrato herbáceo e subarbustivo e um maior valor de riqueza de espécies em áreas com diferentes regimes de fogo, quando comparadas à uma área protegida no Jalapão, Tocantins.

Os valores médios de cobertura de Palmeira permaneceram relativamente constantes ao longo do tempo no controle e nos tratamentos de queima, assim como a cobertura de palmeiras de áreas queimadas em relação a cada controle. Portanto, nem a época de queima e nem o tempo após a queima afetaram este grupo. As palmeiras presentes na área de trabalho são Attalea geraenses Barb. Rodr. e Syagrus loefgrenii Glassman. Palmeiras do gênero Attalea, mais especificamente Attalea humilis, são capazes de prosperar em áreas queimadas, mantendo características morfológicas e de tamanho constantes ao longo dos anos (Souza, Martins \& Matos 2000). Estes dois gêneros são apontados na literatura como tendo alta resistência e resiliência ao fogo (Souza \& Martins 2004; 
Bonjorne de Almeida \& Galetti 2007) e, portanto, explicam a manutenção dos valores de cobertura encontrados e as observações de rebrota e germinação observadas para os indivíduos dessas espécies. É possível que as bainhas persistentes estejam protejam os caules e o meristema apical dessas espécies, garantindo a manutenção dos indivíduos no pós-fogo.

\section{Considerações finais}

A época de queima afetou diferentemente dois dos componentes do estrato rasteiro - graminóides e solo nu - mas após a estação chuvosa essas diferenças desapareceram. Necromassa e arbustos responderam da mesma forma às épocas de queima, mas enquanto que a necromassa não retornou aos valores iniciais um ano após as queimas, constatamos um pequeno aumento na cobertura de arbustos ao longo de 12 meses. Não obtivemos resultados conclusivos para herbáceas não graminóides e vimos que palmeiras não são afetadas pelo fogo. Resumidamente, após um ano das queimas, os valores de cobertura dos componentes rasteiros eram os mesmos de antes do fogo, com exceção do pequeno aumento na cobertura de arbustos e da diminuição na cobertura de necromassa. Vimos que o fogo removeu a biomassa aérea e promoveu o aumento de espaços disponíveis para a recolonização da vegetação. A abertura de espaço promovida pelo fogo e a consequente diminuição da competição podem estar relacionadas com a rápida regeneração dos componentes vegetais. Constatamos também o dinamismo natural da vegetação de Cerrado nos controles. Esse 
dinamismo é influenciado pela sazonalidade climática, que também afetou a regeneração dos componentes do estrato herbáceo-arbustivo nas parcelas queimadas. Uma estação chuvosa foi suficiente para que as diferenças entre as épocas de queima desaparecessem. Portanto, não encontramos que a época de queima exerce, no curto prazo de um ano, um efeito de grande magnitude na comunidade do ponto de vista funcional. Apesar de áreas de cerrado de São Paulo apresentarem inúmeras diferenças quando comparados à áreas de Cerrado do planalto central do país, nossos resultados foram similares aos encontrados por Rissi (2016). Neste trabalho, ela encontrou que épocas de queima distintas provocam efeitos sutis na regeneração e estrutura, mas não afetam a riqueza e diversidade de um campo sujo na Reserva do Tombador, Goiás.

De maneira geral, a estratégia mais comum de recolonização encontrada entre os componentes do estrato rasteiro foi o rebrotamento. Estes resultados evidenciam a resiliência do Cerrado, já que os componentes do estrato rasteiro, com exceção da necromassa, se regeneraram dentro de 1 ano. A resiliência, expressa na recolonização dos componentes rasteiros, pode ser explicada pela pressão histórica do fogo no Cerrado (Simon et al., 2009) e pela existência de mecanismos como a rebrota, que garante a rápida regeneração dos grupos vegetais. Entretanto, a constatação da resiliência do estrato herbáceo-arbustivo não indica a ausência de mudanças na composição do sistema. Para isso, é preciso investigar se o fogo induz a substituição de espécies que integram um mesmo componente do estrato rasteiro.

O manejo de fogo para redução de material combustível e para evitar 
incêndios de grandes magnitudes foi comprovado. De acordo com os resultados, o manejo de fogo pode ser realizado em quaisquer épocas do ano, já que as diferenças entre as épocas de queima desaparecem após um ano. Porém, obtivemos indícios de que a queima pode aumentar a susceptibilidade de invasão por Urochloa brizantha. Isso significa que o manejo de fogo em ambientes invadidos por braquiária deve ser realizado com cautela, até que tenhamos certeza de que o fogo não facilita a proliferação dessa espécie invasora. 


\section{Referências}

Alho, C.J.R. \& Martins, E.S. (1995) De grão em grão o Cerrado perde espaço. Impactos do processo de ocupação (Documento para discussão) (org WWF). Brasília.

Almeida-Neto, M., Prado, P.I., Kubota, U., Bariani, J.M., Aguirre, G.H. \& Lewinsohn, T.M. (2010) Invasive grasses and native Asteraceae in the Brazilian Cerrado. Plant Ecology, 209, 109-122.

Andrade, S.M.A. (1998) Dinâmica do Combustível Fino e Produção Primária do Estrato Rasteiro de Áreas de Campo Sujo de Cerrado Submetidas a Diferentes Regimes de Queima.

Antar, G. de M. (2015) Florística e efeitos do regime de fogo no estrato herbáceosubarbustivo no Jalapão, Tocantins, Brasil . Universidade de São Paulo.

Appezzato-da-glória, B., Cury, G., Misaki, M.K., Rocha, R., Hayashi, A.H., The, S., Society, B., Appezzato-da-glo, B., Kasue, M. \& Soares, M. (2008) Underground systems of Asteraceae species from the Brazilian Cerrado. Journal of the Torrey Botanical Society, 135, 103-113.

ATBC. (2012) Resolution promoting sustainable fire management in cerrado.

Augustine, D.J., Mcnaughton, S.J. \& Frank, D.A. (2003) Feedbacks between soil nutrients and large herbivores in a managed savanna ecosystem. Ecological Applications, 13, 1325-1337.

Baker, W.L. (1994) Restoration of landscape structure altered by fire suppression. Conservation Biology, 763-769.

Bates, D.M. (2010) Chapter 1 A Simple, Linear, Mixed-effects Model. p. 1-26.

Bates, D., Maechler, M., Bolker, B., Walker, S., Christensen, R.H.B., Singmann, H., Dai, B. \& Grothendieck, G. (2015) Package "Ime4". 1-8.

Batmanian, G.J. \& Haridasan, M. (1985) Primary production and accumulation of nutrients by the ground layer community of cerrado vegetation of central Brazil. Plant and Soil, 437-440.

Berardi, A. (1994) Effects of the African grass Melinis minutiflora on Plant 
Community Composition and fire characteristics of a Central Brazilian Savanna. University College, University of London.

Blackburn, T.M., Pyšek, P., Bacher, S., Carlton, J.T., Duncan, R.P., Jarošík, V., Wilson, J.R.U. \& Richardson, D.M. (2011) A proposed unified framework for biological invasions. Trends in Ecology \& Evolution, 26, 333-339.

Bolker, B., Skaug, H., Magnusson, A. \& Nielsen, A. (2012) Getting started with the glmmADMB package.

Bond, W.J. (2004) Fire. Vegetation of South Africa. (orgs R.M. Cowling, D.M. Richardson \& S.M. Pierce), p. 421-446. Cambridge University Press, Cambridge.

Bond, W.J. \& Keeley, J.E. (2005) Fire as a global "herbivore": The ecology and evolution of flammable ecosystems. Trends in Ecology and Evolution, 20, 387394.

Bond, W.J. \& van Wilgen, B.W. (1996) Fire and Plants. Springer Netherlands.

Bonjorne de Almeida, L. \& Galetti, M. (2007) Seed dispersal and spatial distribution of Attalea geraensis (Arecaceae) in two remnants of Cerrado in Southeastern Brazil. Acta Oecologica, 32, 180-187.

Bonnicksen, T.M. \& Stone., E.C. (1985) Restoring naturalness to national parks. Environmental Management, 479-486.

Bunting, S.C., Kilgore, B.M. \& Bushey, C.L. (1987) Guidelines for prescribed burning sagebrush grass rangelands in the northern Great Basin. General Technical Report INT-231. Utah.

Burnham, K.P. \& Anderson, D.R. (2002) Model Selection and Multimodel Inference: A Practical Information-Theoretic Approach (2nd ed).

Bustamante, J., Alvalá, R. \& Randow, C. Von. (2012) Seasonal Variability of Vegetation and Its Relationship to Rainfall and Fire in the Brazilian Tropical Savanna. Remote Sensing - Applications, 77-98.

Castro, A.A.J.F., Martins, F.R., Tamashiro, J.Y. \& Shepherd, G.J. (1999) How rich is the flora of Brazilian Cerrados? Annals of Missouri Botanical Garden, 192-221.

Castro-Neves, B.M. (2000) Comportamento de queimadas, temperaturas do solo e recuperação da biomassa aérea em campo sujo nativo e em capim-gordura 
(Melinis minutiflora). Universidade de Brasília.

Castro-neves, B.M. De. (2007) Efeito de Queimadas em áreas de Cerrado Stricto Sensu e na biomassa de raízes finas.

Céspedes, B., Torres, I., Pérez, B., Luna, B. \& Moreno, J.M. (2014) Burning season does not affect post-fire regeneration but fire alters the balance of the dominant species in a seeder-dominated Mediterranean shrubland. Applied Vegetation Science, 17, 711-725.

Coulloudon, B., Eshelman, K., Gianola, J., Habich, N., Hughes, L., Johnson, C., Pellant, M., Podborny, P., Rasmussen, A., Robles, B., Shaver, P., Spehar, J. \& Willoughby, J. (1996) Sampling vegetation attributes. Bureau of Land Management's National Applied Resource Sciences Center, Denver.

Coutinho, L.M. (1978) O conceito de cerrado. Revista brasileira de Botânica, 1, 1723.

Coutinho, L.M. (1982) Ecological effects of fire in Brazilian Cerrado. Ecology of tropical savannas. (orgs B.J. Huntley \& B.H. Walker), p. 273-291. Springer Verlag.

Coutinho, L.M. (1990) Fire in the ecology of the Brazilian cerrado. Fire in the tropical biota (org J.G. Goldammer), p. 82-105. Springer, New York.

Cronk, Q.C.B. \& Fuller, J.L. (1995) Plant Invaders: the threat to natural ecosystems. Chapman \& Hall, London.

Dasilva, M.A. \& Nogueira, P.E. (1999) Avaliação fitossociológica do estrato arbustivo-herbáceo em cerrado stricto sensu após incêndio acidental no Distrito Federal, Brasil. Boletim do Herbário Ezechias Paulo Heringer, 65-79.

Davis, M. a., Grime, J.P. \& Thompson, K. (2000) Fluctuating resources in plant communities: a general theory of invasibility. Journal of Ecology, 88, 528-534.

Dimitrakopoulos, P.G., Galanidis, A., Siamantziouras, A.-S.D. \& Troumbis, A.Y. (2005) Short-Term Invasibility Patterns in Burnt and Unburnt Experimental Mediterranean Grassland Communities of Varying Diversities. Oecologia, 143, 428-437.

DiTomaso, J.M., Brooks, M.L., Allen, E.B., Minnich, R., Rice, P.M. \& Kyser, G.B. (2006) Control of Invasive Weeds with Prescribed Burning. Weed Technology, 
20, 535-548.

Dolores, M., Carolina, C., Sandra, C., Pillar, D., Fidelis, A., Delgado-cartay, M.D., Blanco, C.C., Müller, S.C. \& Pillar, V.D. (2010) Fire intensity and severity in Brazilian Campos grasslands. Asociación Interciencia, 35, 739-745.

Durigan, G. \& Ratter, J.A. (2016) The nedd for a consistent fire policy for Cerrado conservation. Journal of Applied Ecology, 53, 11-15.

Durigan, G., de Siqueira, M.F. \& Franco, G.A.D.C. (2007) Threats to the Cerrado remnants of the state of São Paulo, Brazil. Scientia Agricola, 64, 355-363.

Eiten, G. (1972) The Cerrado vegetation of Brazil. The Botanical Review, 38, 201341.

Elzinga, C.L., Salzer, D.W. \& Willoughby, J.W. (1998) Measuring \& Monitoring Plant Populations.

EMBRAPA. (1978) Levantamento de reconhecimento dos solos do Distrito Federal. Rio de Janeiro.

Fernandes, P.M. \& Botelho, H.S. (2003) A review of prescribed burning effectiveness in fire hazard reduction. International Journal of Wildland Fire, 12, 117-128.

Ferraz-Vicentinni, K. (1999) História do fogo no Cerrado - uma análise palinológica. Universidade de Brasília.

Fichino, S.B., Dombroski, J.R.G., Pivello, V.R. \& Fidelis, A. (2016) Does Fire Trigger Seed Germination in the Neotropical Savannas? Experimental Tests with Six Cerrado Species. Biotropica, 1-7.

Fidelis, A. \& Blanco, C. (2014) Does fire induce flowering in Brazilian subtropical grasslands? Applied Vegetation Science, 17, 690-699.

Fidelis, A., Lyra, M.F.D.S. \& Pivello, V.R. (2012) Above-and below-ground biomass and carbon dynamics in Brazilian Cerrado wet grasslands (org O Wildi). Journal of Vegetation Science, 1-9.

Fidelis, A. \& Pivello, V.R. (2011) Deve-se Usar o Fogo como Instrumento de Manejo no Cerrado e Campos Sulinos? Número temático: ecologia e manejo de fogo em áreas protegidas, 12-25.

Fiedler, N.C., Melo, D.A. \& Medeiros, M.B. (2006) Ocorrência de incêndios florestais 
no Parque Nacional da Chapada dos Veadeiros, Goiás. Ciência Florestal, 153161.

Filgueiras, T.S. (1990) Africanas no Brasil. Gramíneas introduzidas da África. Cadernos de Geociências, 5, 57-63.

Filgueiras, T.S. (2000) Projeto Biografia do Bioma Cerrado: plantas herbáceas e arbustivas. Cadernos de Geociências, 12, 115-133.

Filgueiras, T.S. (2002) Herbaceous plant communities. Cerrados of Brazil. (orgs P.. Oliveira \& R.J. Marquis), p. 121-139. Columbia University Press.

Furley, P. a. (1999) The nature and diversity of neotropical savanna vegetation with particular reference to the Brazilian cerrados. Global Ecology and Biogeography, 8, 223-241.

Gaertner, M., Biggs, R., Te Beest, M., Hui, C., Molofsky, J. \& Richardson, D.M. (2014) Invasive plants as drivers of regime shifts: identifying high-priority invaders that alter feedback relationships. Diversity and Distributions, 20, 733744.

Gaitán, J.J., Oliva, G.E., Bran, D.E., Maestre, F.T., Aguiar, M.R., Jobbágy, E.G., Buono, G.G., Ferrante, D., Nakamatsu, V.B., Ciari, G., Salomone, J.M. \& Massara, V. (2014) Vegetation structure is as important as climate for explaining ecosystem function across patagonian rangelands. Journal of Ecology, 102, 1419-1428.

Goodland, R. \& Pollard, R. (1973) The Brazilian cerrado vegetation: a fertility gradient. Journal of Ecology, 61, 219-224.

Gorgone-Barbosa, E., Pivello, V.R., Baeza, M.J. \& Fidelis, A. (2016) Disturbance as a factor in breaking dormancy and enhancing invasiveness of African grasses in a Neotropical Savanna. Acta Botanica Brasilica, 30, 1-7.

Gorgone-Barbosa, E., Pivello, V.R., Bautista, S., Zupo, T., Rissi, M.N. \& Fidelis, A. (2015) How can an invasive grass affect fire behavior in a tropical savanna? A community and individual plant level approach. Biological Invasions, 423-431.

Gottsberger, G. \& Silberbauer-Gottsberger, I. (2006) Life in the Cerrado: a South American tropical seasonal ecosystem.

Govender, N., Trollope, W.S.W. \& Van Wilgen, B.W. (2006) The effect of fire season, 
fire frequency, rainfall and management on fire intensity in savanna vegetation in South Africa. Journal of Applied Ecology, 43, 748-758.

Guedes, D.M. (1993) Resistência das Árvores do Cerrado ao Fogo: o Papel da Casca como Isolante Térmico. Universidade de Brasília.

Hanes, T.L. (1971) Succession after fire in the chaparral of Southern California. Ecological Monographs, 27-52.

Hardesty, J., Myers, R. \& Fulks, W. (2005) Fire, ecosystems, and people: a preliminary assessment of fire as a global conservation issue. The George Wright Forum, 78-87.

Haridasan, M. (1994) Solos. Cerrado - Caracterização, Ocupação e Perspectivas, 2a Edição. (org M.N.P. (ed.)), p. 681. UnB., Editora.

Haridasan, M. (2000) Nutrição mineral de plantas nativas do Cerrado. Revista Brasileira de Fisiologia Vegetal, 12, 54-64.

Hoffman, A.A. (2012) Prevention, control and monitoring of bush fires in the Cerrado: Visit to Tocantins and Jalapão.

Hoffmann, W.A. (1996) The effects of fire and cover on seedling establishment in a neotropical savanna. Journal of Ecology, 383-393.

Hoffmann, W.A. \& Solbrig, O.T. (2002) The role of topkill in the differential response of savanna woody species to fire. Forest Ecology and Management, 273-286.

J.A., R., Askew, G.P., Mintgomery, R.F. \& Gifford, D.R. (1977) Observações adicionais sobre o Cerradão de solos mesotróficos no Brasil Central. IV Simpósio sobre o Cerrado. p. 303-316. EDUSP, São Paulo.

Johnson, J.B. \& Omland, K.S. (2016) Model selection in ecology and evolution. Trends in Ecology \& Evolution, 19, 101-108.

Keeley, J., Bond, W., Bradstock, R., Pausas, J. \& Rundel, P. (2012) Fire in Mediterranean climate ecosystems: ecology, evolution and management. Cambridge, Cambridge University Press.

Kier, G., Mutke, J., Dinerstein, E., Ricketts, T.H., Küper, W., Kreft, H. \& Barthlott, W. (2005) Global patterns of plant diversity and floristic knowledge. Journal of Biogeography, 32, 1107-1116.

Klink, C. a. \& Machado, R.B. (2005) Conservation of the Brazilian Cerrado. 
Conservation Biology, 19, 707-713.

Lonsdale, W.M. (1999) Global Patterns of plant invasions and the concept of invasibility. Ecology, 80, 1522-1536.

Machado, R.B., Neto, M.G.P., Caldas, E.F., Gonçalves, D. a., Santos, N. a., Tabor, K. \& Steininger, M. (2004) Estimativas de perda da área do Cerrado brasileiro. International do Brasil, 1-23.

Marinho, S. \& Miranda, H.S. (2013) Efeito do Fogo Anual na Mortalidade e no Banco de Sementes de Andropogon gayanus Kunth . no Parque Nacional de Brasília / DF. 3, 149-158.

Martins, C.R., Hay, J.D.V. \& Carmona, R. (2009) Potencial invasor de duas cultivares de Melinis minutiflora no cerrado brasileiro-características de sementes e estabelecimento de plântulas. Revista Árvore, 33, 713-722.

Medeiros, M.B. \& Fiedler, N.C. (2004) Incêndios florestais no Parque Nacional da Serra da Canastra: desafios para a conservação da biodiversidade. Ciência Florestal, 157-168.

Meirelles, M., Oliveira, R., Ribeiro, J., Vivaldi, L., Rodrigues, L.A. \& Silva, G.P. (2002) Utilização do método de intersecção na linha em levantamento quantitativo do estrato herbáceo do cerrado. Boletim do Herbário Ezechias Paulo Heringer, 60-68.

Mendoncça, R.C., Felfili, J.M., Walter, B.M.T. \& SILVA-JU, N. (2008) Flora vascular do Bioma Cerrado: checklist com 12.356 espécies. Cerrado: ecologia e flora, 423-1279.

Miranda, H.S., Neto, W.N. \& Neves, B.M.C. (2010) Caracterização das queimadas de Cerrado. Efeitos do regime de fogo sobre a estrutura de comunidades do Cerrado: Resultados do Projeto Fogo (org H.S. Miranda), p. 23-33. Ministério do Meio Ambiente, Brasília.

Miranda, H.S., Sato, M.N., Neto, W.N. \& Aires, F.S. (2009) Fire in the Cerrado, the Brazilian savanna. Tropical fire ecology: climate change, land use and ecosystem dynamics (org M.A. Cochrane), p. 427-450. Heidelberg: SpringerPraxis.

Mistry, J. \& Berardi, A. (2005) Assessing Fire Potential in a Brazilian Savanna Nature 
Reserve. Biotropica, 37, 439-451.

Mittermeier, R.A., Myers, N. \& Mittermeier, C.G. (1999) Hotspots: Earth's Biologically Richest and Most Endangered Terrestrial Ecoregions. (org C and C International.). Mexico.

MMA. (1999) Programa de manejo de fogo do Parque Nacional de Aparados da Serra. Brasilia.

MMA. (2004) Programa De Manejo De Fogo Para o Parque Nacional Da Serra Da Bodoquena/Ms. Brasília.

MMA. (2011) Plano de ação para prevenção e controle do desmamatamento e das queimadas: cerrado.

Morgan, J.W. (1999) Defining grassland fire events and the response of perennial plants to annual fire in temperate grassland of south-eastern Australia. Plant ecology, 144, 127-144.

Munhoz, C.B. (2004) Fitossociologia do estrato rasteiro de Cerrado. Tese de Doutorado. Universidade de Brasília. Brasília-DF Brasil.

Myers, R.L. (2006) Convivendo com o Fogo (org TN Conservancy). Tallahassee.

Myers, N., Mittermeier, R.A., Mittermeier, C.G., Da Fonseca, G.A. \& Kent, J. (2000) Biodiversity hotspots for conservation priorities. Nature, 403, 853-858.

Parr, C.L., Lehmann, C.E.R., Bond, W.J., Hoffmann, W.A. \& Andersen, A.N. (2014) Tropical grassy biomes: Misunderstood, neglected, and under threat. Trends in Ecology and Evolution, 29, 205-213.

Pinheiro, E.D.S. \& Durigan, G. (2009) Dinâmica espaço-temporal (1962-2006) das fitofisionomias em unidade de conservação do Cerrado no sudeste do Brasil. Revista Brasileira de Botânica, 32, 441-454.

Pivello, V.R. (1992) An expert system for the use of prescribed fires in the management of Brazilian savannas. University of London.

Pivello, V.R. (2006a) Manejo de fragmentos de cerrado: princípios para a conservação da biodiversidade. Cerrado: ecologia, biodiversidade e conservação (orgs A. Scariot, J.C. Sousa Silva \& J.M. Felfili), p. 402-413. Ministério do Meio Ambiente, Brasília, Brasil.

Pivello, V.R. (2006b) Fire management for biological conservation in the Brazilian 
Cerrado. Savannas and dry forests: linking people with nature (orgs J. Mistry \& A. Berardi), p. 129-154. Ashgate Publishing, Hants.

Pivello, V.R. (2011) The use of fire in the cerrado and Amazonian rainforests of Brazil: Past and present. Fire Ecology, 7, 24-39.

Pivello, V.R., Carvalho, V.M.C. \& Lopes, P.F. (1999a) Abundance and Distribution of Native and Alien Grasses in a "Cerrado"(Brazilian Savanna) Biological Reserve. Biotropica, 31, 71-82.

Pivello, V.R., Shida, C.N. \& Meirelles, S.T. (1999b) Alien grasses in Brazilian savannas : a threat to the biodiversity. Biodiversity and Conservation, 8, 12811294.

Platt, W.J., Evans, G.W. \& Davis, M.M. (1988) Effects of fire season on flowering of forbs and shrubs in longleaf pine forests. Oecologia, 353-363.

Pyke, D. a., Brooks, M.L. \& D’Antonio, C. (2010) Fire as a Restoration Tool: A Decision Framework for Predicting the Control or Enhancement of Plants Using Fire. Restoration Ecology, 18, 274-284.

R Core Team. (2015) R: A Language and Environment for Statistical Computing.

Raij, B. van \& Quaggio, J.A. (1983) Métodos de análise de solo para fins de fertilidade (Boletim técnico 81) Instituto Agronômico, Campinas.

Ramos-Neto, M.B. \& Pivello, V.R. (2000) Lightning Fires in a Brazilian Savanna National Park: Rethinking Management Strategies. Environmental Management, 26, 675-684.

Ratter, J. a., Ribeiro, J.F. \& S., B. (1997) The Brazilian Cerrado Vegetation and Threats to its Biodiversity. Annals of Botany, 80, 223-230.

Richardson, D.M., Pysek, P., Rejmanek, M., Barbour, M.G., Dane, F. \& West, C.J. (2000) Naturalization and Invasion of Alien Plants: Concepts and Definitions. Diversity and Distributions, 6, 93-107.

Rissi, M.N. (2016) Efeito da época da queima na dinâmica de campo sujo. UNESP Rio Claro.

Rocha-e-Silva, E.P. \& Miranda, H.S. (1996) Temperatura do câmbio de espécies lenhosas do cerrado durante queimadas prescritas. Anais do VIII Simpósio sobre o Cerrado/ 1st International Symposium on Tropical Savannas., p. 253- 


\section{CPAC/EMBRAPA.}

Roques, K.G., O'Connor, T.G. \& Watkinson, A.R. (2001) Dynamics of shrub encroachment in an African savanna: relative influences of fire, herbivory, rainfall and density dependence. Journal of Applicated Ecology, 38, 268-280.

Rossi, R.D., Martins, C.R., Viana, P.L., Rodrigues, E.L. \& Figueira, J.E.C. (2014) Impact of invasion by molasses grass (Melinis minutifloraP. Beauv.) on native species and on fires in areas of campo-cerrado in Brazil. Acta Botanica Brasilica, 28, 631-637.

Sala, O.E., Stuart Chapin, F., Armesto, J.J., Berlow, E., Bloomfield, J., Dirzo, R., Huber-Sanwald, E., Huenneke, L.F., Jackson, R.B., Kinzig, A., Leemans, R., Lodge, D.M., Mooney, H.A., Oesterheld, M., Poff, N.L., Sykes, M.T., Walker, B.H., Walker, M., Wall, D.H. \& Sala, O.E. (2000) Global Biodiversity Scenarios for the Year 2100SALA, O. E. et al. Global Biodiversity Scenarios for the Year 2100. Science, v. 287, n. 5459, p. 1770-1774, 10 mar. 2000. Science, 287, 1770-1774.

Salgado-Labouriau, M.L. (2005) Alguns aspectos sobre a Paleoecologia dos Cerrados. Cerrado: ecologia, biodivrsidade e conservação (orgs A. Scariot, J.C. Sousa-Silva \& J.M. Felfili), p.107-118. Ministério do Meio Ambiente, Brasília.

Salgado-Labouriau, M.L. \& Ferraz-Vicentinni, K.R. (1994) Fire in the Cerrado 32,000 years ago. Current Research in the Pleistocene, 85-87.

Santana, V.M., Baeza, M.J. \& Blanes, M.C. (2012) Clarifying the role of fire heat and daily temperature fluctuations as germination cues for Mediterranean Basin obligate seeders. Annals of botany, 111, 127-134.

Scholes, R.J. \& Archer, S.R. (1997) Tree Grass Interactions in Savannas. Annual Review of Ecology and Systematics, 28, 517-544.

Silva Júnior, M.C., Barros, M.F. \& Cândido, J.F. (1987) Relações entre parâmetros do solo e da vegetação de Cerrado na Estação Florestal de Experimentação de Paraopeba, MG. Revista Brasileira de Botânica, 10, 125-137.

Simon, M.F., Grether, R., de Queiroz, L.P., Skema, C., Pennington, R.T. \& Hughes, C.E. (2009) Recent assembly of the Cerrado, a neotropical plant diversity 
hotspot, by in situ evolution of adaptations to fire. Proceedings of the National Academy of Sciences of the United States of America, 106, 20359-20364.

Simon, M.F. \& Pennington, T. (2012) Evidence for Adaptation to Fire Regimes in the Tropical Savannas of the Brazilian Cerrado. International Journal of Plant Sciences, 173, 711-723.

Souchie, F.F. (2015) Rebrota de indivíduos lenhoos em área de Cerrado Sentido Restrito como resposta ao fogo.

Souza, A.F. \& Martins, F.R. (2004) Population structure and dynamics of a Neotropical palm in fire-impacted fragments of the Brazilian Atlantic Forest. Biodiversity and Conservation, 13, 1611-1632.

Souza, A.F., Martins, F.R. \& Matos, D.M.S. (2000) Detecting ontogenetic stages of the palm Attalea humilis in fragments of the Brazilian Atlantic forest. Canadian Journal of Botany, 78, 1227-1237.

Stolle, F., Chomitz, K.M., Lambin, E.F. \& Tomich, T.P. (2003) Land use and vegetation fires in Jambi Province, Sumatra, Indonesia. Forest Ecology and Management, 179, 277-292.

Trollope, W.S.W. (1982) Ecological effects of fire in South African savannas. Ecology of Tropical Savannas (orgs B.J. Huntley \& B.H. Walker), p. 293-306. SpringerVerlag, Berlin.

Vilà, M., Espinar, J.L., Hejda, M., Hulme, P.E., Jarošík, V., Maron, J.L., Pergl, J., Schaffner, U., Sun, Y. \& Pyšek, P. (2011) Ecological impacts of invasive alien plants: a meta-analysis of their effects on species, communities and ecosystems. Ecology letters, 14, 702-708.

Walter, H. (1986) Vegetação e zonas climáticas. EPU.

Whelan, R.J. (1995) The ecology of fire. Cambridge University Press, Cambridge.

Williams, R.J., Cook, G.D., Gill, A.M. \& Moore, P.H.R. (1999) Fire regime, fire intensity and tree survival in a tropical savanna in northern Australia. Aust. J. Ecol., 50-59.

Xu, X., Medvigy, D. \& Rodriguez-Iturbe, I. (2015) Relation between rainfall intensity and savanna tree abundance explained by water use strategies. Proceedings of the National Academy of Sciences, 112, 12992-12996. 
Young, W.C., Mellbye, M.E. \& Silberstein, T.B. (1999) Residue management of perennial ryegrass and tall fescue seed crops. Agronomy Journal, 91, 671675.

Zanchetta, D., Reis, C.M., Delgado, J.M., Silva, C.E.F., Luca, E.F. de, Fernandes, F. de S., Lutgens, H.D., Tannus, J.L.S., Pinheiro, L. de S., Martins, M.R.C. \& Sawaya, R. (2006) Plano de Manejo Integrado. Estações Ecológica e Experimental de Itirapina/SP.

Zuur, A.F., Ieno, E.N., Walker, N.J., Saveliev, A. a, Smith, G.M. \& Ebooks Corporation. (2009) Mixed Effects Models and Extensions in Ecology with R. 


\section{Anexos}

Anexo 1: Resultado da análise de fertilidade de solo.

\begin{tabular}{|c|c|c|c|c|c|c|c|c|c|c|}
\hline$\frac{\mathbb{\sigma}}{\mathbb{Q}}$ & $\mathrm{pH}$ & $\mathrm{Al}+\mathrm{H}$ & m.o. & m.o. & $\mathrm{P}$ & K & $\mathrm{Ca}$ & $\mathrm{Mg}$ & $\begin{array}{c}\text { Areia } \\
\text { grossa }\end{array}$ & Areia fina \\
\hline 0 & $\mathrm{CaCl}_{2}$ & $\mathrm{mmol} / \mathrm{kg}$ & $\%$ & $\mathrm{~g} / \mathrm{kg}$ & $\mathrm{mg} / \mathrm{g}$ & $\mathrm{mmol} / \mathrm{kg}$ & $\mathrm{mmol} / \mathrm{kg}$ & $\mathrm{mmol} / \mathrm{kg}$ & $\%$ & $\%$ \\
\hline 1 & 4,17 & 21,11 & 3,03 & 11,27 & 1,6 & 0,2 & $>0,01$ & 0,15 & 61,29 & 35,68 \\
\hline 2 & 4,24 & 20,02 & 3,07 & 11,28 & 1,6 & 0,4 & 0,64 & 0,24 & 59,39 & 37,54 \\
\hline 4 & 4,17 & 23,21 & 2,72 & 15,5 & 1,7 & 0,3 & 0,14 & 0,22 & 54,1 & 43,18 \\
\hline 5 & 4,2 & 21,33 & 2,34 & 9,86 & 2,8 & 0,2 & 0,22 & 0,25 & 76,37 & 21,29 \\
\hline 6 & 4,23 & 20,67 & 2,98 & 4,26 & 2 & 0,3 & 0,19 & 0,23 & 64,52 & 32,5 \\
\hline 7 & 4,18 & 21,33 & 2,81 & 12,68 & 1,9 & 0,2 & 0,28 & 0,28 & 61,29 & 35,9 \\
\hline 10 & 4,04 & 27,75 & 2,99 & 8,45 & 2,3 & 0,2 & 0,43 & 0,27 & 55,44 & 41,57 \\
\hline 11 & 4,14 & 22,72 & 2,74 & 11,27 & 2,3 & 0,8 & 0,14 & 0,2 & 63,86 & 33,4 \\
\hline 13 & 4,04 & 26,05 & 3,1 & 7,04 & 1,7 & 0,6 & $>0,01$ & 0,12 & 61,12 & 35,78 \\
\hline 19 & 3,97 & 27,46 & 2,71 & 8,44 & 2 & 0,5 & 0,12 & 0,21 & 59,88 & 37,41 \\
\hline 34 & 4,08 & 28,95 & 3,1 & 15,5 & 2 & 0,5 & 0,38 & 0,21 & 70,39 & 26,51 \\
\hline 35 & 3,87 & 34,62 & 3,21 & 25,36 & 2 & 0,3 & 0,54 & 0,46 & 63,98 & 32,81 \\
\hline 44 & 4,05 & 29,18 & 3,95 & 19,73 & 2,5 & 0,6 & 0,69 & 0,36 & 59,71 & 36,34 \\
\hline 45 & 4,16 & 21,78 & 3,66 & 11,27 & 2 & 0,4 & 0,45 & 0,43 & 62,25 & 34,09 \\
\hline 47 & 4,13 & 22,72 & 2,93 & 7,07 & 2,5 & 0,4 & $>0,01$ & 0,23 & 67,46 & 29,61 \\
\hline 48 & 4,17 & 24,46 & 2,87 & 9,86 & 1,3 & 0,5 & 0,58 & 0,39 & 70,53 & 26,6 \\
\hline
\end{tabular}


Anexo 2: Distribuições dos valores da diferença entre tratamento e controle para cada componente do estrato rasteiro. $\mathrm{O}$ eixo $\mathrm{X}$ representa os valores de diferença entre tratamentos e controle para cada componente do estrato rasteiro e o eixo y a frequência dos valores de diferença.

Arbusto

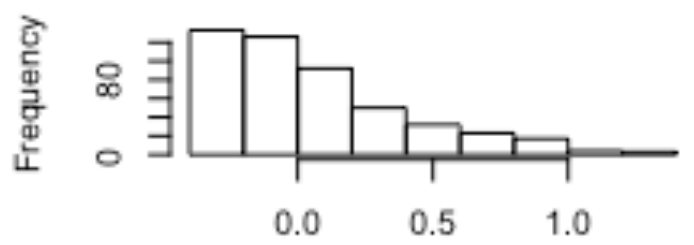

Graminóide

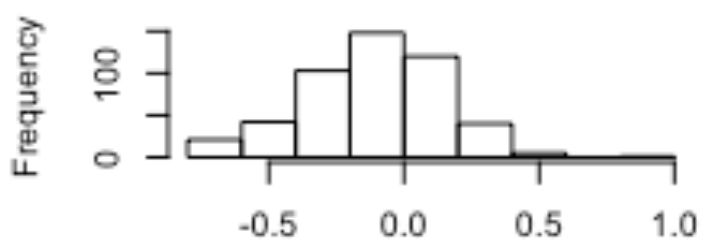

Palmeira

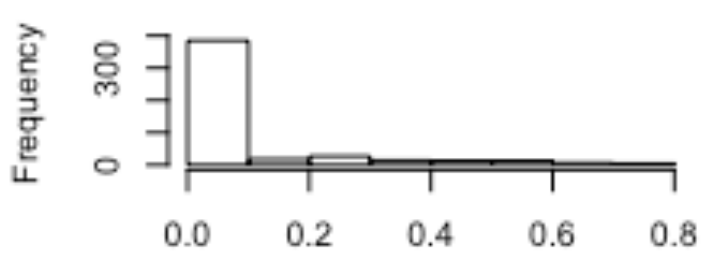

Necromassa

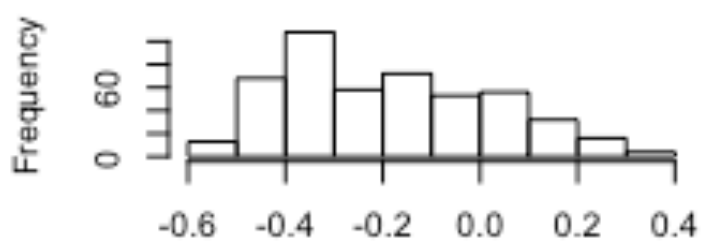

Herbácea não graminóide

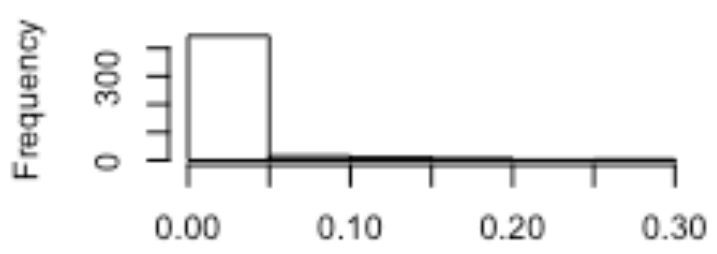

Solo nu

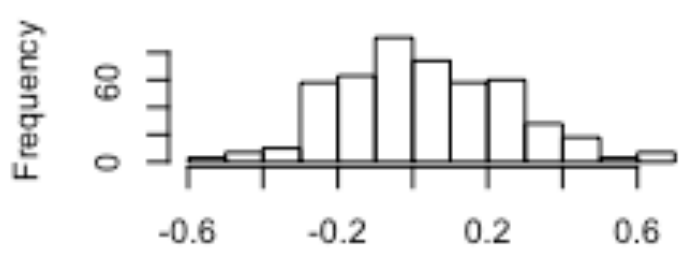


Anexo 3: Resultado da seleção de estrutura aleatória para cada componente do estrato rasteiro. Em negrito os modelos considerados mais plausíveis.

\begin{tabular}{|c|c|c|c|c|c|c|}
\hline \multicolumn{7}{|c|}{ Seleção de estrutura aleatória } \\
\hline Cp & Modelos & Efeitos & $\mathrm{AlCc}$ & dAICc & df & weight \\
\hline \multirow{3}{*}{$\begin{array}{l}\mathbb{0} \\
\mathscr{D} \\
\mathbb{0} \\
\tilde{E} \\
0 \\
0 \\
0 \\
\mathbb{D} \\
Z\end{array}$} & Modelo b & + (tempo|parcela) & -521.4 & 0,0 & 23 & 0,75 \\
\hline & Modelo c & $+(1 \mid$ parcela $)+(0+$ tempo|parcela $)$ & -519.2 & 2.2 & 24 & 0,25 \\
\hline & Modelo a & $+(1 \mid$ parcela $)$ & -477.7 & 43.7 & 14 & $<0,001$ \\
\hline \multirow{3}{*}{ 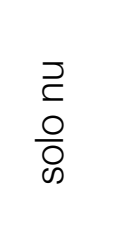 } & Modelo a & $+(1 \mid$ parcela $)$ & -312.0 & 0,0 & 14 & 0,9953 \\
\hline & Modelo b & + (tempo|parcela) & $-300,3$ & 11.7 & 23 & 0,0028 \\
\hline & Modelo c & + (1|parcela) + (0+tempo|parcela) & -298.1 & 14.0 & 24 & $<0,001$ \\
\hline \multirow{3}{*}{ 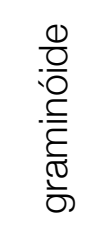 } & Modelo a & + (1|parcela) & -137.4 & 0,0 & 14 & 0,47 \\
\hline & Modelo b & + (tempo|parcela) & -137.2 & 0,3 & 23 & 0,41 \\
\hline & Modelo c & + (1|parcela $)+(0+$ tempo|parcela $)$ & -134.8 & 2.7 & 24 & 0,12 \\
\hline \multirow{3}{*}{$\begin{array}{l}\text { O } \\
\frac{+}{D} \\
\frac{0}{D} \\
\frac{0}{\Delta}\end{array}$} & Modelo b & + (tempo|parcela) & -521.4 & 0,0 & 23 & 0,75 \\
\hline & Modelo c & + (1|parcela) + (0+tempo|parcela) & -519.2 & 2.2 & 24 & 0,25 \\
\hline & Modelo a & $+(1 \mid$ parcela $)$ & -477.7 & 43.7 & 14 & $<0,001$ \\
\hline \multirow{3}{*}{ 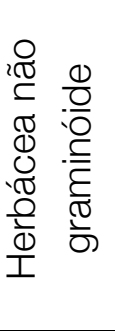 } & Modelo a & + (1|parcela) & $\begin{array}{c}- \\
1648.3\end{array}$ & 0,0 & 14 & 0,949 \\
\hline & Modelo b & + (tempo|parcela) & 1641.9 & 6.4 & 17 & 0,038 \\
\hline & Modelo c & + (1|parcela $)+(0+$ tempo|parcela $)$ & 1639.7 & 8.6 & 18 & 0,013 \\
\hline \multirow{3}{*}{$\begin{array}{l}\frac{\widetilde{\sigma}}{\bar{\Phi}} \\
\frac{E}{\sigma} \\
0\end{array}$} & Modelo a & + (1|parcela) & -482.4 & 0,0 & 14 & 0,949 \\
\hline & Modelo b & + (tempo|parcela) & -476.0 & 6.4 & 17 & 0,038 \\
\hline & Modelo c & + (1|parcela) + (0+tempo|parcela) & -473.8 & 8.6 & 18 & 0,013 \\
\hline
\end{tabular}

